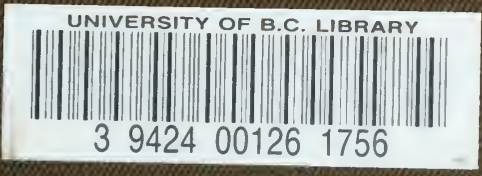

STCRAGE IIEN

FROCESSING-ONE

Lp 1-F 19t U.B.C. LIBRARY 


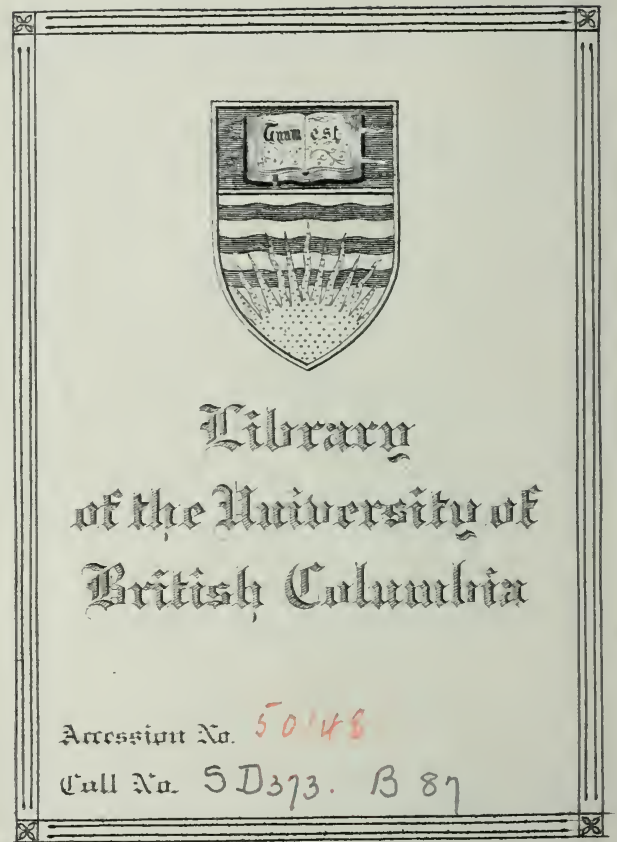



Digitized by the Internet Archive in 2010 with funding from University of British Columbia Library 


\section{WORKS ON FORESTR Y}

By the Rev. J. C. BROWN, LL.D.

I.-Hydrology of South Africa; or, Details of the former Hydrographic Condition of the Cape of Good Hope, and of Causes of its present Aridity, with Suggestions of appropriate Remedies for this Aridity. Price 10s.

In this the desiccation of South Africa, from pre-Adamic times to the present day, is traced by indications supplied by geological formations, by the physical geography or the general contour of the country, and by arborescent prodnctions in the interior, with results confirmatory of the opinion that the appropriate remedies are irrigation, arboriculture, and an improved forest economy; or the erection of dams to prevent the escape of a portion of the rainfall to the sea-the abandonment or restric. tion of the burning of the herbage and bush in connection with pastoral and agricultural operations-the conservation and extension of existing forests-and the adoption of measures similar to the reboisement and gazonnement carried out in France, with a view to prevent the formation of torrents, and the destruction of property occasioned by them.

II.--Water Supply of South Africa, and Facilities for the Storage of it. Price 1Ss 6d.

In this Volume are detailed meteorological observations on the humi. dity of the air and the rainfall, on clouds, and winds, and thunder. storms; sources from which is derived the supply of moisture which is at present available for agricultural operations in the Colony of the Cape of Good Hope and regions beyond, embracing the atmosphere, the rainfall, rivers, fountains, subterranean streams and reservoirs, and the sea; and the supply of water and facilities for the storage of it in each of the divisions of the colony - in Basutoland, in the Orange River Free State, in Griqualand West, in the Transvaal Territory, in Zululand, at Natal, and in the Transkei Territory.

III.-Forests and Moisture; or, Effects of Forests on Humidity of Climate. Price 10s.

In this are given details of phenomena of vegetation on which the meteorological effects of forests affecting the humidity of climate depend - of the effects of forests on the humidity of the atmosphere, on the humidity of the ground, on marshes, on the moisture of a wide expanse of country, on the local rainfall, and on rivers-and of the correspondence between the distribution of the rainfall and of forests- the measure of correspondence between the distribution of the rainfall and that of forests - the distribution of the rainfall dependent on geographical position, determined by the contour of a country - the distribution of forests affected by the distribution of the rainfall-and the local effects of forests on the distribution of the rainfall within the forest district.

IV.-The Forests of England; and the Management of them in Bygone Times. Price $6 \mathrm{~s}$.

Ancient forests, chases, parks, warrens, and woods are described; details are given of destructive treatment to which they have been sub. jected, and of legislation and literature relating to them previous to the present century. 
V.-The Schools of Forestry in Europe: A Plea for the Creation of a School of Forestry in Edinburgh. Price 2s.

VI.-French Forest Ordinance of 1669 ; with Historical Sketch of Previous Treatment of Forests in France. Price 4s.

The early history of forests in France is given, with details of devas. tations of these going on in the first half of the seventeenth century ; with a translation of the Ordinance of 1669 , which is the basis of modern forest economy ; and notices of forest exploitation in Jardinage, in $L a$ Methode $\dot{a}$ Tire et Aire, and in La Methode des Compartiments.

VII.-Reboisement in France; or, Records of the Replanting of the Alps, the Cerennes, and the Pyrenees, with Trees, Herb. age, and Bush, with a view to arresting and preventing the destructive consequences of torrents. Price 12s.

In this are given a résume of Surrel's study of Alpine torrents, and of the literature of France relative to Alpine torrents, and remedial measures which have been proposed for adoption to prevent the disas. trous consequences following from them-translations of documents and enactments, showing what legislative and executive measures have been taken by the Government of France in connection with réboisement as a remedial application against destructive torrents -and details in regard to the past, present, and prospective aspects of the work.

\section{VIII.-Pine Plantations on Sand Wastes in France. Price 7 s.}

In this are detailed the appearance presented by the Landes of the Gironde before and after culture, and the Landes of La Sologne; the legislation and literature of France in regard to the planting of the Landes with trees; the characteristics of the sand wastes; the natural history, culture, and exploitation of the Maritime Pine and of the Scots Fir; and the diseases and injurious influences to which the Maritime Pine is subject.

IX.-Forests and Forestry of Finland. Embodying a dis. cussion of the advantages and disadvantages of Svedjande, the Sartage of France, and the Koomaree of India. Price 6s 6d.

Which will be followed by a Companion Volume, now in the Press, X.-Forests and Forestry of Northern Russia. Embody. ing details of the exploitation of forests by Jardinage, and its effects.

Copies of any of these Works will be sent Post-paid to any address within the Postal Union on receipt by Dr JoHs C. BRows, Haddington, of a Post-Office Order for the Price.

EDINBCRGH : OLIVER \& BOYD.

LONDON : SIMPKIN, MARSHALI \& CO., AND W. RIDER \& SON. Moxtreal : DAWSON BROTHERS. 


\title{
INTRODUCTION TO THE STUDY
}

\author{
OF
}

\section{MODERN FOREST ECONOMY.}

BY

JOHN CROUMBIE BROWN, LL.D.,

Formerly Lecturer on Botany in University and King's College, Aberdeen; subsequently Colonial Botanist at Cape of Good Hope, and Professor. of Botany in the South African College, Capetown; Fellow of the Linnean Society; Fellow of the Royal Geographical Society; and Honorary Vice-President of the African Institute of Paris.

E D I N B U R G H:

OLIVER AND BOYD, TWEEDDALE COURT. LONDON: SIMPKIN, MARSHALL, \& CO., AND WILLIAM RIJER \& SON. MONTREAL: DAWSON BROTHERS. 



\section{P R E F A C E.}

IN the Spring of 1877 , while measures were being taken for the formation of an Arboretum in Edinburgh, knowing something of the constitution and of the work of Schools of Forestry on the Continent, of what was required in order to the economic and efficient conservation, exploitation, and extension of existing forests in our Colonies, and of the studies and mode of study pursued in the University, and in the Watt Institute in that city, I issued a pamphlet entitled The Schools of Forestry in Europe: a Plea for the Creation of a School of Forestry in connection with the Arboretum at Edinburgh, which was addressed 'To the Right Honourable the Lord Provost, the Magistrates, and the Town Councillors of Edinburgh; to the Office-Bearers of the Scottish Arboricultural Society; to the promoters of the purchase of ground at Inverleith to be transferred to Government for the formation of an Arboretum; and all others whom it may concern.'

In this I submitted for consideration the opinion "that with the acquisition of the Arboretum, and with the existing arrangements for study in the University of Edinburgh, and in the Watt Institute and School of Arts, there are required only facilities for the study of what is known on the Continent as Forest Science, to enable these Institutions conjointly, or any one of them with the 
help of the others, to take a place amongst the most completely equipped Schools of Forestry in Europe, and to undertake the training of foresters for the discharge of such duties as are now required of them in India, in our Colonies, and at home.' And I gave detailed information how this might be accomplished, specifying existing classes in which what was necessary was now being taught.

The estate at Inverleith has since been acquired at an expenditure, it is said, of $£ 20,000$-it has been transferred to the Government-and it is being converted into an Arboretum, such as was contemplated. And at a meeting held on the 28th of March last year, presided over by the Marquis of Lothian, while the assemblage was representative of all interests - scientific, practical, and professionalit was resolved:- ' That it is expedient in the interests of forestry, and to promote a movement for the establishment of a National School of Forestry in Scotland, as well as with the view of furthering and stimulating a greater improvement in the scientific management of woods in Scotland and the sister countries which has manifested itself during recent years, that there should be held in Edinburgh, during 1884, and at such season of the year as may be arranged, an International Exhibition of forest products and other objects of interest connected with forestry.' It was then moved, seconded, and agreed:'That this meeting pledges itself to give its hearty co-operation and patronage to the promotion of an International Forestry Exhibition in Edinburgh in 1884; and those present resolve to give their best efforts and endeavours to render the Exhibition a success, and of such importance and general interest as to make it worthy of the name of International.' 
It is in accordance with this resolution, and in discharge of obligations which it imposed, that the following volume has been prepared.

There is, I find, a general impression that the work of a forester is very simple work: he has just to plant seedlings or saplings supplied to him by the nurseryman; to thin out what can be best spared, when, as they grow, they begin to crowd one another; to prune off, if necessary, useless branches; to keep up a good undergrowth to afford shelter to game; and to superintend the felling of trees when they have reac'ed their maturity. And it is thought there is no gre ut need for any School of Forestry or for any training for such work other than may be acquired by acting for some time as a forester's assistant. This, it is thought, may supply in time to come, as it has often done in time past, all that is required to fit the forester to do all that.-And in regard to the forthcoming exhibition again and again I have been told, 'I wonder what you will get to exhibit.' I have no means of knowing to what extent these views may be shared by my readers. But I hope they know better. As botany, contrary to the supposition of many that it only concerns itself with the long unpronounceable Latin and Greek names given to plants, relates to every thing pertaining to vegetation, so forestry or forest science, Forstrvissenschaft, contrary to the opinion that it is limited in its sphere as the opinions I have referred to imply, relates to everything connected with forests or pertaining thereto-EVERYTHING.

It does not come within the scope of my present undertaking to attempt to demonstate this; but having affirmed it I publish the following Introduction to the Study of 
Forestry, hoping by the perusal of it, some may be prepared with greater advantage to visit the Exhibition which in a few months will be opened in the capital.

The following treatises have also been prepared and published with a view of introducing British students of Forest Science to views entertained by many on the Continent, and the appliance of them to practical questions which are cropping up amongst us :-

The Schools of Forestry in Europe: a Plea for the Creation of a School of Forestry in Edinburgh; The Forests of England; and the Management of them in Bygone Times; French Forest Ordinance of 1669; with Historical Sketch of previous Treatment of Forests in France; Forests and Forestry of Finland, embodying a discussion of the advantages and disadvantages of Svedjande, the Sartage of France, the Koomaree of India; Forests and Forestry of Northern Russia, embodying details of the Exploitation of Forests by Jardinage, and its effects; Pine Plantations on Sand Wustes in France; Reboisement in France, or, Records of the Replanting of the Alps, the Cevennes, and the Pyrenees with Trees, Herbage, and Bush, with a view to arresting and preventing the destructive consequences of torrents; F'orests and Moisture, or effects of Forests on Humidity of Climate; Hydrology of South Africa, or, Details of the former Hydrographic Condition of the Cape of Good Hope, and of Causes of its present Aridity, with Suggestions of appropriate Remedies. for this Aridity; Water Supply of South Africa, and Facilities for the Storage of it.

Haddrator, 18 : May, 1884. 


\section{O N T E N T S.}

Overture, . . . . . . . . 1-4

PART I.-The Extensive Destruction of Forests.

Chapter I.-Preliminary Statement, - . . 5-13

Original production of Forests (p. 5) ; Consequences of the Destruction of Forests (p. 10).

Chapter II.-Ancient Forests of Europe,

Ancient Forest-Covering of Europe (p. 14); Existing Remains of Ancient Forests : Greece (p. 16), Turkey (p. 17), Russia (p. 17), Siberia (p. 20), Poland (p. 21), Hungary and Austria (p. 22), Scandinavia (p. 23), Italy (p. 25), Spain (p. 26), Britain (p. 27).

Chapter III.-The Disappearance of Forests in Europe, . . . . . 30-37

Natural Decay and Reproduction (p. 30); Progressive Destruction by Man beyond Restoration by Natural Reproduction (p. 33), and the Result (p. 37).

Chapter IV.-Evils which have Followed the Extensive Destruction of Forests in Europe, 38-101

Section A.-Scarcity of Timber and Firewood, . 38-39

Section B.-Drought, . . . . . 40-56

General Statement (p. 40); Illustrations supplied from Algeria (p. 42); Statements by Schleiden (p. 48), and by Fries (p. 49); Illustrations supplied from South Africa (p. 5l). 
Section C.-Floods, Inundations, and Torrents,

France (p. 57), Spain (p. 58), Hungary (p. 64), Cape of Good Hope (p. 65) ; Origin of Floods and Characteris. tics of Inundations ( $p .66$ ) ; Preventive Operation of Forests when occasioned by Rainfall (p. 67), or by the sudden Melting of Snow (p. 73), with Illustrations supplied from the Department of Vancluse, in France (p. 75); Testimony by M. Jules Clavé (p. 79); Remarks on the Inundation of Toulouse, by the Journal des Debâts (p. 81); and Discussion of Prin. ciples involved (p. 82).

Section D.-Torrents, Avalanches, and Landslips, 84-95

Statements in regard to Torrents $(p .84)$; in regard to Avalanches (p. 87); and in regard to Landslips (p.90).

Section E.-Sand-Drifts, . . . . 95̆-101

Remains of former Forests in Sand Plains (p. 95) ; Illustra. tion of Effects of Destruction of Trees on Sand Plains supplied by Drift-Sands in the vicinity of Danzig ( $p$. 96); Remarks by Surell (p. 100).

\section{PART II.-Elements of MOdern Forest} EcoNomy, . . . . . 102-104

ChAPTER I.-Forest.Conservation, . . 105-106

Chapter II.-Reboisement, . . . . 106-130

SECTION A.-General Advantages Resulting from Reboisement Experienced in Algeria, . . 108-110

SeCtion B.-Effects of Reboisement in Arresting and Preventing the Occurrence of Torrents and Inundations,

Statements by M. Gentil (p. 113); by M. Delafont (p. 116); by M. Surell (p. 116); by Vicomte de Bonald (p. 117); by Edinburgh Review (p. 117); and by Budget Committee of National Assembly of France (p. 118.) 
Section C.-Effects of Reboisement in Fixing down and Utilising Drift-Sand

Work of Herr Soeren-Bioern in the vicinity of Danzig (p. 121) ; Continuation of the Work by Herr Krause (p. 125); Continuation of the Work under Herr Hagen (p. 129) ; Remains of Ancient Forests (p. 130.)

Chapter III.-Exploitation, . . . . . 131

Section A.-Sartage, . . . . 131-137

Sartage in France (p. 132); in North of Europe, \&c. (p. 133); in India (p. 131); Modification of it in America (p. 138.)

Section B.-Jardinage, . . . . 137-138

Section C.—La Wethode à tire et aire, . 138-153

Origin of usage (p. 138); Excerpts from French Forest Ordinance of 1669 (p. 141); Import of the designation (p. 147); Advantages and Disadvantages of the Method (p. 149.)

Section D.-Furetage and Taillis sous Futaie, 153-165

Furetage (p. 153); Modification proposed by M. Guinier (p. 154); Taillis sous Futaiae (p. 169.)

\section{Section E.--La Methode des Compartiments, $\quad 168-186$}

Defects of La Methode a Tire et Aire (p. 165) ; Improvements by Hartig and Cotta (p. 167); Details of the improved Method of Exploitation (p. 175).

Chapter IV.-Sylviculture, 1S7-192

Explanation of the term (p. 187); Illustration supplied by the Culture of the Austrian Pine (p, 189.)

Chapter V.-Study of Pathology, 193-202

Diseases of Trees (p. 193); Notice of Fungi infesting the Austrian Pine (p. 194.) 
PART III.-Forest ADiInISTRATION.

Disadvantages of employing unqualified Managers of Forests (p. 201); Employment of such in France 200 years ago (p. 201); in England within the last 100 years (p. 205); in the Colony of the Cape of Good Hope within the last 50 years (p. 205); Organisation of Schools of Forestry on the Continent of Europe (p. 206); Illustration supplied by the School of Forestry in the Escurial, Spain (p. 20S); Salary and Social Position of Educated Forest Officials (p. 214) ; Pre-requisites for Employment in the Forest Service of India (p. 215); Resultant Pecuniary Profits (p. 223) ; Conclusion (p. 225).

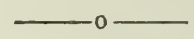

\section{AUTHORS, \&C., Cited.}

AdAM, p. 15 ; Bagneris, p. 15̌3-18S; Blatedi, p. 79 ; Blore, p. 55 ; Viconte de Bonald, p. 117 ; Botssivgalt, p. 70 ; Brandis, p. 215 ; Bretux, 89 ; Broillard, p. 44 ; Bechayar, p. 28 ; Calmels, p. 45 ; Cauvigril, p. 80 ; Cezanse, p. 71-90; Chapular, p. 52 ; Chalmers, p. 27 ; Chessel, p. 44 ; Clave, p. 79.169; Cleghors, p. 13.5, 215 ; Costa DE BAstelica, p. 111 ; Cour's Elementaire de Culture des Bois, p. 159 ; Deherais, p. 45-46; De LA Fort, p. 116 ; Dupis, p. 47 ; Eliser Reclus, p. 44 ; Forests and Forestry of Finland, p. 7, $15,17,157,213$; Fliedier, p. $5 \mathrm{~S}$; Forest Departinent of INdia, p. 215 ; The Forests of England, p. 27, 25, 205; Forests and Moistures, p. 41.75 ; French Forest Ordinance of 1669, p. 39, 13S, 201 ; FrIEs, p. 49 ; Gextil, 113 ; Gorse, p. 67, 87, 90 ; DE LA Grye, p. 161 ; GCINIER, p. 154 ; Hagex, p. 120 ; Hall (p. 65) ; Hartig and CotTA, p. 167-191; HeINDReich, p. 34; HericarT DE ThURY, p. 86 ; Humbolt, 42 ; Hydrology of South Africa, p. 7, 40, 54, 13S; Joumal of Forestry, p. 213 ; Journal des Debîts, S1; Jules MaIstre, p. 54 ; Labuissiere, p. 75 ; London Medical Journal, p. 33 ; Lorerz and Parade, p. 137 ; MACGREGOR, p. 136 ; MAHE, pp. 43, 46, 47, 48, S0; MARNY, p. 16 ; MARsH, pp. $7,9,27,34$; MAURY, p. 44 ; Moffat, p. 52 ; Orlinance of 1669 , p. 141 ; PARADE, pp. 134, 137, 140, 165, 168; Pine Plantations on Sand Wastes in France, pp. 101, 1S9, 192; Rapports Annuels de Meteor. ologie Forestieres, p. 47 ; RACCH, pp. 42, 44, 47; Reboisement in France, pp. 57, 66, 85, S7, 112, 185; RExxaRD, p. 10s; Forests of Northern Russia, p. 138 ; SchleIdEs, p. 4S ; Schools of Forestry in Europe, p. 213 ; V. Schubert, p. 133 ; Serviay Proverb, p. 42 ; Sokainoff, p. 148 ; Sureis, pp. 42, 46, S6, 91, 100, 116 ; Barox F. V. Thuemes, p. 194; Tholard, p. 6 ; Times, p. 206 ; Viollet le Doc, pp. 43 89 ; CAMPBELL.WALKER, pp. .169, 1S0, 224; Water Supply of South Africa, p. 41 ; Wessely, pp. 96, 120. 


\section{NTRODUCTION}

TO THE

STUDY OF MODERN FOREST ECONOMY.

O V E R T U R E.

ACCORDing to old English usage, and in legal phraseology still, the term forest is applicable primarily not to a mass of trees, but to a place of resort and shelter for animals which may be pursued and slaughtered for amusement And it was only in a secondary sense that the term was first applied to the chief characteristic of such a place of resort and shelter-the trees. To many it may appear incongruous to speak of a place as a forest irrespective of trees; but the usage is common in speaking of the deer forests of Scotland; and the usage is justifiable, though it may remind one of the ironical announcement of ' the play of Hamlet, with the part of Hamlet left out.' A like change to that which has taken place in the course of time in the tise of the English term seems to have occurred in the use made of the corresponding terms in French and in German.

In the conservation, culture, and exploitation, or profitable disposal of forest products, considerable differences of practice exist. In Britain we hear much of gamekeepers; on the Continent of Europe we hear much of forestwarders; here the game, there the wood, is the principal object of conservation. In Britain we hear much of arboriculture; on the Continent we hear much of sylviculture; the former refers to woods and plantations, the other term speaks of woods and forests; in the one case 
the unit is the tree, and the wood is considered as the collection of trees; in the other the wood is the unit, and the trees are considered only as its constituent parts. In the former attention is given primarily to the sowing and planting, and pruning it may be, and general culture of the tree; nowhere, perhaps, has this arboriculture been carried nearer to perfection than it has been in Britain; and the effects produced by the resulting woods are wonderful. In the latter, attention is given primarily to the wood or forest as a whole, capable of yielding products which can be profitably utilised; and the result generally is to produce a much greater proportion of fine trees than does even the arboriculture which has been referred to. And not less different is the exploitation of woods in Britain and on the Continent. In Britain the pecuniary returns obtained from woods is considered a secondary matter in comparison with the amenity and shelter which they afford; but on the Continent the material or pecuniary product, or other ecomonic good, is made the object of primary importance.

The arboriculture of Britain may seem to leave little to be desired ; but nowhere, perhaps, are forests treated with greater recklessness than they have been in some of our colonies and dependencies. In India, however, and some of our colonies, an endeavour is now being made to arrest the destructive practices which have prevailed, and to introduce a system of treatment of forests more in accordance with the advanced forest science of the day.

In the United States of America and in Canada there have been effected extensive clearings of forest lands resulting in injurious effects upon the climate, and in a greatly diminished supply of timber, with no prospect of this being compensated by the subsequent growth of trees in the localities. In some of our colonies extensive forests have been treated as are beds of onions, leeks, cabbages, and trnips, in the kitchen garden. 'Trees deemed suitable 
for some purpose desired have been felled, others around them have been left standing, or have been cut down to allow of the felled timber being brought out; and the results have been scarcely less destructive than the forest clearings in the Western World. These results may be seen in what were once forest-lands in the colony of the Cape of Good Hope; and in Europe they may be seen in Northern Russia.

More than 200 years ago France was in danger of being entirely devastated by this system of jardinage in the exploitation of forests, and there was issued an ordinance requiring that crown forests should be divided into a specified number of sections, one only of which should be exploited at a time, so as to allow time for the trees to be reproduced in each before ail the others had been exploited in succession. The measure was hailed as one likely, where adopted, to save not only France, but also other countries in Europe from devastation. But less than 150 years sufficed to show that this was a vain hope, for the reproduced forests were not equal to those which had been felled. And early in the present century there was devised in Saxony a more complicated, but a much rnore efficient method of exploitation. This is being adopted everywhere on the Continent of Europe; it has been introduced with most satisfactory results into the management of forests in India; and the adoption of it seems to be the only means available to prevent the ruin of forests in our colonies, which are now being rapidly destroyed.

In this also the forest is divided into a number of sections corresponding to the time required for the reproduction of the trees. But instead of exploitation being confined to one of these at a time, the supply of wood required is obtained from the felling of the trees in one or more lots, and from the first, second, and third thinnings in others-all being so arranged as to secure simultaneously, and without prejudice to one or other of them, an improved condition of the forest, a sustained supply of products, and 
a natural reproduction of the forests by self-sown seed. All these results are now being obtained by this method of exploitation. It may seem to be the ne plus ultra of forest management. But in its application to any forest the arrangement of details must be based on the knowledge of a number-of a great number-of facts in regard to that forest, for the observation of which there is required an extensive and somewhat prolonged course of education, instruction, and special study.

To supply facilities for acquiring this education and instruction, there have been organised Schools of Forestry in almost every country on the Continent of Europe, most of which are connected with universities, or similar seats of learning. To procure this education and instruction, candidates for the forest service in India are required to attend the School of Forestry at Nancy, in France, their expenses being largely met by the Government. And to secure like advantages for those who may in the future undertake the management of forests in our colonies, or at home, endeavours are being made to secure the organisation of one or more Schools of Forestry in Britain.

The course of studies through which forest officials on the Continent pass, is as multifarious as is that required in this country for admission into the ministry of any of our churches, or for license to practice medicine or surgery, and a corresponding social position is awarded to these officials. Happily for the prospects of success in the endeavours which are being made to secure corresponding educational advantages for foresters in Britain, in some of our universities - for example, those of Scotland--and other educational institutions in the three kingdoms, provisions already exist for the scientific study of most of the subjects to which attention is given in the Schools of Forestry on the Continent. But there is still required, in addition to these, sume provision for directing the studies of candidates for employment of foresters, and for supplying to them the practical instruction specially required for the discharge of the duties to which they aspire. 


\section{$\mathrm{P}_{\mathrm{A}} \mathrm{ART}$ I.}

THE EXTENSIVE DESTRUCTION OF FORESTS.

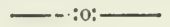

\section{CHAPTER I.}

\section{PRELIMINARY STATEMENT.}

Some 2000 years ago Europe was extensively covered with forests. It is not so now. We have remains of forest trees preserved in peat bogs where no forests now exist; and numerous places bear names given to them in reference to their proximity to forests when they were so named, though there no forests are now to be seen; and we have extensive remains of some of those ancient forests from which some idea may be formed of what must have been the appearance of the country then. But over areas indefinitely more extensive, fields, and vineyards, and cities, have taken the place of the forests; architectural monuments now stand where once stood 'the oak, the monarch of the wood;' and in vain does the sentimentalist sigh for 'a lodge in some vast wilderness, an endless continuity of shade' where are now fields, and manufactories, and populous towns and cities. There all is changed; and science speculates on what might have been the origin of these forests, as history tells only of the disappearance of the forest wilds.

There exists an opinion in regard to the succession in which vegetable organisms of ever higher development appeared on the dry land of the globe, which, though not propounded with such explicit references to ascertained facts as might be desired in a scientific theory, has been 
extensively accepted by scientific men, and the truth of which, so far as is known to me, has never been called in question. In an address delivered before La Ligue du Reboisement de L'Algerie, by Dr Tholard, the founder of the league, there was given the following graphic statement of the views in question :-

"When the mountains arose in the geological revolutions which gave to them birth, they must have presented themselves in the condition of bare rocks, or banks of solidified matter, without trace of vegetation. But soon thereafter moisture in the atmosphere, deposited on their surface, penetrated into fissures, and there expanding in passing from the liquid to a solid state with a fall of temperature, burst asunder the walls of the interstices into which they harl infiltrated, and the work of the disintegration of the rock began. This physical action of the water was followed by a chemical action due to carbonic acid, with which it is always charged, which, combining with the alkaline elements of the rocks, decomposed and dissolved them, leaving a skeleton of rock more easily penetrable by water; and, as a consequence, facilitating its further disintegration. Thus there was produced, self-formed, a layer of vegetable soil, or soil capable of sustaining vegetation, resting almost immediately on the rock as yet unaffected. Then in many places became developed the first formed vegetables, the germs of which had been borne thither by the air; but these, doubtless, were vegetables of simple organisation, the conditions not being as yet favourable to the germination and growth of plants of more complex structure. However low in the scale of vegetable organisation these might be, they continued or carried further the work of disintegration begun by the atmospheric moisture; their rootlets penetrated into the fissures of the rock, and on the death of the plant these became themselves decomposed, leaving thus a path open for water, which by degrees, like an indefatigable miner, continued its work of crumbling down the rock.

'By the decomposition of the rock thus effected, the 
vegetable layer slowly increased, continuously enriching itself with the débris of the plants which it had sustained; and the inferior vegetables were gradually replaced by others of a higher organisation, to give place in turn to vegetables of yet higher rank in the vegetable kingdom, which do not germinate and develope themselves except under the most favourable conditions; and, last of all, to forests. It is thus that through the accumulated work of centuries the mountain, at first a bald and naked rock, has been covered, first with a vegetation of cryptogamic and inferior plants, and been prepared by slow degrees, little by little, to sustain plants of a higher order in the vegetable series, and finally with trees, the seeds of which do not germinate and grow excepting on soil which has been previously occupied and prepared for them by other vegetables, their precursors in the occupation of the soil.'

There are points in this statement to which exception may be taken, but as a popular account of the course of events, it may be accepted without cavil. In Finland: its Forests and Forest Management (p. 27), I have stated what I have seen of cryptogams, herbs, and ligneous plants growing upon the same rock; and in Hydrology of South Africa (pp. 163-164), I have cited the views advanced in Marsh's work, entitled The Earth as Modified by Human Action, in regard to the growth of trees on virgin soil, and on soil which has happened to be cleared of vegetation. Amongst nther things noticed it is stated by Marsh:-

' Whenever a tract of country, once inhabited and cultivated by man, is abandoned by him and domestic animals, and surrendered to the undisturbed influences of spontaneous nature, its soil, sooner or later, clothes itself with herbaceous and arborescent plants, and at no long interval with a dense forest growth. Indeed, upon surfaces of a certain stability, and not absolutely precipitous inclination, the special conditions required for the spontaneous propagation of trees may all be negatively expressed, and reduced to these three:-exemption from defect or excess of moisture, from perpetual frost, and from the depredation of 
men and browsing quadrupeds. When these requisites are secured, the hardest rock is as certain to be overgrown with wood as the most fertile plain, though in drier seasons the process is slower in the former than in the latter case. Lichens and mosses first prepare the way for a more highly organised vegetation, They retain the moisture of rains and dews, and bring it to act, in combination with the gases evolved by their organic processes, in decomposing the surface of the rock they cover; they arrest and confine the dust which the wind scatters over them, and their final decay adds new material to the soil already half-formed beneath and upon them. A very thin stratum of mould is sufficient for the germination of seeds of the hardy evergreens and the birches, the roots of which are often found in immediate contact with the rock, supplying their trees with nourishment from a soil deepened and enriched from the decomposition of their foliage, or sending out long rootlets into the surrounding earth in search of juices to feed them.'

The light which has been thrown by Darwin and others, who have followed in the track of research opened up by him, upon the phenomena of a struggle for life and the survival of the fittest, which is going on extensively in nature, enables us to account satisfactorily for the great extension of forests over Europe and over other lands in which forests predominate. We can see how it may have been brought about, and not only see how ligneous vegetables should have superseded herbs, but understand how these have superseded lichens, and fruitful fields have superseded forests. In the case of the lichen-covered rock each succeeding plant found a soil and condition more favourable for its growth than for the growth of the plant by which it was preceded; and this made way for it after it had served its generation according to the will of God. By a similar process was the soil subsequently prepared for the production of trees, which, in common with their immediate predecessors, could not have flourished at an earlier 
epoch. But we find that man has made the forest to give place to the garden and to the fruitful field produced by man's device. He has handicapped the cereal and the fruit-bearing tree; he has burned or felled the forest; has sown seeds of the vegetables he desired to grow; has promoted the growth of them by all means at his command, and has succeeded to an extent which he never could have done had he sown his seed on the bare rock, or on the sand dune or the heath, or upon the same spot before it had undergoue the preparation through which it has passed.

In view of this we may be led to conclude that one important function of forests in terrestrial economy is to utilise the area covered by them, and while so utilising it to prepare it for being utilised still more by man when he is so advanced in civilisation as to be able otherwise to make use of it to the benefit of himself, his family, and his pcople. But all is not gain. Evil as well as good has followed in the wake of the artificial change. Marsh, in continuation of the statement I have cited in regard to the natural production of the forests on what was long before a bare rock, tells :-

'With the extirpation of the forest all is changed. At one season the earth parts with its warmth by radiation to an open sky; receives, at another, an immoderate heat from the unobstructed rays of the sun. Hence the climate becomes excessive, and the soil is alternately parched by the fervours of summer, and seared by the rigours of winter. Bleak winds sweep unresisted over its surface, drift away the snow that sheltered it from the frost, and dry up its scanty moisture. The precipitation becomes as irregular as the temperature; the melting snows and varied rains, no longer absorbed by a loose and bibular vegetable mould, rush over the frozen surface, and pour down the valleys seawards, instead of filling a retentive bed of absorbent earth, and storing up a supply of moisture to feed perennial springs. The soil is bared of its covering of leaves, is broken and loosened by the plough, deprived 
of the fibrous rootlets which held it together, dried and pulverised by sun and wind, and at last exhausted by new combinations. The face of the earth is no longer a sponge, but a dust heap; and the floods which the waters of the sky pour over it hurry swiftly along its slopes, carrying in suspension vast quantities of earthy particles, which increase the abrading power and mechanical force of the current, and, augmented by the sand and gravel of falling banks, fill the bed of the streams, divert them into new channels, and obstruct their outlets. The rivulets, wanting their former regularity of supply, and deprived. of the protecting shade of the woods, are heated, evaporated, and thus reduced in their former currents,- -but swollen to raging torrents in autumn and in spring.

'From these causes there is a constant degradation of uplands, and a consequent elevation of the beds of watercourses, and of lakes, by the deposition of the mineral and vegetable matter carried down by the waters. The channels of great rivers become unnavigable, their estuaries are choked up, and harbours which once sheltered large navies are shoaled by dangerous sand-bars.

' The earth stript of its vegetable glebe grows less and less productive, and consequently less able to protect itself by weaving a new net-work of roots to bind its particles together, a new carpeting of turf to shield it from wind and sun and scouring rain. Gradually it becomes altogether barren. The washing of the soil from the mountains leave bare ridges of sterile rock, and the rich organic mould which covered them, now swept down into the dark low grounds, promotes a luxuriance of aquatic vegetation that breeds fever and more insidious forms of mortal disease by its decay, and thus the earth is rendered no longer fit for the habitation of man.'

But this is only one of many evils. At different times and in different countries there has been raised a cry that the destruction of forests was being carried on too rapidly and too extensively; and consequent evils have 


\section{PRELIMINARY STATEMENT.}

manifested themselves to an extent which has caused considerable anxiety to men of observation and forethought. The cry has gone up not once only, or from one land alone, but it has been repeatedly heard ; there is scarcely a country in Europe in which it has not been raised at one time or another; and as it has been in Europe so has it been elsewhere. This has been chiefly within the last 250 years; but it has been found that the evil has been going on since a time long before the commencement of the 2000 years which are characterised to us by the march of Christianity and modern civilisation and science; and the effects have been felt both in the Old World and the New. Now, after successive applications of topical remedies to the evils as they manifested themselves in different lands and at different times, modern science, and more especially that in modern science to which the designation 'Forest Science' has been given, has been brought to bear, not without success, upon the discovery of appropriate permanent scientific remedies for the evil in the multiform phases in which it presents itself.

The more pressing forms of the evil were seen in a reduced supply of wood, such as is yielded by timber forests; and of wood, such as is yielded by coppice woods; a diminished humidity of soil and climate beyond what is fuvourable to agriculture and allied industries pertaining to rural economy; the occasional occurrence of devastating torrents and inundations; and the drifting of sterile sands over lands previously fertile and productive.

In regard to some of these phases of the evil it may be stated that the remedy which at once suggested itself as practicable was employed, sometimes with success and sometimes ineffectually; and the accumulated observations of results have not been lost to forest science, or the practical application of that science in furest economy.

There are numerous well-known facts which show that the destruction of single trees, of plots of trees, and in 
some cases, of extensive stretches of forest, have been destroyed by means in operation apart from the doings of man: such as what may be called natural decay; drought and frost; thunder storms and storms of wind and hail and snow; epiphetic and parasitic vegetable growths; and insects, and birds, and beasts.

But to a far greater extent have forests been destroyed by reckless fellings in wasteful exploitations; and by these increased by malversations of officials, and by depredations. To some extent injuries have been done by flocks and herds depastured in the woods. And to a great extent have forests been destroyed by fire applied to the clearing away of trees, in order that the ground might be obtained for agriculture, and by fires attributable to accident, but to accident attributable to the carelessness of man.

The comprehensive view thus taken of the matter confirms the conclusion that the appropriate remedial applications may resolve themselves into endeavours to arrest the progress of destruction, and endeavours to restore again what has been taken away; but it may also have expanded somewhat the conception formed by us of what is required in forest conservation and in forest restoration, and this may call for further differentiations:-

There must be conservation against destruction occurring irrespective of man's agency, against destruction through man's carelessness, against destruction through man's dishonesty, and with this an improved, more ecomonic, and less wasteful forest exploitation; and with this may be combined or conjoined forest restoration, reboisement as a preventive of the formation of destructive torrents and inundations, reboisement as a means of increasing the humidity of the soil and climate, and increasing the salubrity of the atmosphere, and the planting of trees as a means of arresting and utilising drifting sand. Most of what relates to the first of these measures-conservation against destruction, occurring irrespective of man's agency, may with advantage be discussed apart under a discussion 
of the physiology and pathology of trees and arborescent vegetation; and most of what relates to the destruction of forests through the carelessness of man may with advantage be discussed apart under a discussion of the destruction of forests by fire and of preventive appliances.

Most of the other measures specified will be discussed in the sequel under the general head of Forest Economy, inclusive of forest conservation and forest extension and forest exploitation. But first must be established the conviction of my readers that some such extensive destruction of forests as I have indicated has actually occurred, with the results I have alleged. In view of this the immediately succeeding chapters will be occupied with illustrations of what has be:en alleged, advanced in illustration of the meaning of what has been said, but which may be found to be to some extent of the nature of proofs, - such proofs as hypotheses are subjected to by experiments designed to test them by demonstrating their accordance, or their want of accordance, with fact. 


\section{CHAPTER II.}

\section{ANCIENT FORESTS OF EUROPE.}

THE indications of its having been the case that, some two thousand years ago the greater part of Europe was covered with forests, are numerous and varied. And from existing remains of these forests some idea may be formed of what must then have been the condition of Europe: in some regions, but not everywhere, one continuous dense mass of trees; but more frequently extensive stretches of forest, impenetrable to man and beast, but varied with forest glades, the home of the beasts of the forest, and inhabited by a savage people : so named, it may be, from their living in the woods, "wild men of the woods'-Silvagers, sauvages - savages; a people cruel in their revenge when molested by immigrants of greater civilisation, and so cruel in retaliating on those forcibly invading their dwelling-place injuries done to them or imagined, that in the present day the term sarage has become a synonym for cruel; and it is applied to all uncivilised nations, with an emboliea idea that such is their character, though deeds not less to be reprobated than any of theirs have been perpetrated by individuals and nations, the product of the civilisation of modern times, with all the elevating influences which Christianity has yet exercised upon Christendom.

The existing forests of Germany, the Thuringerwald in Gotha, the Schwartzwald or Black Forest in Baden, the Oderswald in Hesse, the Spêssart, between Aschaffenburg and Wurtzburg, and the forests in the Austrian Alps, are all of them only fragmentary remains of the great Hircynian Forest, which originally covered the greater part of Con- 
tinental Europe, and was extensively diffused over the districts now known as Germany, Poland, Hungary, \&c. In Cæsar's time it extended from the borders of Alsatia and Switzerland to Transylvania, and was computed to be sixty days' journey long and nine broad.

So late as the eleventh century, Adam of Bremen, writing of Denmark, describes it as horrida sylvis. There all remains of that ancient forest have disappeared. But in Norway and Sweden, in Finland and Russia, we have remains, or representatives, of the northern skirt of the immense forest which once covered Europe.

In Northern Russia we still have forests through which the traveller, travelling fast as his tarantass and troika can carry him, is days and days passing through a continuous forest of trees, columnar trees, tall and straight, bearing aloft an umbrageous canopy, under the shade of which is induced a melancholy which is oppressive to the soul. In Finland, with its thousand lakes, all is joy and gladness as day after day the steamer wends its way, rounding islands and headlands which are wooded to the water's edge, and present on every change a scene of loveliness.* On the Hartz mountains, again, are found upon a small scale dense forests like to those of Russia, but with variations attributable to hills taking the place of plains, and giving pleasing variety to the scene; and in the Black Forest we meet again with the counterpart to Finland, with forest glades for wooded isles, and fertile fields for fiord-like lakes. These are two types of forests and forest lands widely dispersed over Europe, separated by wider areas which, though not devoid of trees, are altogether devoid of forests. And in these again the former existence of forests is indicated by the names of many places having a reference to some adjacent wood, once growing there, but now no more; while in some cases the remains of the former forest are found buried in the ground, or 
preserved in some peat bog which has been created there.

Of forests in Europe the following account is given in a valuable work on the subject by M. F. L. Marny:-

'Greece possessed scarcely any forests at the Roman epoch. The rapid progress of agriculture had caused the disappearance, or reduced to simple groves, those forests of Erymantheus, of Nemeus, with whose name so many herioc recollections of the Hellenes are connected. These have in our day almost totally disappeared; Tempé was already at the commencement of our era only a shady valley, instead of the thick forest it had been; lastly, Dodona, so renowned for her forest of oaks, had seen her prophetic trees diminishing with the celebrity of her oracle.

'From the time of Pindar, the Altis of Olympia was nothing more than a simple thicket, which bore little resemblance to that sacred wood sonsecrated to Jupiter, like the forest of Dodona, a wood of which it has preserved the name.

'Crete now no longer presents forests ; scarcely do a few thickets of olive trees yet adorn her heights, which were doubtless formerly as shady as those of the Ida of Phrygia It is the same with the Isles of Nanfi, Antiparos, Ipsara, Nio, Samos, and Polycandro. The forests of Chios, formerly so abundant, have abandoned her mountains; for they no longer present any thing but an image of drought and sterility.

'In the Archipelago forests are no longer met with except at Imbros, which is still completely covered with them, and in which abundance of game is concealed under the tall oaks and firs; at Lemnos, not less wooded; at Paros, whose mountains are shaded by oaks, pines, and firs, like those of Mycone, of Thaos. Stampalia, the ancient Astypelea, if it does not afford lofty trees, has at least numerous groups of Kermes oaks, pines, brambles, and maples. 
' In the Ionian Isles the clearance of wood has proceeded more rapidly than in the Cyclades; forests, from which Mount Nero in the island of Cephalonia obtained its name, disappeared after the establishment of the Venetians. The northern part of Corfu, at the same time, remains yet covered with abundant forests of planes, cedars, pines, tirs, beeches, and elms. Teucarlia has beautiful oak-woods, which supply Ithaca with the wood with which it is actually unprovided. Zante, the ancient Zacynthus, which Strabo describes as still very woody, is now completely destitute of forests.

- Turkey presents in our days a state analogous to that of ancient Greece; the distribution of forest vegetation does not appear to have changed much. 'The oak is the kind which forms the basis of it; the predominant species are quercus robur, quercus cerris, quercus pubescens, quercus pedunculata, aegilops, cylindrica, and apenrina; to these species are united, in Albania and at Epirus, as well as in Thessaly, in maritime Macedonia, and upon Tekir-Dagh, the quercus ilex, quercus aciculus, and quercus coccifera. Servia and Bosnia possess the most beautiful forests; in this latter province firs, pines, and birches announce a morè northern vegutation; these kinds are extended upon the southern ridge.

'Russia, which appears to be the last country of Europe that has awoke to civilisation, exhibits still that forest condition which was that of the rest of the world before man had dispossessed the ground of its thick shades, to open a free space for his agricultural labours. In this vast empire forest lines of a prodigious extent run in every direction; in the south forests are little met with except along the rivers, if we except the Black Forest, an immense wood of oaks, which covers a superficies of 4000 versts.

'Yet, in the Crimea, forest kinds become more abundant. Forests stretch over the two slopes of the central range; 
and in the localities where the soil is argilaceous, and consequently humid, the trees reach a great height. Trees are seen, above all, upon the heights which line the coast from Balaklava as far as Aloupka; from the side of Alouchta they form vast forests between Babougine-Yaila and Tebatir-Dagh. The pine of Taurida, which often attains a height of 50 feet, climbs the most elevated summits of Baghtcheh-Terai and of Tchoufout-Kaleh, whose schistous declivities it adorns. The beech, which grows in the environs of Laspi as much as a mètre in diameter, composes the bulk of certain woods.

'In Ukraine, the black earth called by the Russians stepnoï-ezernozem, which constitutes the soil of a part of South Russia, gives rise to forests of a special nature, and of which the principal kinds are oaks, limes, and elms. These trees grow with uncommon vigour, and are associated with an immense number of large pear-trees of a magnificent aspect. Nevertheless this beautiful forest mantle is often etiolated under the pernicious action of drought, which causes the destruction of thousands of trees, and particularly hazels, ashes, and elms; only the species with deep roots escape its devastating influence.

' The governments the richest in forests are those of Archangel, Vologda, Viatki, Olonetz, Perm, Kostroma, Novogorod, Minsk, and Vilna. They are each of them composed of different kinds. In the government of Archangel pines predominate, and lines of them ascend as far as 67 degrees of latitude. In that of Kostroma reign vast forests of limes. In the government of Toula this same kind constitutes also woods of a peculiar physiognomy, on account of the special forms which this tree invests itself with in this country. Its top, instead of the thick ramification which belongs to it in our climates, presents only a very slight development with insignificant branches. The oak also of these forests throws out only a small number of branches, and its leaves, like those of all the kinds in this government, have not that thickness which one admires in the forests of the East; a phenomenon which is partly owing to the constant dryness of the air. 
'These forests of particular kinds, such as pines, birches, limes, oaks, \&c., have each received in the Russian language special names which express the nature of their kinds. The richness of this language to express the idea of a forest demonstrates the ancient predominance of forests in this country. Thus they call a forest of firs, pichtovnikk; one of birches, bereznikt; a thick forest upon a marsh, luiva; debre is a forest placed in a hollow; a forest of pines and birches situated in a sandy country is called horr; one composed of lofty trees is doubrava, \&c. Formerly, when France presented a forest condition analogous to that of Russia, this language designated also by special names each kind of forest; people said a chesnaie, an aulnaie, an urnaie, a boulaie, a possellnière, expressions which fell into desuetude as soon as the forests afforded little else than a mixture of all these kinds.

'Lithuania forms a vast frontier boundary which separates Russia from Poland; it is there that the celebrated forest of Bialowiéza, which extends all over the district of Bialistock, and which still serves as a refuge for the last descendants of the urus of Oriental Europe. This forest is the only one in this region which is wortly the name of primeval forest; for it remained a few years ago abandoned to the operations of nature, and forest science made no provision for its management. It is among these ager woods, which overshadow the source of the Narova, that the urus wanders in company with the buffalo and the elk.

'Anid these primitive scenes of nature there subsists a distinct population, the Ruskes, almost as savage as the animals which surround them. In several forests of Lithuania the beech has entirely disappeared; pines, birches, and oaks replace this tree. In Essthonia, in Courland, limes re-appear, and constitute vast forests.

'In the vicinity of the Oural, the birches, larches, and cedars have ceased to form distinct forests ; they are associated with other kinds, - with firs, which like marshy ground; with pines, which grow upon stony places.

'In going towards Russia from Asia, the forest line is 
arrested only by extreme culd; elsewhere it is propagated with incredible activity. In the government of Kasan reign forests of oaks exclusively ; in those of Irkoutsk and Tobolsk forests of mixel species. On the north the coniferæ predominate; to the south, the lime, ash, and maple. The banks of the Irtisch, the Barnaol, and the Aleï are covered with vast forests of firs.

' Let us advance towards the Altaï chain, let us penetrate into the range of the Saillougueme, and we shall see the forests re-appear more vigorous than those of Siberia. The slopes of Atbachi are furnished with magnificent masses of pines and larches, whilst rhododendrons, dwarf birches, and wild currants, carpet the depths of its valleys. In the neighbourhood of Lake Kara-Kol, upon the borders of Samadjir, this latter kind is united to the fir. Between Ouspenka and the Tome, a forest of black poplars skirts the hills, which become lower as they approach this river. From the Aleï to the banks of the Irtisch stretch vast forests which have not yet been explored. If we re-ascend now those which extend into the government of Yenisei, between the chains of Tazkil and Sayansk, new kinds appear in the forest masses, and give them an aspect more or less monotonous; these are evergreen birches, whose foliage is intermingled with that of the white birch and service-trees, which take rank among the firs.

'When we leave the banks of the Yenesei, and follow the route which leads from Minousink to Touba, we find an uninterrupted succession of woods and forests. The former are composed of agreeable groups of birches, poplars, and willows. The forests less smiling were formerly overrun by the indigenous tribes and their herds of reindeer. In the present day it is with incredible difficulty that the traveller can pass through the forest bounds which divide the country with strppes. Some unfold uninterrupted lines of coniferæ, pines, and firs-these receive in the country the name of llack forests; the others, called white forests, set up, like so many tall masts, long files of white birches, 
'Notwithstanding this vast extent of forests, the epoch is not very distant in which these forests will have disappeared, and made way for meagre plantations, for clumps spread here and there upon the cultivated plain. The Muscovite peasant yields to no other people in his reckless fury in removing the timber. Cultivated lands daily succeed the forests. The sectaries who seek in the depth of the forest a refuge against religious persecution, labour also on their side in the destruction of the woods, and set on fire [?] the retreats which at present screen them from the rigour of the laws.

'At times it is not the flame kindled by the Russian labourer, but the fire brought by the carclessness of the Syrian or Siberian hunter which produces these fatal causes of destruction. The thunder-bolt [?] has equally determined those combustions which annihilated thousands of trees and sables; lastly, the rigour of cold produces also effects analogous to those of fire. If the frost does not reduce the trees to ashes it splits them often through the whole extent of their stem, with a noise that resounds in the steppes like the firing of a cannon at sea. During the winter season the forests remain buried under the ice, which by accumulating overreaches their tops. This terrible cold tinges the larches with different tints, the only trees which remind the traveller, lost in the toundras, of the existence of vegetation. Their bark is black or red acrording as they are exposed to the north or to the south, and this circumstance furnishes a sort of natural compass.

'When the forests have been ravaged by fire or cut down by the axe, the kinds which again spring up over the burned or cleared land present in succession some phenomena of alternations similar to what takes place in America. It is the birch which comes first, in small thickets; then the pines make their appearance. In Poland we meet with only very few forests capable of giving an idea of the ancient forest state of the country. A sample may be seen in the forest of Wodwosco, which 
lies upon the domain of that name, between those of Wraniezko and of Lublowicz. Whilst one part, cleared about forty years ago, affords only a continuation of bushes and thickets, in the midst of which spring up here and there a few alders, maples, or hollies, in that which the hand of man has respected to this day the forest offers admirably tall trees of oak and beech mingled with majestic firs. The bushes disappear, then a thick carpet of moss and heath recover the soil. Beyond, the land loses that uniformity and becomes more broken; a torrent dashes with fracas over the débris of rocks. The trees are crowded together, and their branches, drawn nearer and nearer, end by forming a dome which the rays of the sun seek in vain to penetrate.

'Hungary, less devastated than Poland, has preserved a greater proportion of her forest wealth. Although they also have experienced the effects of the mountaineer's improvidence and the avidity of the commoner, the forests occupy upon her territory an extent of $5,000,000$ hectares. The evergreen forests which cover the heights of Transylvania have singularly to suffer from the absence of all care. These same forests, from which the amentaceæ are generally banished reappear upon the military frontiers of Sclavonia, whose mountains especially they shade. It is more particularly in the district of Tchailkiotes that those lie which have retained the physiognomy of the ancient primeval forests, such as those of Gardinovecz, of Kovill, and of Katy.

'Croatia is still better wooded than the military frontiers. The evergreens give place to species with leaves that fall, especially to beeches and the birch. In the plains and valleys oaks also erect their magnificent trunks. It is only on the frontiers of Illyria and Styria that the pines and firs re-appear. The county of Warasdin alone presents an extent of 14,459 hectares of forests.

'In lower Bosnia and Servia the oak becomes the predo- 
minant kind, whilst this character belongs to the fir in Upper Bosnia and Upper Croatia. In these provinees the firs, which commence at a height from 2,800 to 4,700 feet, cover often lengths of 6,10 , and even 20) leagues. In advancing towards the north of Hungary, the forests approach each other. The evergreens, by their predominance, serve to measure the elevation in latitude. Whilst the oak still prevails in that admirable forest of Bakony, which occupies an extent of 12 miles the counties of Verprim and Szalad, they have almost wholly disappeared in Galicia and upon the declivities of the Carpathians.

'Austria offers, in her northern parts especially, a striking contrast with Hungary. If Styria yet reckons a few fine forests, composed principally of larches and pines, the other provinces begin to feel greatly the want of fuel. In Lower Austria one single forest has remained worthy of attention, it is that of Vienna, whose vast lines of oaks, of ashes, and elms, adorn the Kahlen mountains.

'In Bohemia the forests, composed of the same kinds as in the other parts of the Austrian empire, are so richly furnished that they have to this day been adequate to the demand for consumption, and subjected to extensive fellings, without any yet sensible diminution.

'Let us proceed towards the north, and cross the North Sea, in order to penetrate into the Scandinavian Peninsula.

'In Sweden we only rarely meet with vast forests; the woods are numerous, but little productive. Dalecarlia, Warmeland, the district of Orvebro, are the only countries where arborescent vegetation attains sufficient energy to cover with wood a large extent of country. They are almost always the coniferæ that constitute the basis of these forests. Sometimes, however, the birch replaces them notably in Ostergothland. Sweden, like America and Siberia, has her fires, that deprive in a few moments a 
whole district of its shade; but vegetable life once destroyed revives only with difficulty upon this frozen soil.

'In Norway the forests are more extensive; they are suspended along the Scandinavian Alps, which separate this country from Sweden. The birch reaches there an altitude of 365 mètres. In the diocese of Bergen the fir has still those gigantic proportions of the forests of Switzerland and Germany; but more to the north its size is diminished to stunted proportions, and at the Polar Circle it has totally disappeared; whilst in Swedish Lapland it advances yet to two degrees beyond.

'In Norway it is the birch that really serves as a ladder to regetation; it is the measure of its energy, and marks by the different states through which it passes, in proportion as it rises in altitude, the degree of weakness of vegetative life. To the weeping birch succeeds the betula acer, which replaces the white birch; after which comes the birch of the prairies, which passes in its turn through different gradations of size, and which at the Polar Circle is nothing more than a stunted shrub, of pyramidal form, and covered with moss.

'The Peninsula of Jutland, which in the eleventh century Adam of Bremen designated as horrida sylvis, has gradually lost the greatest part of its woods. One would now seek for them in vain upon the western coast of Schleswig. All the marsh which extends as far as the Eider is completely despoiled of trees. The eastern coast is a little less so, although the woods, almost wholly of beech, are very thinly scattered.

'When we leave Denmark, and re-enter Germany by Holstein, forests become more numerous. Yet the Duchy of Oldenburg announces already, by the rarity of its trees, the vicinity of the Netherlands, where the marsh no longer permits the appearance of forests. 
' Sicily has lost the greater part of the forests which invested the sides of her valleys. The crests of Mounts Gemelli, Heræi, and Nebrodes are only slightly shaded. Etna alone has saved the crown which surrounds the mean region of her summit. The wood of Catania, which constitutes the woody region, is not less than eight, leagues long.

'Sardinia, less unprovided with wood than Sicily, has seen, however, from the time of the first Carthaginian establishments, her forest mantle gradually becoming narrower from the effect of fires and in consequence of the improvidence of the peasants. Forests form still the sixth part of the territory of the island, and several are true primeval forests. This forest line of Sardinia continues beyond the strait of Bonifacio, upon the chain which crosses Corsica almost longitudinally, and the culminating points of which are Mounts Rotondo, Paglia-Orba, Ciuto, and Cordo. These are forests of remarkable beauty. They are principally formed of pines, white and green oaks, chestnuts, junipers, \&c. Olive woods are distributed on several points. In these forests there are grottoes whose entrance is embellished with a multitude of shrubs, and which serve as a refuge to the shepherds and their flocks.

'Italy also possessed magnificent forests, of which there are nothing more than a few rare vestiges. We now find with difficulty the trace of those which the Romans bave signalised for us on account of their extent. What has become of that celebrated Cimian wood, which, from the borders of Lake Ronciglione, spread as far as the centre of Etruria? It is now reduced to a few groups of wood. One might say as much of the forest of Mœsia, of the forest of Alba, of the Sylva Litana, which extended from the source of the Panaro to that of Secchia, and whose name appears to have drawn its origin from the extent it occupied.

'One would seek vainly now for the forest of Aricie, which the Jews doubtless began to destroy, which was established there in the time of Juvenal. 
' Of the forests that Vibius Sequester cites as the most extensive of Italy, that of Sila, in Bruttium, is the only one which has escaped destruction, thanks to the special protection with which it has long been surrounded. Strabo tells us that it occupied an extent of 700 stadia, in the present day, though occupying an area of considerably smaller dimensions, it yet enjoys a notable importance, and is above all renowned for the magnificent pines which rise upon its slopes to a height of 120 or 130 feet. In Basilicate, the fine forests of oaks, which Zeuvie points out in the environs of Lago-Negro, seem to be the remains of the forest of Angitia, in Lucania, which Virgil has celebrated, and which had doubtless given its name to that province (Lucania, from Lucas.) The forest of Garganus, so vast in antiquity, offers now only meagre thickets.

'The forest of Vulsinia exists still in part in the nemoral lines which run over the mountains comprised between the lake of Bolsena and the Tiber, and which is attached to the last remains of the Ciminian Forest which are met with from the Ciminie di Loriana to Tolfa. It is there that the evergreen-oak attains astonishing dimensions. The heights of the Apennines, in the centre of Italy, although abodes more protected from spoilation, have been, however, remarkably stripped. Targioni Tozzetti has signalised the disappearance of a great part of the forests which formerly covered the mountains of the province Lunigiana. 'The great plain of the $\mathrm{Po}$ is completely divested of forests; there is not a single conifera in it. Lastly, the clearance has advanced as far as the reverse of the chain of the Alps which separate Switzerland from Italy, and was remarked thirty years ago in the valley of Aoste.

'Spain has been less fortunate, again, than Italy. The working of the mines from remote antiquity, and the careless improvidence of the Castilian, have hastened the destruction of the arborescent kinds. The centre of the peninsula is now almost totally deprived of trees. A few 
yews, service-trees, and maples, are actually, in SierraTejada, the only vestiges of the forests which crowned these mountains. The Sierra de las Almijarras presents still a few woody crests. Here and there clumps of oaks and firs shade the Sierra de Toloza. In the Sierra Nevada the pine constitutes wood of from 20 to 30 feet; whilst two different species of pines give rise to some forests in Granada. The Balearic Isles are entirely stripped of their trees; and one would seek in vain in the Pityusae (Iviça and Tormentera) for the pines to which they are indebted for their names.'

The description of the other forests of Europe constitutes the special subject of M. Marny's work; but it is given at too great length for quotation; enough has been quoted to indicate that formerly Europe must have been covered with forests.

Moreover, according to Marsh, in Southern Europe, Breul, Broglio, Brolio, Brolo; and, in Northern Europe, Breuil, and the endings -dean, -den, -don, -ham, -holt, -herst, -hurst, -lund, -schaw, -shot, -skog, -skov, -wald, -weald, -wold, -wood, are all etymologically indicative of the places so named having been situated in woods or groves, though it may be no woods or groves are existing there now, and these are numerous.

In England we have not a few of such names; and wo have the names of numerous forests which have partially or entirely disappeared, details of which I have given in The Forests of England, and the Management of them in Bye-gone Times [pp. 136-139; 140-167].

On the maps of Scotland, according to Chalmers, the learned author of Caledonia, there are a thousand names of places derived from forests which no longer exist, and there also we have remains of forests which once covered extensively the land-Ettrick Forest, and the Caledonian 
Forest, and others which have been celebrated in history and in song.*

Chalmers, in his work entitled Caledonia, to which reference has been made, tells that during the twelfth and thirteenth centuries, not only the king, but the bishops, barons, and abbots, had their forests in every district of North Britain ;' and he adds, 'it will scarce be credited that many black moors which now disfigure the face of the country, and produce only barren heath, were formerly clothed with wood, and furnished useful timber and excellent pasturage ; yet it is a fact clearly proved by the positive evidence of record, a great part of which is now without a tree.'

Corroborative evidence of the existence of forests aforetime, where forests now there are none, is afforded by immense quanities of wood found in various places in peat bogs and similar formations.

Similar remains of ancient forests buried in the ground and submerged in the sea are met with in England, details in regard to some of which are given in Forests of England, \&c. [pp. 168-188]. In Ireland also we meet with the remains of buried forests; and in Scotland they are not awanting.

* Mention is made by Pliny of the Caledoniau Forest. The ancient town of Caledonia had become in Buchanan's time, in the 16th century, he tells us, vulgarly (or commonly) called Dunkeld-the Hill of Hazel Trees; 'for here,' says he, 'the hazel tree spreads itself widely in these uncultivated places, and having covered the country with shady woods, gave a name both to the town and to the tribe.' Upon this statement Aikman, the translator of Buchanan's History of Scotland, remarks in a note :- 'This derivation of the name is now generally allowed to be correct, though some Gaelic etymologists derive it from Dun ghael dhun - " the fortress of the Gaels of the hills." (Stat. vol. xx. p. 411.) The name Caledonians, which belonged to the tribe, who formed one part of the Pictish kingdom, Mr Pinkerton alleges was given them by their neighbours, and it would seem means Woodlanders, as their territories were then covered with woods, and especially the vast Sylva Caledonia. (Inq. vol. i. p. 20.)

By Latin writers the name Caledonia was applied to the whole peninsula north of the Forth, and there is reason to believe that, at a time long after the days of Pliny, the whole country was still thickly covered with woods. Buchanan tells:-'Beneath Caledonia, about twelve miles on the same right bank, is Perth. On the left bank, below Athole, looking towards the east, lies the Carse of Gowrie, a noble corn country. Beyond this again, between the Tay and the Esk, extends the county of Angus, or as the ancient Scots termed it Aeneia, by some called Horrestia (so named from the Horesti, a tribe mentioned by Tacitus, but omitted by Ptolemy), and by the English Forestia (woodland). In this tract are the cities of Cupar and Duvdee, which Boethius, desirous of gratifying his countrymen, calls Deidonum (the gift of God), but of which I think the ancient name was Taodunum, that is a hill near the Tay, dun signifying a hill, at the bottom of which the town is built.' 
In Denmark, once the horrid forest, now a land where ancient forests exist no more, luried remains of ancient forests have been found in such abundance, and so preserved, and in such succession of superposition, that they have commanded the attention of some of the first archæologists of the age; and these have been able to furnish us with the details of the order in which different kinds of trees have in succession existed there,-and to carry back our study of prehistoric forests to the times in which were formed some of the Kjökken-müddings of Scandinavia - times so remote that though archæologists speak of them as of eras of unquestionable antiquity, the recital would seem to some to be but the creation of a disordered fancy. 


\section{CHAPTER III.}

\section{THE DISAPPEARANCE OF FORESTS IN EUROPE.}

THE extent to which in different countries there are names of places with a reference to woods where now woods or forests there are none, and remains of trees are found submerged or buried where now trees no longer grow, tells of the change which has taken place in the forestal character of Europe, and accords with allusions and explicit statements preserved by history; and in comparing the present appearance of Europe with what it must have been when a land of forests, it becomes interesting to enquire in what way these forests came to disappear.

There is such a thing as a natural decay of trees, by which I mean a decay which occurs, it may be altogether irrespective of man, and of man's doings. In an old wood there may sometimes be seen staghorn-like branches at the very top, or at the extremities of some of the lower boughs. This is an indication of decay. Sometimes there may be seen on a living tree a dead branch, or an entire side apparently dead, or actually so. Sometimes there may be seen a lofty tree growing with apparent vigour, but with only a hollow trurik, a mere shell remaining; or a tree may be found standing erect but quite dead; or it may be, multitudes of trees lie uprooted and prostrate, dead, or dying. In all such cases a knowledge of the physiology of vegetation may enable an experienced observer to tell at once how the decay, or the death of the trees has come about. Most probably in the first mentioned case the roots of the tree had exhausted the nutriment within reach of the extremities of the rootlets. 
In the second case the evil may have been done by the weight of a load of snow resting on it in winter, or by the growth upon it of some parisitic fungus. In the third case the damage may have been done by a thunderstroke, or through the leaves having become infested with a destructive insect; in the next case the decay of the trunk may be attributable to a twig having been broken by some bird or beast; while in the last mentioned case all may have been the consequence of a gale. Such accidents are of frequent occurence.

But all the destruction caused or occasioned thus is as nothing compared with the destruction which has been occasioned by man. In the organic structure of man, and in many other organisms besides, there may be seen at times a remedial operation going on ascribed to what in default of fuller knowledge has been called the vis mediatrix; so do we find in operation in primeval forests a remedial process whereby trees thus destroyed are replaced by others-it may be their superiers in the vegetable scale; but the destruction effected by man has been carried on so extensively as to render in general this provision unavailing or insufficient to repair his devastating work. Sometimes this destruction by him has been wrought with a purpose; sometimes it has been wrought only in recklessness of consequences; sometimes his only purpose may have been to obtain a beam or a switch; sometimes it may have been done to clear the ground for agriculture ; sometimes through his sending his flocks or herds into the forest for pasture without any thought of damage ; sometimes through his kindling a fire wherewith to cook his jrovisions, and neglecting to extinguish it on leaving; sometimes through his throwing down a burning match after lighting his pipe; sometimes through his burning the bushes, or grass, or herbage, outside the wood to clear the ground for the plough, or with a view to securing a new succulent crop for his herds, and not keeping fire under control, and the extensive destruction of forests was the consequence. 
From the time when arborescent vegetation entered on the struggle for existence with the herbaceous vegetation which may at first have taken possession of the soil, if such there was, which struggle was to issue in the survival of the fittest, up to the period when victory was secured by the trees; and for ages thereafter, the forest was inaking increase of itself like the growing babe, the growing boy, the growing youth, and the man in his prime, up to middle age and beyond it. There was waste going on; again and again, times innumerable, the leaves, one by one, died and fell from the tree-one by one they fell, individually unmissed, but in their totality considerable: that was waste; and other leaves and fruits were eaten ere they were so mature as to fall. But beyond these a destruction of whole trees-patriarchal trees, monarchs in the woodoccasioned by bird, or beast, or insect it may be, or by the winds of heaven, was going on all the while : a spray got broken, or a leaf in falling carried with it a portion of the bark; the moisture of rain, or dew, or hoarfrost, or snow, got access to the wound; the moisture evaporated, but somehow or other the torn wood got oxydised, rotting as does the stake planted in the ground, at the junction line between wind and weather; and the decay spread, slowly it may be, very slowly perhaps, but there was no occasion to take account of time. We are speaking of the working of Him with whom a thousand years are as one day, while at other times one day is a thousand years. The result was the total destruction of the tree. It fell and perished. But for ages the destruction was as nothing to the increase; waste went on, but the increase by growth exceeded this, and the forest continued year by year, century by century, to make increase of itself. Thus it continued till man came upon the scene, and then began another era the issue of which we have not yet seen.

The recuperative power of a forest is wonderful; but with the coming of man upon the scene there came a disturbing element against which it could maintain a 
struggle for a time with some measure of success, but before which it has, let us hope only temporarily, succumbed. By that recuperative power, for ages all waste by natural causes in primeval times was replaced, and not only so, but the woods continued to extend themselves, and make increase; but with the introduction of this disturbing element all has been changed. Where the restoration was equivalent to the destruction, the equipoise has been disturbed; where the growth or production was in excess of the waste, this has been reversed. There may have been aforetime, as now, extensive destruction of forests by natural causes, and doubtless there were, but in process of time the loss appears to have been repaired and the forest restored. I have intimated that even after the introduction of this disturbing element the struggle was maintained for some time with success; and from incidents in this struggle we may form some idea of the greatness of the recuperative power and the mode of its operation.

It is frequently the case that where forests happen to have been cleared away by accidental fire, forthwith a fresh crop of trees, sometimes of the same kind as those destroyed, but frequently, perhaps more frequently, of a different kind springs up. A similar occurrence has frequently been seen in connection with the destruction of herbaceous plants. After the great fire of London, in 1666, there sprung up profusely on the streets flowers which had not been seen there before the fire; where a piece of quicklime has fallen upon a moor the vegetation on the spot has perished, but oftentimes there has appeared in its stead a tuft of white clover; when the foundation of St. George's Church, in Capetown, was dug, there appearcel on the rubbish a luxuriant crop of a plant previously unknown in the locality; and in the London Medical Record. of 1871 we read:

'The mines of Laurium, which gave rise recently to such lively diplomatic discussion, are generally known to be largely encumbered with scoriæ, proceeding from the working of the ancient Greeks, lut still containing enough 
of silver to repay extraction by the improved modern methods. Professor Hendreich relates, according to L'Union Médicale, that under these scoriæ, for at least 1,500 years, has slept the seed of a poppy of the species Glaucium. After the refuse had been removed to the furnaces, from the whole space which they had covered have sprung up and flowered the pretty yellow corollas of this flower, which was unknown to modern science, but is described by Pliny and Vioscorides. This flower had disappeared for fifteen to twenty centuries, and its reproduction at this interval is a fact parallel to the fertility of the famous "mummy wheat.",

Many like cases are mentioned by Marsh* in regard to the unexpected appearance not only of herbaceous, but also of ligneous vegetables. In Northern Europe I have had details given to me in regard to numerous cases of coniferous woods having been destroyed and birches springing up in their place. The remains of trees found at different depths in peat-logs in Denmark testify to a continuous succession of forests of different kinds of trees having appeared in the same locality. The laws regu. lating the succession have to some extent been evolved, and attention has been given to sources whence the seeds have proceeded; but it is the fact alone with which we are at present concerned. In a volume entitled Réboisement in France (pp. 45-47) I have cited cases of extinct torrents which have been extinguished by the natural extension of forests over ground which had been previously denuded of these; and in the American State of Ohio there exist remarkable mounds and earthworks, constructed by man's device, overgrow with a dense clothing of forest not distinguishable, or scarcely distinguishable, in dimensions or character of growth from the neighbouring forests, the soil of which had probably never been disturbed. Such has been the recuperative power of the forest, and such is it still; but in the unequal strugole with man forests have 
at length extensively disappeared. Whether this has been a blessing or a curse affects not the fact, which is such as I have stated.

Without speaking presumptuously of what must havelbeen the purposes of God, as if He were altogether such an one as ourselves, or forgetting that all that the more moderate theologians speak of are the Attributes of God, for which they claim no higher position than that they are what they or others in their ignorance attribute to Him, we may reverently speak of what has actually occurred. In doing so the fact which has been stated may be accepted; and with it the additional fact, that as the earth advanced through its changing conditions, it became progressively prepared and fitted for the flora of the present; and in like manner for the fauna of the present; and also for the residence of man, who found in the forests a shelter and a home; but who found also there materials which he could make use of in effecting many of his purposes : building a house or place of shelter, fencing cultivated spots to keep off the beasts of the field, and making implements for which he had occasion, and weapons which he could make use of in hunting, or in defending himself and his family, if not also in committing injury and wrong; but who even then may have begun to find these sheltering forests a cumbrance, preventing him from artificially cultivating, so extensively as he desired, other plants which were good for food. Then by fire and axe he may have sought the removal of at least a portion of them; and effecting this, he may have found, though he may not have realised, or even understood, or even perceived the fact, that in the centuries of growth through which these trees had passed, they had prepared a soil for such cultures as he wished to practise; and that the ashes remaining, after he had consumed them by fire, promoted the growth of the plants he was cultivating. And in process of time, with increased experience of this, and intensified energy, he may have proceeded more and more extensively to fell and to destroy, till the 
forest first becoming a fruitful field, then partially, but to a great extent, the site of industrial establishments, and the site of cities, and the dwelling-place of a population advancing in civilisation, and in intellect, and in culture, with results which are now to be seen.

Such is one view of what has occurred, but there is yet another.

The forest was the paradise of the 'wild man of the woods.' It was his Eden, his garden of delights ; but ere he left it he began to destroy it, and his descendants, his improved descendants, have carried on the work of destruction initiated by him, and they have substituted for the paradise of Eden the paradise-I had almost said the 'fool's paradise' - of modern life in the capitals and pleasure haunts of what is called advanced civilisation. The advancement is great, but the cost has been considerable. Forests, or trees of which forests are composed, are still useful in the world's economy. The supply, though great, was not inexhaustible. Destruction has in many places been carried so far that privation has proved hurtful in its effects. And now there must be a judicious conservation and exploitation of what remains; aye, and in some places man must restore again what he had taken away, or the consequences may be fatal.

What seems to me to be an apt illustration of what has been going on suggests itself. In the animal ecomony there may be seen and traced in the life history of every man who lives to extreme old age, a process which is similiar to what has occurred in the history of the ancient forests of Europe: in the infant, in the child, in the youth, in the man in the prime of life, the man in middle life, and in the man in old age, there is going on simultaneously a correlative process of growth and decay, of nourishment and waste, of assimilation and elimination. Many among us have been eating for twenty, for fifty, it may be, for eighty vears. What has become of all the material we have eaten in all these years? Whereas we might by this 
lime have equalled the elephant in bulk, we seem to have been for years of the same size and our bulk unchanged. It may seem to be so; but it is not exactly so. Never have we lifted a finger, never have we unconsciously winked, but the act has occasioned a waste of tissues of the body ; and as it is with these so it has been with every act of our life; and the foor we have taken has gone to supply this waste, and therefore have I spoken of these two processes being correlative. If, however, we were by a well-known practice to represent the measure of these processes at the progressive stages of man's life by a line we should find that the form taken by neither would be a straight line, but that of a curve, starting from a low point, gradually ascending, and again descending: little being eaten in childhood; more in youth and in manhood; less again in old age. But it would be found that the curve representing the waste and elimination, though similar in its general outline differed from this in its curvatıre; the curve representative of the quantity of food assimilated in the early life representing an excess above that of waste, growth in stature and in bulk being a consequence; with the two curves approaching to parallelism in middle life: but the assimilation being then slightly in excess of wastc. is accompanied by a slight increase in bulk but not in stature; while in old age the curve of assimilation is far below that of waste and elimination, with the accompanying result that he who was once a strapping youth, and presented afterwards a noble manly figure, has become a little wee, wee old man.

Thus has it been with forests in Europe. Once they covered extensively the whole land, now they are reduced in most lands to a limited area, and in many localities they have entirely disappeared, while in others, though they still retain a footing, they look like things which are ready to perish and vanish away. 


\section{CHAPTER IV.}

\section{EVILS WHICH HAVE FOLLOWED THE EXTENSIVE DESTRUCTION OF FORESTS IN EUROPE.}

\section{Sectiox A.-Scarcity of Thiber and Firewood.}

LARGE timber is every year becoming more and more scarce; and had it not happened that iron is extensively used instead of it the deficient supply would have been felt painfully, In some of the extensive forests whence supplies of timber are obtained, large areas, embracing most of those from which timber can easily be brought out, bave been cleared of trees yielding such timber as is desired. This has now to be obtained from areas more remote, and more difficult of access, and thus the expense of bringing the timber to market has become greatly increased; prices have risen, and they have been prevented from rising higher only through the extensive use of iron in shipbuilding and other industries in which timber was formerly employed. In many cases the increased price is not sufficient to cover the increased expense of bringing the timber to market. In Russia I was informed that to such an extent was this the case that by some the timber trade was continued only because they were already in the trade with established connections, and with skill and capital invested in the enterprise ; moreover, wood-cutters were in debt to them, and these men having to purchase from them their supplies they had thus a narrow margin of profit which still made the prosecution of the work remunerative, and a little-a very little more. And the distance which such timber has to be brought from the place of growth to the port of shipment is still progressively becoming greater and greater.

As with timber, so is it with firewood in some countries in 
which this is reckoned among the necessaries of life. In these the demand for firewood is such that there must be kept up a supply; but this is done with a rise in price, which rise is ever increasing as the supplies have to be brought from ever-increasing distances. Thus it is in the larger cities of Russia; and there in mining districts the continuation of smelting and manufacturing operations has in many cases been found to be unprofitable. In India, some twenty years ago, the destruction of forests in connection with the construction and the working of railways, imperilled the very existence of large communities through the diminution thus occasioned in their supply of fuel needed for lesser industries, and for the preparation of their food. In Siberia and in Mongolia dry cow dung is extensively made use of by the Mongols, under the name of argol; and in South Africa the same material and sheeps' droppings called mist constitute in many districts the only fuel made use of. But from this the Indians shrunk; and, some influenced perhaps by religious prejudice, woulù have died rather than make use of such fuel. With the abundant supply of coal which exists in Britain, this evil may not be felt here; but it is otherwise elsewhere.

In a volume entitled French Forest Ordinance of 1663: with Historical Sketch of Previous Treatment of Forests in France, I have given details of the crisis produced in France, which called forth the memorable saying of Colbert, minister of Louis XIV., France perira faute des Bois! and the delight with which this Ordinance, designed to arrest the destruction of forests, was hailed in other countries in Europe in which it is still spoken of as the F'amous Ordinance of 1669, tells of the extent to which the evils mentioned were then prevalent.

Of such evils it may be alleged that they are simply the privation of what has been destroyed, in accordance with what is taught to children, that they cannot both eat their cake and keep it, spend their shilling and retain it. But other evils have followed. 


\section{Section B.-Droughts.}

More generally felt, perhaps, than the scarcity of timber and firewood, is the effect produced upon the humidity of a country by the destruction of its forests. There is, I believe, much of prejudice and much of error mixed up with the prevailing popular beliefs on this subject; but the confirmation of the underlying fact given by scientific observations may warrant us in receiving, if necessary with some allowance, the testimony which so many are ready to bear-accepting the fact though explaining differently in what way the fact has been produced. Again and again one hears that Spain has been ruined through drought consequent on the destruction of her forests; and, as if by some general concensus, there have poured in upon us, from lands remote from one another and diversely conditioned, tales of privation, if not of distress, occasioned by aridity consequent on the destruction of forests, reminding one of the narrative given of the troubles and losses of Job-while one is yet speaking in comes another; and while he is yet speaking, another; and while he is yet speaking, another.

It is a prevalent opinion that trees attract clouds and rain; and that mountains and the sea do the same. The phenomena which have given rise to these opinions can be otherwise explained, and that more satisfactorily, by supposing the clouds to have been formed where they appear, and not been merely attracted thither; and that that does take place can be proved.

In a volume entitled Hydrology of South Africa; or, details af the former condition of the Cape of Good Hope, and of the causes of its present aridity, with suggestions of appropriate remedies for this aridity, I have shown that the desiccation of that country is attributable, primarily, to the drainage of much of the rainfall from the land to the sea; secondarily, to the evaporation of much which is not so carried away, which evaporation, at one time greatly 
retarded by the existence of forests, has for a considerable time been going on unchecked in consequence of the extensive destruction of herbage and trees. Facts might be cited to show that such is the case with Spain in an almost equal degree, and that such is the case to a lesser extent with the greater part of Central and Southern Europe.

In a second volume, entitled Water Supply of South Africa, and Facilities for the Storage of it, I have shown that notwithstanding the aridity of South Africa there is still a sufficient supply of moisture there to fertilise extensively the country, if that moisture were husbanded and properly applied. The same may be said of Spain where this is being done to an extent of which few have any conception. By storage and irrigation, and by conservation, restoration, and extension of forests, it is sought to minimise as much as possible the effects which have followed the destruction of forests in that land.

In a third volume, entitled Forests and Moisture; or Effects of Forests on Humidity of Climate, I have discussed many of the views which have been advanced upon the subject-views in regard to the action of each leaf, and views in regard to the action of forest masses-with the conclusion that the production of forests in the localities in which they have existed has been greatly influenced by the distribution of the rainfall, or the humidity of atmosphere upon which the rainfall depends; and that their subsequent effect upon the atmosphere has been within certain limits to equalise the distribution of the rainfall in time and in space. Thus:

Where the land is densely wooded the rains may be found diffused more or less equably over several months in the year, and may frequently be of a drizzling character, while in a land similarly situated, devoid of trees, rain falls irregularly in what seems like thunder plumps, and, in extreme cases, whole years may pass without rain, as is the case in the Karoo, South Africa; and the rain in the forest land may fall pretty equably over the whole district, 
while in the land devoid of forests it falls now here, now there, falls, it may be, in torrents, deluging the land, while extensive districts are left dry-both occasioning great inequality in the distribution even where the quantity of rain falling may be proximately equal; and the inequality in benefit from what falls is made still greater by the torrential occasional rains draining of rapidly to the river beds, and by them to the sea, while the woodlands absorb and retain a much larger portion of what falls upon them. And thus is fulfilled what is written-' The earth which drinketh in the rain that cometh oft upon it, bringeth forth herbs, meet for those by whom it is dressed, and receiveth the blessing of God: but that which beareth thorns and briars is rejected, and is nigh unto cursing.'

In works on Forest Science, published on the Continent, there abound statements relative to the effect of forests in maintaining humidity of soil and climate.

The following more popular allusions to the effect of forests upon the humidity and consequent fertility of a country I find amongst others cited in Le Bulletin de la ligue du Reboisement de l'Algérie. I have numbered them to facilitate reference to any, should this be desired.

1. 'In felling trees growing on the sides and summits of mountains, men under all climates prepare for subsequent generations two calamities at once-a lack of firewood, and a want of water.'-Humboldt.

2. 'Whoever kills a tree, kills a Servian.'-A Servian Proverb.

3. " Replant or be accursed!" may every one of his fellow citizens say to the landholder who uproots his forest; "You are refusing to us water." - Rauch.

4. 'Now may be seen clearly whither tends this fatal connection of cause and effect which begins with the destruction of forests, and ends in the miseries of the population: dooming thus the man to share the ruin of the soil which he has devastated.'-Surell.

5. 'It is always hazardous to interfere, however slightly, 
with that which nature has arranged by the work of time - the work of ages. There is often destroyed in a few days by man, through ignorance or cupidity, the work of hundreds of centuries; then, full of surprise at the disorder occasioned by himself, he accuses Providence, makes processions and neuvaines [nine days' devotions, an observance practised in the Romish Church], in order to conciliate God; but taking good care not to think of himself as the principal cause of the evil from which he is suffering.' Viollet-le-Duc.

6. 'It is especially necessary in warm countries to preserve the forests, because on the one hand they keep down the temperature, and because on the other they induce rains, without which there is no vegetation possible. The salvation of the colony of Algiers can only at this price be secured.'-Mahé.

7. 'By the single act of a pioneer settler clearing virgin soil, he alters the network of isothermal, isothermal, and isochimenal lines [lines of equal mean temperature, of equal summer temperature, and of equal winter temperature] over a country. One may say, in general terms, that the forests are similar to the sea in their influence, reducing the natural difference of temperature in the different seasons, while the destruction of forests increases the difference between the extreme heat and the extreme cold, imparts greater violence to atmospheric currents and to torrential rains, and a protracted duration to droughts.

Marsh fevers even, and other epidemic diseases, have often made an irruption into a district when woods, or simple screens of protecting trees, have fallen under the axe. As for the water-flow, and the climatic conditions on which it depends, one cannot doubt for a moment that the clearing away of woods has had the effect of disturbing its regularity. The rain, which the interlaced branches of the trees allow to fall drop by drop, and which would swell up the spongy mosses upon which it fell, or which would trickle slowly across the dead leaves, and the long fibrous masses of the roots, flows away at once with rapidity over 
the soil to form temporary streamlets, in place of sinking into the ground to descend to the depths and rise again in fertilising springs, or glides rapidly along the surface, and goes to lose itself in rivers and floods. The ground above becomes arid in the same proportion as the running waters increase below. The full river flowings become changed into inundations, and devastate the adjacent country, where immense disasters follow.'-Elisée Reclus-La Terre.

S. 'In the place of the fertile fields of cis-Atlantic Africa, we find now nothing but plains rendered sterile by desiccation and the absence of trees.'-A. Maury-Histoire des Grande Forêts de la Gaule.

9. 'In proportion as the ancient forests disappeared, springs dried up, certain races of animals died out, and winds which were previously unknown made their appearance. The land daily loses some element of its fertility; from its bosom, which continuous mutilations devastate, there come forth hosts of evils, the saddening influences of which mar the enjoyment of our transitory existence.'Rauch-Régénération de la nature végetale.

10. 'From Madrid to Jerusalem history and geography tell the same tale: forests given up to sheep, forests destroyed; mountains devoid of woods, mountains devoid of life.'-Broilliard-Les Massifs de Sapin et la disette de Bois en Franse,

11. 'The members of the Congress in Algiers who have gone through the different provinces of the colony, have been struck with the state of devastation in which they have seen many of our forests. Exploited on no settled system, left open and subjected to depredatious by the natives, desolated by frequent fires, ruined by the passage of flocks of goats and of sheep, which devour the young twigs and shoots, our forests are far from yielding to the country the revenue which might be obtained from them ; it is a source of wealth not yet exploited, or exploited with reckless waste, which is still worse. We have seen forests of the Thuya, in which the young trees have been literally annihilated by the goats.'-Chesnel-Genie Civil. 
12. 'It is not wars which have brought most evil upon the region of the Mediterranean, but aridity, brought on and aggravated by the reckless destruction of woods, and by the excessive abuse of pasturing sheep on the mountains.'-Dehérain.

13. "The clearing away of woods-in that lies the principal cause of the arrest to which agriculture has been subjected in Algeria.'-M. Calmels-Génie Civil.

14. 'With a view to preserve our nomades from utter ruin, the Administration has adopted a measure which is likely to be afterwards bitterly deplored : it has authorised the depasturing of flocks in the State forests. Now, to let sheep, goats, and camels ramble in the woods, or rather bushy shrubberies, of Africa, is to doom these to a rapid disappearance, while the forest should be preserved as the most precious of all possessions, extended and carefully treated as the most powerful agent in promoting fertility.

'The clearing away of forests, which induces aridity, appears to me to be the cause of sterility.'-Dehercin-Professor in the Museum of the School of Grignon-Génie Civil.

15. 'The phylloxera has its propagation facilitated, or has the way prepared for it by the most powerful and most general enemy of this entire region. It is manifest that this is the enemy, which equally with that or still more, should command our attention and our vigilant watchfulness, and that against which we ought to contend with our greatest energy.

'With us it is the enemy not only of the vine, but of all our cultures: this enemy which successively and progressively has made the peasant to give up the culture of flax, of hemp, of maize, and of grain ; this enemy which has constrained us to substitute for the culture of the cereals, which had become almost unproductive, that of the vine, an arborescent culture with deeper roots; this enemy, which is increasing every day, will ere long come to ruin even the culture of bushes and fruit-trees; this enemy as terrible, as immediate, as the phylloxera, is the DROUGHT.' -Jules Maistre. 
16. 'Algeria in her turn is passing through a crisis, ont of which she ought to come more vigorous; at the present time she is wholly for the culture of the vine, and perhaps she will yet find that evil which is expected will come upon her to turn her from the way in which she is advancing with such vigour; it is a certainty that the culture of the vine will lead during the next few years to riches hitherto unknown, and will certainly contribute in a large measure to the progress of Algeria; but it is necessary to bear in mind that there is no culture more dangerous, and it is not without trembling that one looks forward to the ravages which the invasion of the phylloxera will occasion in a country prosecuting too ardently the creation of vineyards; the evil will be terrible, and progress will be completely arrested. But Algeria rewooded and irrigated is proof against every catastrophe, for all kinds of culture are then open to ber.'-Déherain.

17. 'It may be said that the measure of attention given to trees indicates the condition of the agriculture and civilisation of a country.'-Mahé.

18. 'On the presence of forests on the mountains depends the existence of crops, and the life of the population. Here the existence of wood is no longer, as it is on the plains, a question of convenience; it is the question of " to be or nat to be." '-Surell.

19. 'In a forest the mean temperature is always lower than it is in a denuded country; but the difference is less marked in winter than it is in summer; the maximum temperatures are always lower, and the minimum temperatures are always higher. In a forest the reduction and increase of temperature always advances more slowly; the temperature there is always more equal in the day and in the night, between one day and another, and from season to season : sudden changes of temperature, if they do not last long, do not make themselves felt; from all which we are warranted in concluding that forests tend to keep down the general temperature of a country-on the other hand they tend to diminish the degree of sudden changes 
and to avert thunder storms.'-Rapports Annuels de Météorologie Forestière.

20. 'The chemical action of forests explains moreover the property possessed by some kinds of trees to produce a sanitary effect on localities and districts by decomposing or arresting gasiform deleterious elements.'-Mahé.

21. 'The immense extent of the area occupied by forests on the earth may be considered proof that nature designed to assign to them some action in the terrestrial phenomena.'-Dupin.

22. 'Forests, waters, and prairies, are the three great laboratories of nature whence proceed all the good things which ought to minister to man's happiness on the earth. Forests manifestly, next to the sun, are of the greatest service; they seem to have a reaction on all the harmonies of the globe. Under the truly happy influence exercised by them everything prospers,'-Rauch.

23. 'By the majestic calm of its silence, by the sounds produced by its animation or its agitation, by the intensity of its verdure, and by the varied tones of its tints, by its essences or perfumes, by its pure atmosphere, by I know not what enchanting prestige, by its harmouies as by its contrasts, this sweet and mysterious society of trees which we call by the name of forest, communicates to us the most lively and most contrary impressions. The soul of the forest seems to act upon our own, and to cause it to vibrate in unison.'-Nahé.

There may be much of sentimentalism in much of this, but it tells how forests are looked at by some of the distinguished students of forest economy of the day. One more, and I have done.

24. "To give a résume of what has been said-the forest occupies an important place in nature, in commerce, in agriculture, and in hygiene. It creates soil out of everything, and breaks this up and enriches it; it equalises and regulates the temperature, and the flow of water; it is our best safeguard against inundations; it renders salubrious 
at once the earth and the atmosphere; it refreshes the moral and restores the physical in man; it gives to him enjoyment in the beauties of nature, through the splendour of its vegetation. We see in these, titles to protection against the abusive treatment to which it is subjected. It is for nations, but above all for governments, to take good heed.'-Caveant Consules-Mahé.

In most of these, if not in all of them, I find a designed or undesigned reference to the effects of forests in maintaining humidity of soil and climate, the loss of which, though in some cases it may have been beneficial to man, has been extensively so disadvantageous to man as to warrant its being spoken of as an evil. More detailed and specific statements are not alacking. The following are cited by Schleiden in his work entitled The Plant: a Biography :-

'Almost everywhere,' says Schleiden, Professor of Botany in the University of Jena, ' in the great characters in which nature writes her chronicles, in fossilized woods, layers of peat, and the like, or even in the little notes of men, for instance in the records of the Old Testament, occur proof, or at least indications, that those countries which are now treeless and arid deserts, part of Egypt, Syria, Persia, and so forth, were formerly thickly wooded, traversed by streams now dried up or shrunk within narrow bounds; while now the burning glow of the sun, and particularly the want of water, allow but a sparse population. In contrast must not a jovial toper laugh indeed, who looks from Johannisberg out over the Rhine country, and drinks a health in Riudesheimer to the noblest of the German rivers, if he recall the statement of Tacitus, that not even a cherry, much less a grape, would ripen on the Rhine! And if we ask the cause of this mighty change, we are directed to the disappearance of the forests. With the careless destruction of the growth of trees, man interferes to alter greatly the natural conditions of the country. We can indeed now raise one of the finest vines upon the Rhine, 
where two thousand years ago no cherry ripened; but on the other hand, those lands where the dense population of the Jews was nourished by a fruitful culture are in the present day half deserts. The cultivation of clover, requiring a moist atmosphere, has passed from Greece to Italy, from thence to Southern Germany, and already is beginning to fly from the continually drier summers there to be confined to the moister north. Rivers which formerly scattered their blessings with equal fulness throughout the whole year, now leave the dry and thirsty bed to split and gape in summer, while in spring they suddenly pour out masses of snow, accumulated in winter, over the dwellingplaces of affrighted men. If the continued clearing and destruction of forests is at first followed by greater warmth, more southern climate, and more luxuriant thriving of the more delicate plants, yet it draws close behind this desirable condition another which restrains the habitability of a region within as narrow, and perhaps even narrower, limits than before. In Egypt no Pythagoras need now forbid his scholars to live upon the beans; long has that land been incapable of producing them. The wine of Mendes and Mareotis, which inspired the guests of Cleopatra - which was celebrated even by Horace - it grows no more. No assassin now finds the holy pine-grove of Poseidon, in which to hide and lie in ambush for the singers hastening to the feast. The pine has long since retired from the invading desert climate to the heights of the Arcadian Mountains. Where are the pastures now, where are the fields around the holy citadel of Dardanus, which at the foot of the richly-watered Ida supported three thousand mares? Who can talk now of the "Xanthus," with its hurrying waters? Who would understand now the "Argos feeder of horses?"

In view of this waste Schleiden writes, if not in the words, yet following the train of thought of one of the noblest veterans of our science, the venerable Elias Fries, of Lund: 'A broad band of waste land follows gradually in the steps of cultivation. If it expands, its ccntre and cradle 
dies, and on the outer borders only do we find green shoots. But it is not impossible, it is only difficult, for man, without renouncing the advantage of culture itself, one day to make reparation for the injury which he has inflicted : he is appointed lord of creation. True it is that thorns and thistles, ill-favoured and poisonous plants, well named by botanists "rubbish plants," mark the track which man has proudly traversed through the earth. Before him lay original nature in her wild but sublime beauty, behind him he leaves the desert, a deformed and ruined land; for childish desire of destruction, or thoughtless squandering of vegetable treasures, have destroyed the character of rature; and man himself flies terrified from the arena of his actions, leaving the impoverished earth to barbarous races or animals, so long as yet another spot in virgin beauty smiles before him. Here again, in selfish pursuit of profit, consciously or unconsciously, he begins anew the work of destruction. Thus did cultivation, driven out, leave the East and the deserts perhaps previously robbed of their coverings. Like the wild hordes of old over beautiful Greece, thus rolls this conquest with fearful rapidity from east to west through America; and the planter often now leaves the already exhausted land, the eastern climate becoming infertile through the demolition of the forests, to introduce a similar revolution into the far west. But we see, too, that the nobler races, or truly cultivated men, even now raise their warning voices, put their small hand to the mighty work of restoring to nature her strength and fulness in yet a higher stage than that of wild nature: one dependent on the law of purpose given by man, arranged according to plans which are copied from the development of manhood itself. All this, indeed, remains at present but a powerless, and for the whole, an insignificantly small enterprise, but it preserves the faith in the vocation of man and his power to fulfil it. In future times he will and must, when he rules, leads, and protects the whole, free nature from the tyrannous slavery to which he now abases her, and in which he can only keep her by 
restless giant struggles against the eternally resisting. We see in the gray cloudy distance of the future a realm of peace and beauty on the earth and in nature, but to reach it must man long study in the school of nature, and, before all, free himself from the bonds of that exclusive selfishness by which he is actuated.'

During a residence of some years at the Cape of Good Hope, where I held with the Chair of Botany in the South African College the appointment of Colonial Botanist, I travelled extensively both within the colony and beyond its limits, and had opportunities of observing effects produced by the destruction of forests in South Africa, and of hearing from others, credible witnesses free from prejudice, statements of facts observed by them. All that I saw and heard was in accordance with the statements quoted.

South Africa has an arid climate, and an arid soil; but years of drought are occasionally followed by destructive inundations. The geological formation, the physical geography, and forest clumps in the interior, tell that it was otherwise in bygone times. The first mentioned does so by alluvial and lacustrine deposits; the contour of the country tells of extensive denudation by aquatic currents; and there are in the interior clumps of Adansonia digitata, and also of other trees, which appear to be the produce of seeds which germinated when the localities in which they grow were a little, and only a little, above the level of adjacent water. I have published some details in regard to these, and may advert here to the following circumstances indicative of their bearing upon the matter in hand. The clumps are generally on rising grounds, in the middle or on the sides of what appear to have been water-basins; the trees in each clump are apparently of one age, but different clumps are apparently of different ages, and in some cases those of greatest altitude above the sea level are of greatest age, an illustration of which is supplied by Mopane trees, appar- 
ently a species of Bauhinia, in the Shua valley, in the district of Limpopo. By the deceased Mr James Chapman, a man careful in his observations, I was informed: "The Mopane trees are small in the lower portion of the Shua valley'-which is the part which I presume would be longest under water - 'but they are larger and stronger the higher that valley is ascended.'-in proportion, that is, according to my assumption, as the soil has been longer free from the covering of water - ' and very much larger in the vicinity of the river Naté, which comes in a direction from the town of Moselekatsi, where they have attained a considerable magnitude'-which I attribute to that part having emerged from a waste of waters at a much earlier period, while waters covered to a considerable depth the lower-lying lands.

In whatever way and at whatever time forests may have been produced in South Africa, there are indications that the land was at one time much more extensively covered with forests than it is now ; and there is evidence that forests once existed there which have in some cases been cleared away and in others greatly reduced in extent. To South Africa, in the region of Natal, was given by Vasco de Gama, in 1495, the name of Terra de Fume, and the extensive burning of bush, herbage, and grass, the smoke arising from which procured for it that designation, has been continued on to the present time, apparently, both by native tribes and by European colonists, throughout a period of well-nigh 400 years, and probably from times long anterior to the time of that discoverer. Not only have Dr. Moffat, Dr. Cassils, Dr. Livingstone, and others conjectured, from what may be seen going on in the present day, that this long-continued practice of burning off the dry or hard products of vegetation must have had the effect of destroying many trees, but some of them have told of stumps and other remains of burnt trees seen by them; and to these I have referred as indications of the land having been at one time much more extensively covered with rorests than it is now. Moffat tells of 'the 
accidental destruction of whole plains of the Olea, or wild olive, by fire near Griquatown. There the stumps still remain, or at least were in existence some years ago, and I have never heard of their disappearance.' To these I refer as evidence that forests once existed where now there are none. Moffat further testifies in regard to the Bechuanas, amongst whom he laboured, 'that they are a nation of levellers . . . cutting down every species of timber without regard to scenery or economy. Houses are chiefly composed of small timber, and their fences of branches and shrubs. Thus, when they fix on a site for a town, their first consideration is to be as near a thicket as possible. The whole is presently levelled, leaving only a few trees, one on each great man's fold, to afford shelter from the heat, and under which the men work and recline.' There are countries in Europe in which were this done the forests might be reproduced by self-sown seed, but it is not so now in any part of Africa which I have visited; and Moffat tells that of whole forests where the giraffe and elephant were wont to seek their daily food nothing remains. "When the natives remove from that district, which may be after only a few years, the minor species of the acacia grows, but the acacia giraffee requires an age to become a tree, and many ages must pass before they attain the dimensions of their predecessors. In the course of my journeys I have met with trunks of enormous size, which if the time were calculated necessary for their growth, as well as their decay, one may be led to conclude that they sprung up immediately after the Flood, if not before it.'

The European colonists have done as the native tribes did before them, and by burning the grass and by reckless felling of trees, forests have been reduced in extent, or altogether cleared away. The mode of exploitation is that known in France as Jardinage: for a small fee a licence to cut and bring out of the forest a waggon-load of some specified timber is given, and the licence-holder helps himself. Thus forests of the Cape cedar, Widderingtonia 
juniperoides, which gives their name to the Cedar-bergen of Clanwilliam, the whole of which chain of mountains was once studded with these trees, have now almost entirely disappeared. It is only the great extent of the forests of George of the Kingsna and of Kaffraria which has prevented these forests from yet attaining a like condition. And a mountain adjacent to Somerset, it has been reported to me, has been entirely cleared. Bush fires have aided in bringing about this result. I have seen in the Colony mountain-sides naked and bare, which some years before were covered with trees. What I have stated has been confirmed by many of my correspondents :-

There has been reported to me details of a forest fire on 15th December 1865, which was occasioned by four natives kindling a fire on the pasture land of Galger Bosche, and was so extensive that the smoke extended to and beyond Bedford, a hundred miles distant; and on the 9th February 1869, there occurred a like fire, which desolated a tract of country 400 miles long, and varying in breadth from 15 to 150 miles. I have given details in Hydrology of South A frica, pp. 175-194.

Consequent upon the destruction of forests there has been extensive desiccation of soil and climate, alternations of long-continued drought with destructive floods, and indications that the sequence is that of cause and effect. Dr Moffat tells of the arid region of his missionary labours, that in his settlement at Latakoo, the natives were wont to tell of the floods of ancient times, the incessant showers which clothed the very rocks with verdure, and the giant trees and forests which once studded the brows of the Hamhana hills and neighbouring plains. They boasted of the Kurruman and other rivers, with their impassable torrents, in which the hippopotami played, while the lowing herds walked to their necks in grass, filling their makukus with milk, making every heart to sing for joy. Now all that is a thing of the past. I have visited a farm where it may be said they had had no rain for three years. I had once to ride eighty-four miles before I could reach a 
fountain where my horses could drink, and on another occasion I had to send my horses at mid-day six miles off the road to slake their thirst, while I and my companions rested. But towards the close of the year in which I left the Colony (1867) there occurred a flood, the damage occasioned by which to roads and to house property at Port Elizabeth alone was estimated at from $£ 25,000$ to $£ 30,000$. Within a year thereafter a similar destructive torrent occurred at Natal, in regard to which it was stated that the damage to public works alone was estimated at $£ 50,000$, while the loss to private persons was estimated variously from $£ 50,000$ to $£ 100,000$. Towards the close of 1874 still more disastrous effects were produced by torrential floods; according to the report given by one of the Colonial newspapers the damages done could not be estimated at much less than $£ 300,000$. According to the report given by another, the damage done to public works alone was estimated at $£ 350,000$. In stating that there are indications that the sequence of these phenomena to the destruction of forests is the sequence of effect and cause, I refer not to what has been observed elsewhere, or to what has been ascertained in regard to the effect of trees in arresting the flow of the rainfall, but to this:-I have been informed in many cases on the spot, that the felling of clumps of trees had been followed within a very short time by the stoppage of fountains, the flow of which had previously been perennial; I have myself noticed on the ascent of a treeless hill, a stream six inches deep the whole depth of the road within twenty minutes after the fall of rain had commenced; and by experiments made on Wynburg Hill, by Mr Wm. Blore, M.L.A., Fellow of the Meteorological Society of London, and Secretary of the South African Meteorological Society, to test some statements I had made, it was found that the evaporation from a jar sunk in cleared ground was more than double that from a jar of the same diameter about 120 feet distant, when it was partially shaded, but not covered, by a bush : the former being, in the same time, 1.854 inches, the latter $\$ 963$ inches, gave an 
excess of 991 inches. The experiment was repeated with similar results. By another experiment it was ascertained that while the deposit of dew on a green surface amounted to 4.75 , that on a white surface amounted only to 2 , or less than half the quantity. He further ascertained that while the difference of temperature in the water in the two jars employed in the former experiment was only a few degrees, the difference of temperature between black ground and ground shaded by bush was about 25 degrees Fahr., which would occasion a vastly greater difference in the amount of evaporation than that which occurred in his experiment. In illustration of what is implied in the result of the experiment made by $\mathrm{Mr}$ Blore, the excess of evaporation from the more exposed jar above that from the jar partially shaded, but not covered, being an inch, more strictly, upwards of ninety-nine hundredths of an inch, of water, and more than double that of the latter, Mr Blore remarks :--'An inch in six days (the time consumed in that experiment) will give for 102 days, the ordinary duration of the hot, windy, and dry season in the district, 17 inches. This is equal to about three hundred and eighty-four thousand $(384,000)$ gallons per acre, and supposing 1000 acres had been burned, blackened, and dried, what with sunlight, fire, heat, and wind, the evaporation would be an excess of three hundred and eighty-four millions $(384,000,000)$ of water above what would have been evaporated if the bush or grass had been left unburned.' And I add, a fortiori, if the forest had not been destroyed.

\section{Section C.-Floods, Inundations, and Torrents.}

It may be more difficult to prove to the satisfaction of all that devastating inundations which occur from time to time in countries on the Continent of Europe are consequence of the extensive destruction of forests, than it is to prove that the scarcity of timber and firewood from which many has suffered is attributable to that, and that desicca- 
tion and drought follow the destruction of forests; but it is a point upon which many students of forest science have no doubt; and on the assumption of its being a fact established beyond controversy, are based some of the most important operations of forest economy in several of the countries of Continental Europe. Of the floods in question I deem it expedient to give details in greater number, and to a greater extent than to others less conversant with these may seem to be called for, hecause I have found in some cases in which a knowledge of the facts was of great importance in view of interests at stake, there was a lack of information both in regard to the magnitude of the evil, and in regard to the connection of this with the absence of forests in the basin upon which the rains fell.

As introductory to the study of such operations, and to the study of phenomena upon which they are based, it may be mentioned that never do we hear of such inundations originating in densely wooded lands, such as predominate in the north of Europe, but in treeless mountain basins or mountain ridges; that the formation of torrents has followed the denudation of mountains of forests; that the extension of extinct torrents has followed the natural reproduction of the forests destroyed; that torrents have been extinguished, and the formation of torrents has been prevented, by artificial reboisement, and in some cases a belt of forest stretching acrost a mountain slope, has had a similar effect.

\section{Sub-Section 1.-France.}

In a volume entitled Reboisement in France, many illustrations of these several allegations may be found.

In this volume (pp. 328-334) are given, amongst accounts of other inundations, details of the inundation of the Garrone in 1875 , by which, in Toulouse alone, 900 persons, it was reported, perished, 600 houses in the town and 2000 in the environs were said to have been swept away; and the 
phenomena are studied in the light of the facts which have now been stated.

It is the magnitude of the evil thus occasioned alone which is here brought under consideration. The history of France, and of other countries on the Continent, embodies accounts of many such inundations in preceding times, and since then, from time to time, like inundations have occurred. The flood of 1875 was the most destructive flood of the century; but though floods of such magnitude are infrequent in the valley of the Garrone, scarcely do twenty years ever pass without the occurrence of a flood of serious importance; and so frequent have they been in the course of the century that to some it has appeared that the periodicity involves a cycle of ten years rather than twenty, as by others had been supposed to be the case. Such seems to be the cycle for the Loire and the Rhone, in which floods occurred in 1846, 1856, 1866, and 1876 .

\section{Sub-Section 2.--Spain.}

In October 1879 great desolation was occasioned in Spain by the Minda and Segura being flooded by a heavy rainfall. It was such that it awoke an interest, and called forth sympathy, throughout Europe, and in lands far remote.

In the course of the following year the scene of this disaster was visited by a member of my family, my sonin-law, Pastor: Fliedner, of Madrid, who has given of it the following account:-

' Nearly a year has passed since the fearful news of the floods in Murcia spread throughout Europe and across the ocean, awaking everywhere sympathy and active help. It may be of interest to our readers to learn something of the force and extent of these floods, of the devastation spread by them, and of the wonderful rescues, and gracious aid of God, from the very scene of the misfortune, whither a tour of evangelisation led us.

"If to any region in Spain the words "It was like unto 
the garden of the Lord" are applicable, they are so to this splendid plain. The diligent hands of the Arabs had divided the rivers Sangonera and Segura into thousands of streamlets, and led them throughout the whole valley; and wherever under the burning sun of Spain there is an abundance of water we have almost tropical vegetation and incredible fertility. In my host's garden I saw stalks of the sunflower which in two or three months had grown to a height of from 15 to 20 feet, and which, being as thick as a man's arm, served as supports to the vine. Engrafted shoots reach in the course of a year a height scarcely attained in the north of Europe in three or four years. The whole plain is divided like a garden in plots, which for the most part are devoted to the cultivation of garden plants, the principal article of commerce and source of wealth to the inhabitants. At the same time olive, orange, lemon, and pomegranate trees are not wanting. The laurel rises to the height of a tree, and towering above all are seen the beautiful crowns of the elegant palm trees, That one fearful October night seemed to be destined to destroy all this beauty, and in many a spot it in reality turned this Paradise into a desert, covering the most fruitful parts, for years to come, with sand.

'This time it was rather the Sangonera than the Segura which caused the disaster. It is said to have received its name from Sangre negra (black blood), at the time when the Arabs in a bloody and decisive battle destroyed the hosts of Murcia, and the river, swollen with black blood, washed the bodies of the slain away to the sea. Waterspouts and violent showers between two mountain chains had, within the space of a few hours, turned the plain into a sea, which, with a hoarse rushing like that of distant thunder, dashed down into the valley. It was the night of the 14th October-a night which will not easily be forgotten by the inhabitants of the plain. Flight was impossible; but a few houses, amongst the thousands with which the plain was studded, resisted the force of the 
waters; hundreds were swallowed up by the flood, and through the rushing of the waves were heard the cries of anguish of the unfortunates who were struggling with death, or who had been separated by the surging waters. In furious haste the waters swallowed up the plain, broke through the railway dam into the village of Alcantarilla, hurried on to the village of Nonduirmas, which they left almost entirely in ruins, and dashed onwards towards Murcia, bearing along with it human beings, animals, trees, and houses. My host in Alcantarilla showed me from his balcony the extent of the great flood, more than a league in breadth; it reached to the sierra, the mountain chain of Carrascoy. One would imagine it to be impossible that such a large plain could be converted so suddenly into a sea. But when we set out on our journey through the plain traces of devastation were but too plain. For nearly a mile the railway dam was thrown down, having torn down along with it a little house which till then had resisted the waves. Great masses of sand covered the once so fertile fields, and of the village, Voy Negra, almost nothing but ruins was left. Voy Negra means "black news," and is so called because hundreds of years ago the dwellers in Murcia there heard the sorrowful news of the defeat of their soldiers by the Arabs. This time the waters brought even blacker news with the ruins and dead bodies which they carried in their fatal depths. What misfortunes, terror, efforts for deliverance, fear, and death struggles are concealed in the darkness of this single night! There a family seek salvation on the roof of a neighbouring house, less exposed than their own to the fury of the waters; but whilst the first house remains standing, the second buries the whole family in its ruins! Another hut is thrown down; but whilst the father is able to save himself by clinging to a fig tree, his wife and children are helplessly lost!

'We entered a little hut; a hole was burned in the roof, which, like the most there, consisted of plaited cane with tiles above; on the three walls which remained 
standing, we could see how high the water had stood-but a few feet from the roof. In that fearful night a mother with her two little children, one of them a suckling, was swimming in her bed. The water rose higher and higher; all hope of escape seemed lost. She tried to break a hole with her hands in the cane roof in order to save herself there, but in vain. Then she seized the light and burnt a hole in the canes, large enough to let her through. She pushed back the tiles and set her little boy upon the roof, then she held her baby out with one hand and helped herself after with the other. Half naked she sat there with her children on that fearful night. The house before them became a prey to the waves. One wall of her house fell too, but the roof held out, and with the morning the longed for rescue came, through two brave young fellows from Alcantarilla, who risked their lives to save her.

'Thank God many a song of valour might be sung; very many deeds of heroie courage were successfully done in spite of hindrances and darkness. The excellent troups of country police, the Guardias civiles, helped with zeal and abnegation; but they were soon called back to the little town, because the lower part of it had also fallen a prey to the waves. There, too, houses and walls fell; single individuals were saved, others were buried in the ruins, or drowned in the waters.

'But the saddest fate of all was that of the village of Nonduermas, which lies about half way between Alcantarilla and Murcia. We did not go by the road, but followed the path which the raging flood had broken for itself. There every house and every tree tells its own sad tale, and louder than all do the heaps of ruins scattered throughout the entire plain proclaim that there once diligent people lived in their own huts, and cultivated and watered the fruitful land. Our guide, Pedro, was himself one of those who had passed that fearful night outside. We stopped at one ruin after another and listened to his account. Here a little girl of five years who had rescued 
herself in the branches of a fig-tree from the falling ruins of the house had held out the whole night; here the father, who had spent the night in the house of his absent master, found in the mornirg but one child remaining, who had climbed upon a beam for safety. In another house the father sought safety in a mulberry tree, which still towers over the ruins in the courtyard; 20 paces off is the fig tree which saved his children, and at a five ninutes' walk on the banks of a deep canal, which brings the waters of the Segura into the plain, is the trembling reed to which the mother clung, until almost unconscious she was rescued.

'The force of the water is beyond all description. Great heavy millstones were carried away to a distance of many yards. A noria, one of the heavy ancient water-wheels which have descended from the times of the Moors, exactly alike in form to those used in Egypt thousands of years ago for irrigation, was carried to a distance of fifty feet without being destroyed. In Pedro's house the whole yard was filled with mud, so that he had to dig deep passages in the earth in order to find his plough. The mules and donkeys had literally to be dug out of the sand in which they were half buried in their very stable, which fortunately lay high. It was half sad half comical to hear his description of how, as the waters rose, he bored a hole in the wall so as to be able to reach the hay-loft, and how his children, and even his corpulent better-half, clambered up and crept through, for "nothing is impossible in such a case of need." He at least had no death to lament in his own family, though he had lost a sisterin-law.

"Thus we reached Nonduermas. Had this village but remembered its name, "Sleep not," better on that fatal night! But ruin broke in on it like a flash of lightning with the rushing stream which here broke through the railway dam for the serond time, and threw a large piece of it down, dashed against the brick houses, and cast one after another to the earth. The streets of the village are 
nothing but ruins. The water is still standing in large pouls in some places. But a few well built houses served as places of refuge for those who were able to make their escape. Out of a population of from three to four hundred seventy-nine perished that night, the fourth-part of the whole number of inhabitants. At present there stands on the open place beside the church a well built wooden barracks, which serves as a dwelling place for many of those who remaiu. The same committee of aid that built this has built several new stone houses. Thousands of articles of clothing are being distributed amongst those who only escaped with their lives; and yet, gratefully as all this is acknowledged, the greatness of the misery does not seem to have been much lessened. At least not in the country, for there it is not enough to give the people money to rebuild their houses; a new means of gaining a livelihood must be found for them until, perhaps after years, they can free their fields, which formerly sustained them, from the sand under which they are buried. We can, however, testify that the people are busily at work; everywhere they are to be seen digging away the sand, removing the ruins, and building new houses - a proof that the charity bestowed upon them is not wasted.

'Much has been done in the way of private charity by the Spaniards. Help from abroad has not been withheld, and has been gratefully acknowledged; and there are capable individuals on the committee of help who not only look to giving momentary help, but also see that by making new roads and better canals, work is given to those who have none, and a similiar misfortune be hindered for the future. Murcia, too, suffered much. The whole of the southern suburb is destroyed. From many a roof the unfortunates had to be rescued by ladders ere the whole house fell in. Along the whole road the traces of the destructive element are to be seen. It must have been a sadly grand and imposing sight to see this endless waste of waters, over which, the palms which grow in great 
numbers in this region alone, raised their crowned heads. The stream flowed on towards Orihuela, but the inhabitants, warned by the telegraph, could at least all save their lives; neither was the loss of property so great, as the force of the stream had lessened, and the masses of sand, which further up had destroyed the fields for a long time to come, were farther below inconsiderable. Murcia, as the capital of the Province, and in a better position, through its influential relationships with the capital, to make its requests heard, has been far better attended to than Alcantilla, and the surrounding plain, although the latter suffered far more. It was, therefore, doubly pleasant for me to be able to distribute, through the secretary of the committee of aid there, the gifts which had been sent to me for this object, although if more had been sent we would have had no difficulty in disposing of them, for the necessity in many families was still very great.'

I have before me details of several like floods which have occurred in Europe of late years. Prominent amongst these is that which devastated an extensive region in Hungary in 1879, while there was passing through the press a New Forest Law, enjoining, amongst other things, the planting of trees as a means of preventing landslips, torrents, and inundations, and of arresting drifting sands. Personal Notes by an eye-witness were published in Blackwood's Magazine (vol. cxxv., June 1879, pp. 728-747). And second in magnitude to this was one was one which devastated extensive districts in Switzerland, the Tyrol, and Northern Italy in 1882. Of all I may say that each had characteristics peculiar to itself, determined by local circumstances or conditions, but in this they were similar-they originated in treeless regions ; and I know of no other similar floods having occurred in densely wooded lands. The flood of 1879 in Hungary came through wooded mountain ravines to the plain, but the origin was beyond, and the floods traversed the forests 
in river beds in which these forests could exercise upon them but little influence.

Such floods are not peculiar to the Continent of Europe: elsewhere, under like conditions, like floods have occurred.

Captain Hall, in his Manual of South African Geography, says (p. 95)-'In Great and Little Namaqualand, the Kalihara Desert, and the whole of the region situated on the southern slope of the Nieuweveld and Roggeveld Mountains, whole years may elapse without the phenomena of a running stream, and yet the magnitude of the dry water-courses of the Buffalo, Hartebeest, and Oup or Borradaile River, all tributaries of the Orange, show how immense must be the torrents that sometimes sweep along them. The writer of this has seen the bed of the Great Fish River perfectly dry, and within twenty-iour hours a torrent thirty feet deep and several hundred feet wide was roaring through it. In February 1848 the Kat River suddenly rose upwards of fifty feet in the course of a few hours, sweeping seventeen feet above the roadway of a stone bridge at Fort Beanfort, supposed to have been built high enough to leave a clear waterway to the highest flood ever before remembered. The Gamtoos, Gauritz, and all the other rivers draining the Karroo, are also subject to very sudden rises, although generally but dry water channels. The periodical rains falling in the mountains near its sources, between September and March, also swell the Orange River to a great extent, and large portions of land along its banks are then inundated.'

In an official report which 1 made to the Government of the Colony in 1864, it is stated:- ' I have seen the Tarka, the Fish River, the Keiskamma, and the Buffalo in their might. I have crossed the bed of the first-mentioned in a box suspended from a rope stretching from trees on the opposite banks, while the river torrent was tearing along liclow, twenty-two feet deep, as ascertained by measurement, where forty-eight hours before the depth was only eighteen iuches. I have been told by a gentleman who had given 
special attention to the subject, of the mean rise of a number of rivers in the same district being twenty-eight feet; I have been told by the same gentleman of a maximum rise of sixty feet; and I have gone over the scene of devastation occasioned by the sudden rise of a river to a height of seventy feet above its usual level.'

It was in the basin of the Gamptoos, at Hankey. In the volume already cited, Reboisement in France (pp. 335339), I have given details of the inundation which it occasioned, and of the consequent destruction of life and property; and in the volume entitled Hydrology of South Africa (pp. 229-247), I have given details of several of the floods and inundations previously mentioned [ante p. ̌̌5].

There are cases on record of great sudden falls of rain, such as on previous occasions, when the basin of reception was devoid of trees, had given rise to floods of a threatening and destructive character occurring after that basin hacl been replanted, being carried slowly away without damage or danger to life or property; and a broad girdle of trees on a mountain side has sufficed to arrest the flow and coalescence of streamlets rushing from the summit after a heavy rainfall or a sudden thaw.

Of such and such-like phenomena many cases are embodied in the volume I have cited, Reboisement in France.

An inundation is simply a flood of such magnitude that the surface surmounting the banks of the river bed, it flows over and spreads upon the land beyond. Most floods may be attributed to heavy and long-continued rains, or to the melting of great quantities of snow. Forests both arrest and retard the flow of the rainfall, and retard the melting of snow, and the flow of the produce, and thus it is that they prevent inundations. The inundation in France which we have had under consideration was attributed to the simultaneous occurrence of continuous heavy rains and a sudden melting of snow on the mountains, both of them incidents of annual occur- 
rence, but at times some days or wceks apart. The best preventitive of the catastrophe would have been the reboisement of the mountains; but the action of the woods and forests on plains, or what pass as plains, is the same.

In a paper on this sulject, read at a meeting of the Societe d'Agriculture de la Haute-Garronne on the 26th July 1877, by M. De Gorsse, it is stated:-'An inundation may be attributable as a matter of fact to two different causes ; it may be occasioned by an extraordinary flood of very short duration, the consequence of a violent storm, of a long continuance of rain, or of a sudden melting of snow; or it may be occasioned by the progressive filling up of a river bed by the deposit of material torn away from the sides of mountains which are furrowed by them. These causes may act separately, but most frequently they are combined. In both cases the duration of the flood is the decisive co-efficient of the inundation; for supposing it were protracted, the flow of the same quantity of water being effected gradually, the overflowing of the banks would be averted. When a single second suffices for the delivery of many thousand cubic mètres of water can it be surprising that a gain of some hours for the delivery may at times save a country from a most dreadful scourge? It is then evident that all circumstances which tend to protract the flow diminish the danger, whilst those which concur to diminish the time of the duration of the flood aggravate the peril.

'Now the action of forests in retarding the flow is very powerful if a storm or a continuance of rains fall upon a wooded slope, [and the effect will be esentially the same on a comparative plain]; a great quantity of the rainfall will from the first be arrested by the foliage and by the branches of the trees, which will subsequently restore it to the atmosphere, or transmit it to the ground, according as rise of temperature supervening in this air, now saturated with moisture, may permit evaporation to resume activity, or as the agitation of the air shall determine the 
fall of the drops of rain temporarily retained by the foliaceous surface of the forests. Of these two masses of water the first is evidently withdrawn from the contingent of the inundation; and the second does not reach the ground until after a detention more or less prolonged, the effect of which is to prolong the duration of the flood.

'The quantity withdrawn by evaporation from the leaves is undetermined. Many experiments have been made with varying results, ranging from 15 to 79 per cent., in the vicinity of Paris.* The conditions under which different results have been obtained, to which the differences are attributable, have not been ascertained. A difference in the kind of tree; in temperature at the time; in the violence of the storm, are only a few of the first suggested conditions. The average will probably be found to be much nearer the lesser number than the greater: if we suppose it to be 20 per cent., or one-fifth of the whole rainfall, on a given spot during the continuance of the rainfall, this would occasion an enormous diminution of the flood. And such a diminution, in many cases, might prevent the occurence of an inundation.'

But beyond this there is the prolongation of the flood occasioned by the retention for a time, more or less protracted, of the rainfall in the forest soil in so far as this may be in excess of what would have been the case had the ground been bare. M. de Gorsse remarks, in continuation of what I bave already cited:- 'As for the water which falls upon the ground, it immediately divides itself into three distinct portions, one which is absorbed by the layer of dead leaves, and by mosses, lichens, and herbs of all kinds, which carpet the surface of the forest; another which infiltrates into the ground, in proportion to the degree of its permeability, to go to be stored up in the lower reservoirs giving birth to springs; and lastly, the excess of both, representing the superficial sheet of water, which, flowing across the thousand obstacles of the forest,

* See Suite a L'etude sur les Torrents des Alpes, de M. Cezanne, p. 96. 
arrives at the bottom of the valley with a rapidity of flow which is greatly reduced.

'Can it be doubted that, as a matter of fact, the trunks of the trees and shrubs, the clumps of bushes and briars, the tufts of heaths and brooms, the banks of rocks, and the incalculable mass of vegetable detritus which covers the soil of a forest, are so many barriers, against which the flow comes to break its impetuosity, to lose its force through sub-division, and to arrest its speed? And ought not the result of the combined action of this multiplicity of obstacles be the reduction in the speed of the floods, which we are desirons to secure.'

The author quotes in support of his views several statemade by M. Cezanne, and he alleges that in whatever way it may be effected, there is no doubt as to the result. But beyond this mechanical action there is another which may also be called mechanical, but the operation of which is different, though contributing to the same result. In regard to this M. Gorsse says:- "To this action of the covering of the ground succeeds that of the soil.

'The soil of a forest absorbs and retains a quantity of water much more considerable than other soils. To satisfy ourselves in regard to this, it is only necessary to consider what are its constituents, and what is the action of the different elements of which it is composed.

' First of all, its surface is covered with a thick layer of dead leaves, and with a carpet of moss, of lichens, and of herbage of all kinds, which cievelope rapidly under the vault of the trees. This covering, so eminently spongy, gorges itself with moisture, imbibes the water, and pertorms the function of immense natural reservoirs, from which subsequently the vegetables pump up the aliment of their transpiration, and springs draw their supply, a double guarantee for a more regular delivery. This is the principal cause of the coolness and humidity under the shade of trees, which is so persistent for a long time after the cessation of the rain. There is not a peasant, a huntsman, or a tourist, who has not had experience of the fact, 
suffering in a severe cold the penalty of an imprudent fancy for a walk in a forest on the day following a storm. And as for foresters, the repeated rbeumatisms to which, alas! they are doomed, do not they present every day, even to the most sceptical, a demonstration cruelly eloquent?

' Under the influence of atmospheric agents this enormous mass of vegetable detritus is decomposed rapidly to form a bed of detritus and humus* which attains sometimes an enormous thickness under the mantle of dead leaves; and it may be imagined that the soil of forests must be infinitely richer in this vegetable constituent than is all other agricultural soil by reason of the quantity of the vegetable matter with which it is strewn, and which rots there, being so considerable. Now it results from researches by Schuebler, reported and prosecuted by Boussingalt, to determine the physical properties of different kinds of earth, that humus is the substance which, of all others, manifests the greatest avidity for moisture. It is by no trifling difference that humus distinguishes itself in this respect from the other earths which were made the subject of experiment. For its absorbent power is about eight times that of sand, from two to six times that of different kinds of calcareous earths, and from two and a half to five times that of the different argilaceous earths.t It may be imagined, then, what an important part in regard to inundations must be played by soil possessing so developed a hydroscopic property. It never happens that in any storm, whatever may be its intensity, the layer of humus imbibes the water to such an extent as to be completely saturated, or that the rainfall forms currents on the surface of a well-wooded soil. One may say then that a forest may easily drink in the whole of the water produced by a most violent

4 The earth in the upper portion of the vegetable soil proceeds from the more or less advanced decomposition of the organic detritus of plants. The humus constitutes the more soluble and assimilable portion of this regetable soil.

$\dagger$ Boussingalt, Economie Rurale considérée dans ses Rapports avec la Chimie, la Phisique, et la Météorologie. 2 Edit. T. i. p. 600, \&c. 
storm; and we may assume the occurrence of a succession of very long continued rains to be necessary to accomplish the complete saturation of the bed of humas. Be this as it may, in any case the flowing sheet of water on the surface of the ground is diminished by an immense body of water absorbed and retained by the soil of the forest; and the unnumbered difficulties which it encounters in flowing over the surface, come to complete the first beneficial effect of the forest.*

'Under the humus we come upon vegetable soil proceeding from the disintegration of the rocks, under the combined action of water and the atmosphere. We cannot enter here on the consideration of the mechanical operations and chemical actions which occasion and expedite this destruction of the rocks, but we may look at the influence of the physical properties exercised by the vegetable soil of the forests. This matter has been treated thoroughly by M. Marchand, Sub-Inspector of Furests, in the first chapter of his interesting study, Sur les Torrents des Alps. The experiments of Thurmann which he reports show that the absorption of water by earth is proportional to their condition of sub-division, and as the roots of trees have evidently the effect of breaking up by division ad infinitum, and in every way, the layers which they traverse, it naturally follows that the vegetable soil of forests is eminently hydroscopic. But in addition to the augmented hydroscopicity imparted to the vegetable soil by the ultimate ramification of ligneous roots; this endows it in sub-dividing it with a considerable permeability. This latter property is one which must not be confounded with the former, as the one is the faculty of absorbing and retaining water, while the other is the faculty of allowing it to infiltrate and pass beyond itself, or be retained in

* The following statement by M. Cezanne may give some idea of the importance of this power of absorption :- "The earth of forests with a density equal to 1.225 retains 1.99 of its weight of water (Gasparin); it follows that if there be a layer of 10 centi. metres -4 inches - of earth saturated and swollen by moisture, it might retain a rain. sheet of $\mathbf{2 4}$ centimetres, or half of the rain which falls in a year in Paris.' - Suite a L'Etude sur les Torrents dos Haute Alps. 2 Ld. T. ii. p. 177. 
grosser pores; and this evidently plays an additional and jmportant part, as it diminishes the flowing sheet of water which is making for the river by the volume of water infiltrating through the ground. And, furthermore, this permeability is communicated by means of the roots to the sub-soil-that is to say, the layer upon which the vegetable soil rests. Let one then imagine what an immense quantity of water comes to be engulfed in these canals, a veritable drainage by inuumerable ramifications.

'A very considerable diminution of the volume of a flood is a corsequence resulting from the diversified action of the mode and power of the operations which have been thus brought under consideration. This has been brought prominently forward by the hydrologic experiments of IIM. Jeandel, Cantegril, and Belland, Gardes Generaux des Forêts, who made it the subject of a Memoir addressed to the Academy of Sciences in 1861. Their observations were made in two basins of the Meurthe, which were absolutely different in regard to the superficial condition of the ground. And they have proved that the co-efficient of superficial flow and the co-efficient of inundating action are at least twice as great in the basin devoid of wood as they are in the wooded basin; or, in terms more generally intelligible, that forests reduce by at least one half the chances of inundations. We cannot, without overstepping the limits of the restricted outline which we have laid down, enter here into an examination of the criticisms, sometimes bitter and often unjust, which have been made upon this remarkable and conscientious work, and of the replies made in defence of it. Let us only say that the authors of the Memoir have at least a right to claim that they have formulated general laws which render an account of the observations collected by them in the circumstances in which they found themselves placed. That, if they had been placed in circumstances ditferent from these, they might have obtained results and numbers somewhat different, is possible. But that the import of these results 
would have been different is altogether inadmissable, for their conclusions are the entirely natural consequence of the phenomena which would have been produced in the order which we have established, and which appear to us to be indisputable.

'The most disastrous inundations are those which proceed from the sudden melting of snow, in consequence of the volume and the instantaneous character of the flood which may be thus produced. Without wishing to attribute to this cause alone the cataclysm of 1875 , which was beyond doubt produced by the coincidence of most formidable meteorological phenomena, we consider that this must have exercised a very decided influence on the deplorable result. The danger arising from this complication was so great that General de Nansouty, whose devotedness everybody in the Pyrenees acknowledges and admires, ${ }^{*}$ observing the mass of snow which fell on the 21 st June, its slight consistency, the elevation of temperature, and the direction of the storm-clouds, understood at once the imminence of a sudden and fearful irruption of water into the valley of the Adour. His assistant, by heroic devotion, braved the tempest, descended to Campan, and giving timely notice to the Mayor and inhabitants, was enabled to save or spare the valley a portion of the disaster with which it was threatened.

'No doubt, then, this sudden melting of the snow was one of the determining causes of the catastrophe of 1875 . Now forests exercise a direct influence on the melting of snow; they retard it. Who has not observed that snow remains under forest masses many days after the bare slopes surrounding them have been completely divested? By protecting the soil against the heat of the sun's rays,

General de Nansouty was Director of the Observatory of La Plantade, establishod on the peak of the Midi de Bigrore. IIe was enabled to announce fifteen hours in advance the terrible inundation which was about to ravage the basins of the Garonne and the Adour. - Notes accompanying the Report of $M$. Alicot on the draft of a Law relative to the Reboisement of the Mountains, passed in 1977 by the Chamber of Deputies. 
and by sheltering it from the blasts of south wind which bring to Europe a portion of the burning heat of the sands of the desert, the covert of trees destroys two causes which, singly or conjointly, bring on the sudden debacles of spring. Under their nave of verdure the melting of snow goes on always insensibly and gradually, never suddenly and in a mass.

'We read in a report addressed by M. Fare, DireetorGeneral of Forests, to the Minister of Finance, relative to the nature and utility of the new law on the reboisement of the mountains, presented to Parliament in 1877 :-

" "Being very elevated, the Alps extend very often into regions of long-continued and long-lying snows. They receive the snows over an extensive area, they preserve them for a long time, and thus they accumulate there the more. On the return of spring the sun, by reason of the latitude it has attained, has then great power. Often there supervene burning winds from the south which expedite still further the effect of the direct rays of the sun. The result is that the melting of the snow, instead of going on gradually, is effected all at once, in two days the flood has passed on and the debacle is terminated.'

"What is affirmed of the Alps may be applied with a slight deduction to all mountainous countries, and one can well imagine that on slopes divested of trees, rain and snow storms, encountering no moderators of their action and their violence in the natural screens and shelters of woods, must be followed by fusions, sudden and of an abundance proportionate to the areas of these immense reservoirs. But the beneficent roll of forests is not limited to the protection which they afford to the portions of the basins which they cover. Discharging the duty of gigantic and multiplied barrages, they oppose also their innumerable obstacles to the flow of the inundating sheet proceeding from the sudden debacles in the pasturages and glaciers with which they are crowned.'

Additional information in regard to the immediate and 
the secondary effects of trees in arresting the flow and escape of the rainfall, and thus equalising to some extent the flow of rivers, is embodied in a volume entitled Forests and Moisture; or Effects of Forests on Humidity of Climate, pp. 212-254.

Besides citing this, let me add that in a paper in the Revue des Eaux et Forets, for April 1866, there are given the following striking illustration of the effect of woods on torrents :- - The State possesses, in the department of Vancluse (writes the forest conservator, Labuissière), a forest of more than 3000 hectares, situated on the portion of the mountain Luberon, nearest to the valley of the Durance. This region is very much cut up, and traversed in all directions by very narrow and deeply embanked ravines in the midst of masses more or less dense of Aleppo pines and green oaks.

'These ravines are almost the only outlets for the transport of wood, in consequence of the difficulties which would be encountered, and the expense which would be incurred, in making more practicable ones on the rapid declivities, strewn with enormous masses of rock. There exists one so situated, called the Ravine de Saint-Phalez. The direction is from north to south, in the midst of a mass of Aleppo pines in a state of growth more or less compact.

'Its length, and for four kilomètres, or from the road from Cavaillon to Pertuis, to the domain of Saint-Phalez, of an area of about 50 hectares, forms the bassin de réception of the torrent.

'This land is well cultivated; there are no declivities too steep for cultivation; it comprises vineyards, meadows, and arable land; the soil is argillaceous.

' The ravine of Saint-Phalez receives many affluents, the most important of which is that of the Combe d'Yeuse, which joins it near the summit, where are some hundred mètres of the cultivated grounds of which I have spoken.

'The ravine de la Combe d'Yeuse is of much less considerable length than that of Saint-Phalez; it is scarcely 
two kilomètres. It is strongly embanked, surmounted by steep declivities, covered with green oaks of eight or ten years' growth, and with Aleppo pines of different ages. Its bassin de réception, of about 250 hectares, or 113 acres, comprises the whole slope, precipitately inclined, with a general south-west aspect; it is closed at the top by a deep bed of rock cut into peaks of the most imposing aspect.

"The geological formation in both is absolutely the same, as are all the other conditions, at all the points which I have examined. In no part is to be seen either spring or appearance of humidity; no water is seen excepting at the time of the storms or great rains, and this water soon passes away, with the differences which will afterwards be mentioned. At all other times these ravines are of a desolating aridity.

'In the night of the 2nd and 3rd September 1864 there fell a rather abundant rain over all this portion of the mountain. In the morning the argillaceous grounds of Saint-Phalez were saturated, of which evidence was found by any one attempting to cross them. The ravine of Saint-Phalez, the receptable of the surplus water, had flowed but slightly; that of the Combe d'Yeuse remained dry.

"The day of the 4th September was very warm; a water-spout borne along by a south-west wind struck. on the Luberon. Its passage did not last more than forty minutes; but scarcely had it come when the torrent of Saint-Phalez became awful. Its maximum deliverance was about two cubic mètres. It did not flow more than fifty minutes; but with an average delivery of half a cubic mètre ; it had then passed in all 15,000 mètres of water. Its height had been $0.04 \mathrm{~m}$; each square mètre had received 40 litres, and the 50 hectares of Saint-Phalez 20,000 cubic mètres. The ground had only retained 5000, which is sufficiently explained by their argillaceous character and their state of saturation the night before. While the torrent of Saint-Phalez flowed, filled from bank 
to bank, seizing and carrying off rocks which had been employed to form a road which was believed to be safe against all contingencies, that of the Combe d'Yeuse and all those traversing wooded lands remained dry, or gave only an insignificant quantity of water.

'On the slope opposite to that of which I have been speaking, in the valley of the Peyne, a carriage-road newly formed did not experience the least injury throughout the whole of the portion of it passing through the forest of the domain; but at its issue, on the lands of the Libaude and of the Roquette, it had been, so to say, destroyed. A cart loarled with faggots was upset and smashed by the waters, which flowed from all the cultivated slopes, and tore along, with the noise of thunder, at the bottom of the ravine.

'My good fortune secured to me another subject of study on the same ground.

' On the 25th of October following I went to the sale of the fellings of the Tarascon, where there fell an abundant rain. 'T'he next day (the 26th) the weather was clouded. I set off for the Luberon in the hope of arriving there at the same time as would a storm of rain, which I saw approaching. I arrived first; the rarine of Saint-Phalez was still moist, from the passage in small quantity of the waters of the night before; they had served, as appeared, to saturate the lands of the domain, as had previously happened on the 7th [3rd ?] September.

'I had scarcely gone over two kilomètres in the ravine when the water began to rush with great violence; ten minutes later it precipitated itself in its ordinary canal d'ecoulement, completing the work of destruction begun in the month of September. The lands of Saint-Phalez had absorbed but little or none of the water that day.

"The storm was not of long duration-an hour at most. The time was unfavourable for collecting on the ground exact measurements, but I reckon that the torrent delivered, at its maximum, somewhat less water, perhaps, than on the 4th of September. The flood, however, was 
more frightful; it swept away rocks with so much the greater ease that nothing had been repaired since the first storm, which had left the stones dug out, and without bond of cohesion among themselves.

'To gain the forester's house, which was on the slope of the left bank, it was necessary to make a long circuit-to go round the domain of Saint-Phalez, and to cross the grounds belonging to it, in which one sank to the depth of 0.30 mètres, or 12 inches. Before arriving at my home, I had still before me the ravine of the Combe d'Yeuse, and I feared I should be stopped there by a new obstacle. I was agreeably surprised to find it dry. An hour after the storm the ravine of Saint-Phalez had ceased to flow.

'It rained throughout the whole of the 28th, without there being anything to remark similar to what had happened on the preceding days. The only effect of this was that on the evening of the 30th, near the forester's house, and at 200 or 300 metres from the ravine of Saint-Phalez, there was seen going down, in that of Yeuse, a small fillet of clear water; its volurne increased perceptibly during the three days, to diminish in like manner during the two which followed; its passage broke down a little of the footpath which goes along the valley, but caused only a damage easily repaired. But this footpath presented nothing of the solidity of structure of that of the Combe de Saint-Phalez, built on enormous blocks of rocks which had stood for several years, and which had allowed of passage with a waggon some days before its destruction by the storm in September. If the Combe-d'Yeuse had yielded as much water as that of Phalez, and if these two masses of water had come at the same time, the damage caused in the plain must have been considerable, and the Durance, which received these waters, would have been so much the larger.

'Thus we have two torrents very near and under the same conditions-except that the basin drained by the one 
comprises 50 hectares of cultivated lands, that of the other 250 hectares of woodlands. The first receives, and allows to flow away, the waters of the greater part of a storm in a few hours at most, causing thereby considerable damage; the second, which had received a greater quantity of rain, stores it-keeps it for two days-evidently retaining a portion of it, and takes three or four days to yield up the surplus, which it does in the form of a limpid and inoffensive stream.'

M. Jules Clavé, writing on the effects of forests in increasing humidity of soil, says :- 'When Napoleon was taken to Saint Helena,' writes M. Blanqui, ' the English felt the necessity of occupying Acension Island, which was then only a barren rock, scarcely covered with a few cryptogamic plants, and there they stationed a company of a hundred men. At the end of ten years this little garrison had been enabled, by dint of perseverance and plantations, to create a soil on the island, and from this to draw some water. It was abundantly planted with vegetables. Such was the result of plantation upon a rock in midocean!

'But why should we seek so far away for the proofs of phenomena that are renewed daily under our eyes, and of which any Parisian may convince himself without venturing beyond the Bois de Boulogne or the forest of Meudon? Let him walk out, after some days of rain, along the Chevreuse road, bordered on the right by the forest of Meudon and on the left by cultivated fields. The amount of rain that has fallen is the same on both sides, and yet the ditches by the roadside along the edge of the forest will be still filled with water, proving the infiltration going on from the wooded soil, while already for some time those on the other side, adjoining the cleared fields will have been dry, after having served their purpose by a sudden flow. The ditch on the left will have emptied itself in a few hours of all the water, which the one on the right will take some days to convey to the bottom of the valley.' 
In accordance with this it is mentioned by Mahé :- ' In France, in the Montagne-Noire, experiments have been made in two different valleys, the one wooded, and the other denuded of wood; and it has been ascertained that the first gives off immediately after rain less water than the second, but on the other hand this becomes rapidly dried up, while the former feeds the stream throughout the entire year. And it has been observed that while in denuded regions the heaviest rains fall in the summer, in wooded districts they fall in the autumn and winter - that is to say, during the season in which, according to Belgrand, they contribute most to feed the water-courses. These observations, made by Maistre in Aude, are of indisputable explicitness in their teaching; the results show so evidently that the aridity of a country goes on increasing with the clearing away of woods, and that the water-courses which formerly gave movement to mills have to-day no longer sufficient water to do so.

'Cauvigril has in like manner observed that a stream, that of Cauman, which takes its rise in a forest district belonging to that same forest of the Montaigne-Noire, formerly gave movement to fulling mills, but after the clearing away of the forest the flow became so irregular that the mills had to stand still through part of the year. The commune, however, having recently replanted the forest, the Cauman has resumed its former rigime, and the works go on now without interruption.'

I have had occasion elsewhere to state that the Alpine torrents are traced by Surell to two sources - the melting of snow about the beginning of June, and storms of rain occurring about the end of summer. The inundations in the Garonne valley was occasioned by similar causes, but by these operating simultaneously, and this in the Cevennes and in the Pyrenees at the same time. In accordance with what has now been stated, when a basin drained by a river is covered by vegetation the flow of the water is retarded, diffused, and protracted; but when mountains 
upon which the rain falls are devoid of vegetation, the rain rushes off as does water on the roof of a house-and thus was it here.

The Journal des Debats thus explains the phenomena of these inundations:-

' It is the chain of the Cevennes which canses these immense disorders. Between the sources of the Loire and the Hérault the Cevennes are 3,700 feet high. All this surface is composed of granite impermeable to the rains. 'l'he river waters rush over this ground with immense rapidity, but do not enter it. The chief streams rising there are the Dour, the Ervieux, the Ardéche, and the Gardon, affluents of the Rhône; on the west, the Lot and the T'arn, affluents of the Garonne; on the north, the Loire and its tributary the Allier; on the south, the Hérault. The Ardéche, whose basin is only 2,492 kilomètres, has enormous rises. At the bridge d'Arc the struam rises to nineteen mètres above the lowest level, and pours down at a rate of 7000 cubic mètres per second, almost as much as the Loire at Tours. An equal violence is registered in the Dour, the Ervieux, the Gardon, the Isère, the Drôme, and the Durance. Since everything depends on the rainfall, it is obviously impossible to calculate with certainty beforehand. Every year the Cevennes cause vast "spates" in the largest rivers in France--the Rhône, the Loire, and the Garonne. All the streams of the regions are torrents. The southern part of the Cevennes, the Black Mountain, and the Corbières exercise a great influence on the small Mediterranean streams between the Rhône and the Pyrenees. A rain of 200 millimètres, which has no perceptible effect elsewhere, causes in these parts a sudden flood.'

In general the rains fall there in May, and being then comparatively cool, they melt but little of the snow, and How away as they fall. But when they fall in Jume, as this year they did, they are somewhat tepid, and falling upon the snow, melt it rapidly, and the watery produce is added to the rainfall; thus two sources of flood are com. 
bined, and disastrous consequences not unfrequently follow. And thus, as has been stated, was the late flood produced. Persistent rains from the north-west fell upon the Cevennes and the northern slope of the Pyrenees. This was preceded there in some cases by a heavy fall of snow ; and there was over all the higher-lying lands the snow which had fallen in the course of the winter. This snow was dissolved; all the tributaries of the Garonne were flooded simultaneously; and we see the result.

In such a case time is everything. It may make all the difference between the loss of life and property, and perfect safety to both, if a body of water, such as was here precipitated from the mountains, shall rush past a given point in four days on take fourteen for its flow-flowing in flood, but never rising above the height of the containing banks. And it may make a very great difference, though not so great, if a flood and inundation come suddenly in the night, without notice or warning, and if it come after twelve or twenty-four hours' notice of its coming.

Thus is it with floods in the Seine and in the Loire. Warning is given by telegraph all along the course of these rivers that a flood is on its way, and the inhabitants on their banks are prepared when it comes; and thus, as has been stated, the inhabitants of Orihuela, in Spain, were enabled to betake themselves to a place of safety before the flood of the Sangonera reached their town.

But this could not be done in the case of this inundation. There is an observatory at Pic-du-Midi, a spur of the Pyrenees, and it seems that General de Nansouty, who commands there, would have been able to give timely warning of the coming inundation had the observatory been in telegraphic communication with the threatened towns and villages, - at all events along the course of the Adour. $\mathrm{He}$ did, as we have seen, warn the people in the valley of Campan of what was to be expected from a heavy fall of snow in the mountains, which snow had suddenly commenced to melt under the influence of the rain and westerly wind: on the first appearance of danger, on 
the night of the 22nd June, M. Beylac descended the mountain during the most fearful weather to spread the alarm; but the floods in all the tributaries of the Garonne were so sudden that to give extensive warning was impossible. Had the bassins de reception of all these streams been wooded it would have been otherwise, but they were to a great extent devoid of vegetation.

Very different had been the result had like warning been given along the course of the Garonne of the coming flood from one to twelve or twenty-four hours before it reached the different towns and villages destroyed; and very different had been the case had the waters which swept along in a torrenuial wave taken fourteen days to flow past any and every point on its course! It may be, that never would it have risen so high as to imperil a single house, and that in consequence of the timely warning given not one life would have been lost! It is sivid by' a writer I hive quoted, - ' If this observatory [that on the Pic-du-Midi], now isolated on the peak, were bound to the plain by telegraph, the General might transmit to the officials of the Ponts et Chaussées previsions of the last importance. In the same manner a station should be made on the Corbiéres. As soon as the quantity of rain falling on these cliff's became dangerous the authorities would be warned.'-Yes ; but this, if combined with a complete reboisement and gazonnement of the mountains, would give them longer time to prepare for what was coming. Aud it may be asked, Why has this not been done? An answer is forthcoming, and that not the answer which might be expected, that, as has been stated, 'Between the sources of the Loire and the Hérault the Cevennes are 3,700 feet high. All this surface is composed of granite, impermeable to the rain, and to plant such either with herbage or with trees is impossible;' but the answer, that the work is being done as fast as money and men and material can be found, and that already, previous to this inundation, all that could be done up to that time had been accomplished. It is often easy to tell, after an event has occurred, how it 
might have been prevented; and it may be that had these inundations been foreseen, operations which would have to some extent modified or prevented them would have been prosecuted with the vigour called forth by a race against time, in preference to some others which have not been ineffective, but the execution of whicb might without series consequences have been postponed; or, at all hazards, grants on a scale of magnitude equalling or exceeding those made previous to the war would have been made, and the difference between these and the amounts actually granted spent exclusively on the valleys and basins of reception drained by the upper waters and affluents of the rivers by which such devastation has been wrought. The legitimate use now to be made of such reasonings is, to prepare for the future in accordance with the suggestions suggested by the past. And this, I have no doubt, will be done.

\section{Section D.-Torrents, Avalanches, and Landslips.}

In connection with what has been said of floods and inundations, mention has been made incidentally of landslips, and torrents, and alluvial deposits, which are also attributable to the clearing away of forests. In proceeding to supply details in regard to these, I deem it proper to premise that it is not alleged that all such accidents are attributable to this cause; all that can be shown is that some such have been thus occasioned.

In the language of our countrymen the designation torrent is applied to the rushing body of water in a river bed, in contradistinction to the inundation of the lands beyond in such a form as has been referred to in the preceding chapter. But the term is applied in France to another phenomenon, and in lack of an English term of corresponding import to this, I so apply it here, namely, to the mountaiu bed of the waters, along which they escape from the basin of reception, rushing to the lower lying lands 
on the plain, often undermining the confining banks on the right hand and on the left, bringing down the overhanging masses, and sweeping along the détris and covering fertile lands many feet deep - it may be fathoms deep - with stones, and clay, and rubbish, which no appliances of man can remove, and which doom the land to sterility in all coming time-the disturbances of the angle of stability affecting the ground at a level far above that of the torrent, and sometimes occasioning landslips of the most serious importance.

There may not at first sight appear any connection between the destruction of forests and the occurrence of such phenomena, and yet, as a sand-drift has been known to originate in the uprooting of a bush, miniature torrents have been known to originate in the displacement of a stone half-buried on a mountain side. And by Surrell it has been demonstrated that all the torrents on the Alps - and the Alps are in many places scarred with these-are attributable to the destruction of forests on the mountains. 'The demonstration is of a most conclusive charactershowing that such has been the case in times past; that such is the case still; that former torrents have become extinct through the spread of arborescent vegetation over the basin of reception; and that the artificial planting of trees, or bushes, or herbage, on appropriate sites, has extinguished torrents which immediately before were in full play.

Many of the phenomena accompanying the creation of these torrents are most remarkable, including stones torn from their beds, propelled above and beyond the rushing water, and advancing through the air in front of the walllike front of the mountain wave.* But what is of more economic importance is the value of the property, lands, orchards, and houses undermined and carried away; and 
the extent of fertile land lost irretrievably by being covered up with the débris. And what chiefly concerns our present argument is the connection of forest destruction with these, as the cause or occasion of the evils occurrent.

In the localities affected the consequences are only second, if indeed they be second, to the consequences of floods and inundations on the lower lying plains. The area of land immediately affected niay be smaller; but the loss is absolute and permanent. The proofs, or indications, of these having been in many cases occasioned by the destruction of forests, and being in all, attributable to the treeless condition of the ground upon which the rain had fallen, are such as I have stated.

It is to M. Aléxandre Surell, Ingenieur des ponts et chaussées, now Director of the Chemin de Fer du Midi, that we are indebted for the cliscovery, study, and exposition of the pbenomena in question. He has been followed by the late Ernest Cézanne, Ingenieur des ponts et chausées, and Representative of the High Alps in the National Assembly, and by others. The volumes cited being charged hard with details of facts, and their reasonings upon them, I consider it unnecessary to refer further to this. Since that volume was published, voluminous reports of works of reboisement in the mountains of France, with a view to arrest and prevent such evils, which have been executed, have been issued by the Government; and similar works have been executed elsewhere, as in Switzerland and in Spain. But I content myself with citing the following testimony, which corresponds fully with many occurring in the volume to which I have referred.

M. Hérecart de Thary, in his Potamographie des HauteAlps, writes :-

'In this magnificent basin (that of Embrun) nature has done everything with prodigality. The inhabitants have blindly enjoyed these favours: they have slept in the midst of these gifts. Wretches that they are, they have inconsiderately carried axe and fire into the forests, which 
shaded and protected the precipitous mountains, the unknown source of their riches. In a short space of time the naked meadows have been ravaged by the waters: torrents have swollen up: they have precipitated themselves with fury upon the plains: they have cut away, torn down, and undermined their bases. Extensive lands have been carried away; others have been buried up with the dêbris; these have been covered with rocks, or they present now to the eye only sterile gravel. The ravages are going on still; and ere long these torrents will have annihilated this beautiful basin, which lately might have been compared advantageously with the richest countries possessed of what is most fertile and is best cultivated.'

Numerous details -I had almost said innumerable details - of phenomena like to those mentioned are given in a volume entitled Reboisement in France; or, Records of the Replanting of the Alps, the Cevennes, and the Pyrenees, with trees, herbage, and bush, with a view to arresting and preventing the destructive consequences of torrents, in which are given a résume of Surell's study of Alpine torrents, of the literature of France relative to Alpine torrunts, and of remedial measures which have been proposed for adoption to prevent the disastrous consequences following from them,-translations of documents and enactinents, showing what legislative and executive measures have been taken by the Government of France in connection with reboisement as a remedial application against destructive torrents, - and details in regard to the past, present, and prospective aspects of the work.

In regard to the effect of forests in preventing the occurrence of avalanches, M. de Gorsse writes in a paper read before a meeting of the Agricultural Society of the High Alps, on the 2nd July 1879, relative to the influence of forests on inundations, which has already been cited :-

'All know the cause of the avalanche and the action which it takes; in spring; under the heat of the solar rays, 
or under the breath of the warm south winds, the upper layer of the field of snow begins to melt. The water thus produced sinks by infiltration to the ground, warms it, thaws it, and detaches thus the lower bed of ice which was intimately bound with it. From the time that the equilibrium is disturbed at this point the snow mass sinks down, and slides under the action of its weight. The shock propagates itself to surrounding masses, the impulsive force extends to the inferior fields of snow. And the avalanche, enlarged by the enormous mass of earth and rocks which it tears from the sides of the mountain, precipitates itself to the foot of the valley amongst rumbling sounds-sounds and claps resembling those of thunder, scattering in its passage ruin, desolation; and death.

'There suffice often in the season of debacles the slightest rise of temperature, the least change of weather, or the vibrations communicated to the atmosphere by a rifle-shot, to determine the setting off of an avalanche. Sometimes, on the other hand, the least change in slope, or a slight elevation in the ground, suffices to arrest a sliding snow mass, or to alter its direction. A forest, especially if it be situated at but a short distance from the point where an avalanche originates, acts in this way. But if the commencemert of the avalanche be at too great an elevation above the wood, the impulsive force may have become too great, and the acquired speed too giddying for the obstacle to resist it; and then the forest may be violently swept off and hurried along by these impetuous torrents of snow, or be crushed under their mass. Thus it is not so much in stopping the sliding down of the avalanches, when once the movement has commenced, as in preventing the formation and setting out of these that woods and masses are so eminently useful. Every bush in a forest, every trunk of a tree, or stem of a shrub, by creating a division in the field of snow at the first, diminishes the mass, and the weight of the avalanche, which is the primary and essential condition of its slipping. 
And these present moreover at the same time so much resistence to be overcome, and are so much support given to the maintenance of the equilibrium of stability ; acting in the same manner as do sustaining piles, which are sometimes fixed in slopes, which are too mobile and too steep, in order to prevent landslips; and thus do these numberless firmly rooted trunks retain the snowfields on all surfaces covered with them. Such is the mechanical action of the forest of piles devised by the genius of Gaubert to protect the military hospital of Bareges against the avalanches by which it is threatened. And without more than a moments pause we may tell that these piles employed as expedierts designed to meet the requirements of the moment, have been followed by efficient reboisements, and the construction of barrages, which have produced the happiest iesults.

'The protective efficiency of forests has been put pro. minently forward by all authors who have written on the subject. In their interesting work, entitled Les Glaciers, MM. Zurcher and Margolle remark (p. 192) :- "The village of the St. Gothard owes its preservation to a small forest of fir-trees situated on the brow of the mountain which dominates it, and thus this forest has become for the inhabitants an object of the greatest care. They have surrounded it with a hedge to prevent the access of cattle, and very severe penalties have been decreed for men who may be guilty of the least damage to these sacred trees."

"The same fact is mentioned by Viollet-le-Duc in his Etude du Massif du Mont Blanc.

'M. Philippe Breton, engineer-in-chief of roads and bridges, charged with the special service of the Etudes des Torrents des Alpes, after having cited an example of the influence of forests on the extinction of avalanches in the basin of La Romanche, adds:- "This example proves, then, two things: (1) In certain localities the effect of a good forest system may suppress, or at least greatly reduce, the damage done by avalanches, and this simple reduction may suffice to avert grievous consequences; (2) we find 
in mountains with great wooded slopes, below these the fields and dwellings enjoy a certain security, thanks to the existence of the forest; but if this forest come to be ravaged, avalanches immediately make their appearance, and carry destruction to the lower lying properties. It would be easy to give the names of more than one hamlet in the mountains which is thus protected by a forest, the inhabitants of which bave no idea that their existence depends on that of the forest."

The landslip differs from an avalanche; but against this evil also protection is afforded by woods and forests. M. de Grosse having occasion to state that inundations are sometimes attributable to the filling up of the river bed with mud, and sand, and gravel, and stones, brought down by floods, adverts to allegations which had been made that the quantity of matter thus deposited was too inconsiderable to justify the importance attached to it by him and some others, and having in defence adverted to the fact that the quantity was by no means inconsiderable, he goes on to say:- 'Now forests exercise a most powerful influence on the consolidation of the soil and the maintenance of earth and rocks on the slopes of the mountains. They act both by the trunks and the roots of the trees: by the trunks, in arresting the fall of dislodged rocks which were rolling over the slopes devoid of woods, towards the bed of the torrents; by the roots, in opposing an invinsible resistance to the diluent action of water, and insurmountable obstacles to landslips. It is in making a trench in a forest, and observing the inextricable interlacing of roots in which are enclosed clods of earth and fragments of rocks, that one can alone form any idea of the intensity of these resistances. "Vegetables," somewhere says M. Cezanne, "always consolidate the soil ; the roots are like the meshes of a net; they let pass the

* Philippe Breton, Ingenieur des Ponts et Chaussées, Etude d'un Systeme Gieneral de Defense Contre les Torrents des Alpes. Concertee entre les Fonctionnaires des Forêts et des Ponts et Chaussees (p. 39). 
water and retain the matter which the water was taking with it in its course." The chopped straw which we knead into the clay, is it not designed to augment the solidity and consistercy of the clay masonry? What else does art do here than copy nature? Let the engineers who think we exaggerate cast an eye over their accounts, and compare the value which they assign to rubbish under woods, and to rubbish under uncovered land. They will find in the considerable augmentation of the former the measure of the action which we are seeking to demonstrate.'

The action of trees in preventing avalanches is two-fold. The interlacing of the roots tends greatly to consolidate even arable earth; and while most landslips are occasioned by the undermining to a short depth of the superficial layer of a slope, this is generally occasioned by a rush of water produced by the rainfall in some more elevated locality ; and the unvarying effect of reboisement in the basin of reception as to prevent the formation in this way of torrents.

In regard to erosions thus produced, M. Surell writes in his Etude sur les Torrents des Hautes-Alpes:-

'The torrent which dashes a great body of water over very steep slopes undermines and eats away with fury the base of the banks. These fall in, and little by little pull down towards the bed the adjoining property, which is finally engulfed by the waters. As the banks are generally very deep, their fall brings in its train effects the results of which extend far from the spot. All the surrounding land is disturbed. Some portions undernined subside, others slip, others break away, leaving deep crevices. Along the two banks of the torrent may be seen large chinks or rents running parallel to the bed. These subsidences, these rents, and this disturbance spread from place to place, repeat themselves to incredible distances, and end by including the whole sides of the mountain within the range of the effects. There are many quarters 
which can be named which the erosion of torrents have made so unstable that it has become impossible to build upon them. On the left bank of the torrent Les Moulettes there may be seen houses belonging to the village of Les Andrieux, which have been rent at a distance of more than 800 mètres from the bed. On the highway, No. 91, opposite Les Ardoisières, we have an example of a considerable revers of a mountain eaten away by the Romanche and disturbed by continual movements of the soil. The instability of the soil has compelled many families to abandon cottages situated at a great distance from the river. One could scarcely comprehend that that could be the cause of movements so remote, if the analogy of facts and other evidences had not proved it to be so in a manner the most irresistible.'

Numerous cases are referred to in a note followed up with the remark,- 'I have thought it right to multiply citations, because the cause of these movements has been often misapprehended, and notably so in the case last mentioned. The inhabitants attribute it to some particular character of the ground. Having under their eyes only the case of their own locality, they are not aware that it is a phenomenon quite general and common to all torrents.'

He specifies movements of the soil in the mountain of Saint Sauveur, over against Embrun, brought about by the torrent of Vachères, and by a great many other torrents of the third class ; also similar movements in the district of Vabries, mined by the torrent Crevoux on the left bank, and in the district of Villard Saint André, by the same torrent on its right bank; it is stated that this ground had become more mobile subsequently to the formation of a canal for irrigation; accounts are given of similar movements attributable to the torrent of Sainte-Marthe, near Caleyères, in connection with which it is stated that there was there a mill apparently on the point of being engulfed, and of movements, attributable to the torrent Merdanel, above Chadenas ; and it is stated that very violent movements have been observed in the districts of the Diveset, 
of the Labéoux, of the Rabioux, of the Boscodon, of the Ruisseauioux (Lauterat), \&c. And he goes on to say,'There are whole villages built in bassins de réceptions which are threatened to be engulfed in this manner by the torrents. Every year the torrent acquires more of the ground, and the village abandons to it several cottages. These facts demonstrate the encroaching march of these water-courses. Little threatening at first, they increase in size, they extend themselves, and soon they reach the habitations built without mistrust at a great distance from their banks. There were, before the thirteenth century, on the borders of the Ralioux, near to Châteaureux, a monastery inhabited by the Benedictines. At a later period the monks deserted it through fear of its being engulfed, and now one sees the ruins suspended in the inidst of the river's banks.

' There are threatened with a similar fate the village of Lacluse, by the Labéoux (Dévoluy); that of the Hières, by the Mauriand; that of the Arvieux, by the Moulettes; the hamlet of the Marches, and the hamlet of the Maisonnasses, by the torrent Rousensasse, on the right bank of the Drac (Champsam).'

Having specified these as villages or hamlets exposed to a fate similar to that of the Benedictine Monastery, whose history is given, he goes on to say,- Most frequently the undermining of the soil is done gradually, and this action is the more slow and the more regular in proportion to the extent of the region. The great mass of ground deadens the movements, and impresses them with a kind of continuity. But at other times also the soil detaches itself suddenly, as if through the effect of a blow. It is thus that in the valleys of the Dévoluy, some years ago, a fragment of the mountain Auroux, covered with cultivated fields, precipitated itself, in one block, into the gorge of the torrent Labéoux. The commotion occasioned by this frightful fall was felt at a considerable distance, in the village Lacluse, and the inhabitants attributed it to an earthquake. The cause was no other than erosion by the torrent, whieh had sapped the base of the ground. 
'This may demand some explanation.

' Many lands are formed of parallel banks, disposed in flat layers and raised up on great inclinations. Often an interposed bed, more soluble or less tenacious, is decomposed or disintegrated by infiltration. If it happens at the same time that the under banks be attacked by the current at the foot, an enormous weight of ground finds itself suspended over an abyss; the force of adhesion being weakened, it no longer suffices to keep together this mass and to attach it to the body of the mountain; it is then detached in a mass, and it slides over the surface of the decomposed bed as on an inclined plane. One may indeed see similiar landslips frequently occurring in the limestones of the lias formation, which decompose with the greatest facility, and which often present a schistose stratification; this kind of ground extensively prevails here. In other cases the grounds have been formed of the débris of the upper parts of the mountains; they compose a rough mass without stratification, and most frequently without consistency, covering the stratified nucleus of the mountain, and forming on its surface beds of great thickness. It rarely happens that a bassin de réception does not contain within its circuit a large strip of this quite recent formation, for it is into the scooped out parts that the débris have had to roll and rest. And one may easily see that the erosions which take place in such grounds, when they attack the foundation of very high banks, must force the soil to detach itself in great masses; and the fractures will take the form of immense prisms, in accordance with laws similar to those regulating land-shoots (pousée des terres). So that it is in the abundance of certain kinds of earths, and in the composition of the soil itself, that we find the secret of the principal power of these torrents.'

It is established beyond all question that reboisement is an efficient preventitive; and in manifold cases torrents ard landslips have made their appearance after, but only after, the destruction of forests in the basins of reception 
and on mountain slopes. Therefore are such reckoned amongst evils which have been occasioned by the extensive destruction of forests,

\section{Section E.-SANd-Drifts.}

Amongst other evils attributable to the destruction of forests, besides those which have been noticed, are sanddrifts. It has been found that the uprooting of a busb on a sand-plain, bound down with verdure, has been like the first percolation of water through some crevice in the retaining embankment of the sea: the drift has gone on increasing and extending with the effect of covering a large area of fertile fields with sterile sand, rendering them as sterile as the sand upon the sea-shore.

In the sand-drifts of the Bannat in Hungary there exist roots of trees and pipes of agglomerated sand supposed to have been formed by accretions around roots of trees which have been decomposed and removed by subsoil moisture. Large remains of roots have been found in the steppes of Southern Russia. In what are now called the Landes of the Gironde there stood formerly sea ports and towns with trees, if not also forests, as part of their environment. And remains of ancient trees have been found at intervals in sand-plains from the Bay of Biscay along the coasts of the Atlantic and the Baltic, till we reach the continuation of these in Russia, Poland, and Hungary. But this may be insufficient to warrant the allegation that wherever sand is now drifting the drift is attributable to the destruction of the forests of which these are the remains. All that can be affirmed is that thus they may have originated; that by restoring of such woods the drifting of the sand may be stopped; and that no more effectual remedy for the evil has been found. And the legitimate inference is that thus the sands of the steppes and sand-plains of Europe, covering, as they do, an immense area, may have been bound down of old; and that the destruction of these forests, in whatever way this may have been effected, once 
more set them free, occasioning many of the sand-drifts of the present day.

Of fixed sands being set free to drift, and to desolate fertile lands through the destruction of trees, an illustration is supplied by the history of drift-sands in the vicinity of Danzig.

'Amongst the more extensive sea-shore sand-hills,' writes Herr IVessely, in his treatise entitled Der Europïishe Flugsand und seine Kulture (pp. 221, \&c.), 'may be reckoned those on the gulf of the East Sea, through which, flowing past the great commercial town of Danzig, the Vistula empties itself into the sea; the sand-hills there rise to the height of 180 feet above the sea-level. These dunes, which are continuous from the present mouth of the Vistula, and indeed from Neufaehr to Kahlberg, extend over some six German miles [a German mile is equal to four and a-half English miles], were by man's haud, and through man's spirit, first created and then subdued, and were thus in a sense made a practice ground and high school for Seestrand Dunenbau, or culture on sea-side dunes. As is pretty generally the case on the coasts of the Baltic, the dunes here, with a solitary exception, were on the slope towards the sea, and were exposed without defence to the blast of the sea breeze, which would allow no tree planted by the hand of man to thrive, were by Nature herself, covered with white pines and all kinds of bushes, and, promiscuously among these, heather, and mosses, and grasses-in a word, with plants of one kind or another, and so protected against the sea breezes. But the unreasoning greed of man destroyed these woods, uprooting even the stumps of the trees, allowed the cattle continuously to wander about upon the dunes for pasturage-in short, treated these so recklessly that the protecting cuvering of them disappeared, and the masses of sand of which they were composed became exposed to the drifting action of the wind.

'As a consequence of this, the dunes naturally began 
moving and advancing, propelled inland. At first only mearlows and fields were covered by them, but soon the inhabited places were threatened.

'So early as the beginning of the last century the two villages, Kleinvoglers and Schmergrube, were completely buried, and the village Polski, with the exception of two groups of houses, was covered up by the dunes which had been set in movement. And at that time man had learned so little as to how he might oppose his own strength, knowledge, and power, to the devastating operations of the elements, that these devastations were regarded with a stolid resignation as an unavoidable fatality.

'About the middle of the century the dunes lying nearer to Danzig [which is situated about four miles from the Baltic], through the barbarous treatment to which they had been subjected, and more especially in consequence of the destruction of the woods upon them, began to spread and to advance towards the fertile district beyond, which occasioned no little trouble and anxiety. More especially did they advance upon a forest of pine trees belonging to the town of Danzig, four German miles [or eighteen English miles] long, and year by year additional strips of this forest were buried under their masses of sand.

'The only means of help against the advancing tide of sand which suggested itself to the people of that time were erected on the ridges of the most advanced dunes, consisted of hedges, of posts, and pine branches, which with an expectation that they would arrest the sand to seaward which was being put in movement, and so prevent the further advance of the destructive march of the dunes on the landward districts beyond. 'This end was, however, by no means accomplished, because great masses of sand accumulated before the fences, and on this account again and again new fences required to be constructed above the old ones, but the wind still bore a great deal of sand over the fences, and though the evil might be diminished, it was in no way overcome. Moreover, the ever 
quickly increasing height to which the fences were being raised was seen to be in the highest degree demanding of consideration. This was bringing ever nearer the danger of a breaking through of the accumulating sand, which, should it occur, would entail a fearful destruction of property-one in no way less than if the dunes had been left to advance as they were doing before this attempt at the stoppage of them had been made.

'In this dilemma the Philosophical Society of Danzig in 1768 offered a prize for the best answer to the question, What are the most efficient and least costly means of preventing the continuously progressing sanding up of the Danzig links, and of preventing the further growth of the sand dunes?

- Titius, Professor of Natural History in Wittenberg, who previously had been in Danzig, gained the prize. Titius, in a treatise On the Restoration of the Woods on the Coast, especially plantation of White Pine, as the only means of effectually arresting the calamity, showed that thus only could the sand be prevented from drifting inland. First of all, there might be planted, with a view to giving stability to the sand, the Arundo arenaria, which had done good service in Denmark, in Zealand, and North Jutland; and subsequently trees might be planted along the seashore in strips protected by fences.

'The most intelligent suggestions of this prize essay, however, did not yet obtain a practical application; on the contrary, they went on heaping fences upon fences on the crests of the dunes, and by so doing brought the threatened pine tree forests still more under the sand-drift by the material which was thus collected. The necessary funds required for this,' Herr Wessely adds sarcastically, 'were given gratuitously by the inhabitants of the threatened places!

' By the want of such fixity as may be imparted by a covering of vegetation, and by the interlacing of the long roots of trees, the dunes may prove an insufficient barrier against even a deluge occasioned by inundation. 
'The mobile sand in the district under consideration supplies an illustration. In the early spring of 1840 there occurred near Neufaehr a disastrous, sudden, and utterly unexpected outburst of the Vistula through the dunes which had been formed there, and which were then about 90 feet in height. In the darkness, intensified by a snowstorm, of the night between the 1st and 2nd of February, the inhabitants of Neufaehr were bronght into great distress and alarm by an abnormally high water in the Vistula, and were completely occupied with their troubles, which were great enough, when at daybreak on the morning of the 2nd, some of them, amongst whom was the Dune Inspector, Krause, discovered in the midst of the fearful devastations which had alrealy been effected what had happened but a little way off, which was such a catastrophe as had never before been heard of.

' In order to the right understanding of it, it must here be remarked that the Vistula, before emptying itself into the sea, flows for a long way almost parallel to the shore, and in passing by Neufaehr bends towards the site of this place, so as to approach it within a distance of 35 fathoms. 'The local condition of the place leads to the conclusion that there at one time a branch of the stream must have flowed into the sea, which, through some peculiarity of it, and more especially the sanding up of the sicle towards the sea, became closed; and what consequently occurred was that the stretch of dunes was there of a much less elevation than elsewhere, and was traversed by a sponge-like watery portiun, drawn out to a point in the direction of the sea, which was always wet, and in a high flood of the river was covered with water three feet deep. The level of the stream was higher than this ground; and from this there was a constant percolation of water.

'As now on the day in question the Vistula, which was laden with large masses of ice, was unusually swollen, being as much as eighteen feet above the level of the sea, could not be withstood even at the expense of percolation, such as had hitherto been sufficient. The percolation con- 
quered, and took the form of an actual outburst and rupture, with consequences which may be more easily imagined than described.'

All of these evils were evils consequent on the destruction of woods. And as it was there, so has it been elsewhere.

Of what has been effected in France, Surell, to whom we are indebted for the discovery and exposition of the natural history of torrents, has written:- There the roads, the dwellings, the cultivated crops, have been swallowed up by mountains of moving sand, as in the Alps they have been buried by the dejections of torrents. And there may be cited entire villages doomed to destruction, while the time of their perishing may be predicted with precision, as the scourge advances with a regular step. Had it been left to itself, the department of the Landes would have seen its littoral transformed by insensible degrees into a desert of sand, interspersed with perfidions marshes, which, extending themselves from the Adour to the Garonne, and marching onwards towards the interior of the country, were threatening to invade every place up to the gates of Bordeaux.

'When, in 1780, Bremontier, Ingenieur des ponts et chaussées, after having attacked on its scientific side the phenomenon of the march of dunes, came to propose a regular project of plantations as the only defence which could be opposed to them successfully, there were not awanting those who cried out at first in regard to what was called the impossibility of applying his system.

' It is the misfortune of some men, of too positive a nature, to see nothing, and believe nothing, beyond what is already existing before them. To them everything, save the palpable reality present to them, is a Utopia or dream, as if reason did not permit us to foresee and affirm with complete certainty absent facts known through the logical connection which they sustain with other facts already, known to us. 
'To-day, the Administration, enlightened by half a cen.. tury of experiments, and master at last of the subject, has organised in the Landes a number of works, the admirable success of which is beyond description.'

Details are given in a volume I have published, entitled Pine Plantations on Sand-Wastes in France, in which are detailed the appearances presented by the Landes of the Gironde before and after culture, and the Landes of La Sologne; the legislation and literature of France in regard to the planting of the Landes with trees; the characteristics of the sand-wastes; the natural history, culture, and expluitation of the maritime pine and of the Scotch fir; and the diseases and injurious influences to which the maritime pine is subject. 


\section{P A R T I I.}

\section{ELEMENTS OF MODERN FOREST ECONOMY.}

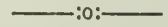

More than one-not only once, but again and again-may have felt prompted while reading or glancing over the preceding pages to ask, not for information but as an expression of superior intelligence, What have droughts, and floods, and landslips, and such narratives as have been given, to do with Modern Forest Economy? And therefore I may state that the object of Modern Forest Economy is in its details to counteract some one or other of the evils which have been spoken of, or others like unto them which have resulted from the destruction of forests; and in its entirety to restore to a nation, and through it to the world, what has been lost through that destruction having been carried so far as it has been, so far as this can be done under existing conditions. And the details in question have been given that it may be known what are the evils which it is sought to counteract, and what are some of the more striking forms which these evils have taken.

In view of what has been stated in preceding chapters, one of the first things which will suggest itself to an intelligent student of the case, as desirable to be done with a view to arrest the evils resultant from the destruction of forests is to prevent, so far as possible, all reckless or even unprofitable destruction of these, including in this all waste in the necessary exploitation of them. Endeavours have been made to accomplish this.

The phenomena, and what may be called the natural 
history, of the destruction of trees have been carefully studier, and remedial and preventive measures have been devised and applied. Measures have been adopted so to arrange the sites of felling and the successions of these so as to secure as much protection as possible against the violence of wind for all forests, and more especially the protection of these while the trees are young; by legislative enactments the destruction of forests on the mountain sides and mountain summits has been prohibited; and even the exploitation of such, when belonging to private proprietors, has been made subject to the approval of the forest officials of the State. 'The natural history of fungi, of insects, of birds, and of beasts, which are injurious to trees, and the effects produced upon trees by different species of these have been studied; and foresters have been instructed in the results obtained in order that they may be made acquainted in its manifold aspects with the evil which is thus done, and know how intelligently to follow in each case such preventive or remedial treatment as may be expedient in the management of forests under their charge, or what to advise in any cise in which their advice may be sought.

The destruction of forests occasioned by fire has been studied in its different aspects; and salutary restrictions have been imposed upon practices which imperil forests by originating what may be called accidental fires; and in so far as fire and the woodman's axe are employed in the exploitation of forest lands and forests, appropriate measures of precaution and prevention against waste have been prescribed and extensively adopted.

But together with endeavours to arrest the progress of waste and destruction much is being done to replenish exhausted forests, and replant forests which have been destroyed, and create forests where the want of them is painfully felt.

And in the exploitation of forests, whether indigenous or artificially created, it is sought so to conduct this as to secure simultaneously sustained production of wood, a 
progressive amelioration of the condition of the forests, and a natural reproduction of this by self-sown seed.

Some of the measures which have been adopted will now be brought under consideration. But it may be noted that all that is contemplated is to supply such information as may be sufficient to enable the general reader to understand what has been done, and to enable the professional student thus to enter upon and prosecute with some appropriate preparation a more exhaustive study of the various measures thus brought under his notice, and others connected with them in practice.

In the absence of English designations appropriate to different methods of exploiting forests recognised in Modern Forest Economy, I fall back upon those applied to these in France. 


\section{CHAPTER I.}

FOREST CONSERVATION.

AGAIN and again, within the last five hundred years, attempts have been made to arrest the destruction of forests. When kings and nobles were hunters, and, though they needed not to do so, lived to hunt the beasts of the forest, cruel and disgraceful sanguinary laws were enacted for the conservation of the forests, as a means of preserving the game for these men to have the pleasure, and a monopoly of the pleasure, of killing them. Upwards of 200 years ago the famous saying of Colbert, France perira en faute des Bois! was caught up and re-echoed far and near. In England, again and again, an endeavour more or or less earnest was put forth to prevent the destruction of our woods. In the beginning of the present century Lord Nelson raised a warning voice like to that of Colbert; and the echo of this has been heard in our day; it is modified indeed by circumstances, but the ground-note is the same. From India, from the United States of America, from Canada, from Astraulasia, and from both the southern and the northern extremities of Africa, as in one place and another it was perceived by observant patriots that the destruction of forests was going on too fast, and was being carried too far, has the voice of warning been heard.

In Russia, with its apparently interminable forests, a calculation has been made of the cubic measurement of the annual production of wood by growth in all the forests of the Empire-perhaps it would be more correct to speak of it as an estimate, as only a proximate result could be expected; and an estimate of how much is annually consumed, in yielding firewood, and wood for the cabinetmaker and the carpenter, and timber for buildings and 
erections, and the construction of ships, and to meet the demands of the export trade ; and the consumption having been found to be greatly in excess of the production, a calculation has been made of how long it will take to bring upon the Emvire the fate dreaded by Colbert for his country, if the production and destruction be not speedily equalised. Similar calculations have been made in America and elsewhere ; and the voice of warning has been heard here and there and everywhere. Well will it be for those who hear to take warning!

Precautions against the destruction of forests by cattle generally take the form of an absolute prohibition of the depasturing of cattle, more especially of sheep, and still more especially of goats, in the forest when the trees are young, and of the goats at all times-of the fencing in of the forests, and the fencing of roads through the forests, along which flocks or herds may have to go to localities iu which it may be less dangerous and be deemed desirable that they should be pastured-and of the imposition of heavy penalties upon both the herdsmen and the owners of cattle found trespassing.

For the preservation of forests against destruction by depredations the means employed resolve themselves into strict surveillance, and severe punishment of transgressions, and the extinction, by legitimate and equitable arrangement, of existing servitudes and rights of usage.

As precautions against the destruction of forests by fire, there are enforced strict prohibition or careful regulation of the use of fire in every form within the precincts of the forest, and within prescribed distances from its perimetor ; the creation of cleared spaces around forests, and traversing them as lanes in different directions, with a view to arresting the spread of fire from without, and of fire advancing within their bounds; and the instruction of the adjacent population in means to be employed in the extinction of fires in a woodland, and the enforced requisition of their attendance and help in such work when fires occur. 


\section{CHAPTER II.}

\section{R E B O I S E M N T.}

BESIDES endeavours to secure the conservation of existing forests, woods are being extensively planted with a view to restoring the forestal condition of lands which have had their forests more or less extensively impoverished or destroyed. Sometimes this is done as a profitable culture; but more frequently, and much more extensively, is it done with a view to securing again some of the advantages which have been lost through the destruction of forests, or to secure for lands devoid of these, advantages similiar to those enjoyed, or which have been enjoyed, in proximity to forests of greater or less extent.

Details of measures adopted to secure exemption from devastating torrents and inundations, and from devastating drifting sands, have been given in volumes referred to in preceding chapters.

Of these operations the arresting of sand-drifts may seem to be the most important where these are the scourge of the district. Where floods and inundations are the scourge, the sufferers may feel that the prevention of such calamities is what is of most importance to them. But the effect of forests on the humidity of soil and climate is of importance to a much more extensive and more widely diffused population. And the creation of forests with a view to secure this may, where either of the other evils referred to prevails, have the effect of, at the same time, counteracting that.

In preceding pages there have been adduced several statements in regard to Algeria. That land supplies illustrations of the good which may be affected in various ways by the extensive plantation of woods. 
While drawing upon Algeria for illustrations of general advantages resulting from reboisement, I shall adduce illustrations of the effects of reboisement in arresting and preventing the occurence of torrents and inundations from what has been seen in the Alps; and in illustration of the effect of reboisement in fixing down and utilising drift sand I shall cite some accounts of what has been done in Northern Germany : premising that illustrations of each of these categories of advantages equally striking might have been drawn from other lands besides these.

\section{Section A.-Gexeral Advantages Resulting fron Reboiseyent Experienced in Algeria.}

A colonist from Boghari wrote some years since:'Twenty years ago we had numerous flocks, thanks to the splendid pasture lands; and when we wished to see the desert it was necessary to go on horseback from 45 to 50 kilomètres. To-day we have no longer any trace of pasture lands, and therefore no flocks; and as for the desert we have no occasion to go so far to see it; leaving the threshold of our houses, we step at once on to the sand-deep and far-extending sand.'

The picture is saddening, contrasting as it does with the amenity of numerous country mansions in Britain and elsewhere surrounded by woods and lawns produced by planting and culture. But like measures have, in proportion to the extent, produced like amenity there.

II. J. Reyuard, Sub-Inspector of Forests, writing on the restoration of forests and pastures in the south of Algieria, in the province of Algiers, cites the following statement:'The probable results of these combined works will be, the rendering more regular, and approximately more uniform, a climate which is violent and extreme in its sudden variations; the amelioration of the régime of the rivers, producing in turn an augmentation of the delivery by the springs, and rendering more regular the flow of streams and rivers, which at present have all the charac- 
teristics of the most dangerous torrents ; the restoration of pasture lands of great extent; the sritlement of the native tribes, which are still nomadic, and the introduction of a European element, which of itself is capable of giving to pastoral industry all the development which it can take in Algeria.'

He goes on to say-'The influence on the Tell of this region so restored will be beyond all question considerable, rendering the climate more temperate, the rains more frequent and more regular; making possible to the Algerine colonists the rearing of cattle on an extensive scale; presenting to the Arab proprietors, who are forced to yield their lands to European industry as the only means of drawing from it great prufit, a new field of activity better proportioned to their means of action; giving to commerce and industry new products; and, in fine, ensuring political security by peopling the frontiers of the Sahara.

'And in a general point of view this restoration will be a commencement of taking posstission of that Central Africa, towards which almost all modern nations to-day direct their desires and ambitions.'

At a conference held in Algiers on the 11th November 1S81, M. Reynard, in the course of an address delivered by him, said:- ' This work of the reboisement of five millions of hectares is a kind of speculation which only the State could undertake. The revenue, the interest of the half milliard thus invested, will be reimbursed to it by the increase of the public wealth, by the extension of its governmental power, by the development of industry, of commerce, and of agriculture, not only in the colony, but even in the metropolis itself. To form an estimate to-day of what will be the value of these returns would be to enter upon a calculation as impossible as if at the commencement of the great public works of this century they had made an attempt to form a correct estimate of the future returns of the imposts. In France would not any one have been reckoned a fool at that time who 
should have announced there the present amount of the budget of the receipts of the metropolis?

'In Algeria it should certainly suffice if the annual increase of taxes should amount to five millions through the assured protection to agriculture afforded by the forests, to justify an annual expenditure of five millions in works of reboisement or of improvement of existing forests. The State ought not to seek indeed more than a simple equilibrium of expenditure and income in the Budget. I do not know what time and what works will be necessary to secure this annual augmentation of the revenue; but forest science and forest economy affirm unhesitatingly that it would require less time for the existing fatalistic inertia to lead to a much greater diminution by the gradual increase of aridity, and by the uncertainty of the crops, which is becoming greater every year.

'Between these two alternatives, that of seeing the receipts by degrees disappearing, or that of maintaining an equilibrium in the budget by means of a productive expenditure, a modern nation cannot hesitate.'

\section{Section B.-Effects of Reboisenent in ArResting} and Preventing the Occurrence of Torrents AND INUNDations.

While in Algeria we see such results as have been stated obtained elsewhere from extensive plantations in mountainous regions, we find equally satisfactory results obtained by the replanting of mountain basins and mountain slopes.

While Bremontier was towards the end of the last century musing on the waste of land covered by the dunes of Gascony, and the means of reclaiming those sand wastes, it was perceived by others that the continuous destruction of forests, and more especially the destruction of these on the mountains, was producing disastrous consequences. And more than one attempt was made by legislative enactment to arrest the evil and reverse the 
process. The increasing scarcity of wood for fuel and other economic purposes demanded and received attention, but it was seen that an improved forest economy, whilst it might secure the conservation of existing forests, and the utilising of these to the benefit of the proprietors and of the nation, must be accompanied by a replanting of the mountains of woods where they had been denuded of these, and elsewhere if the threatening calamity was to be averted.

In 1793 Fabre showed that torrents were attributable to the destruction of forests on the mountains. In 1841 Surell showed that torrents appeared and disappeared as forests were destroyed and reproduced. In 1872 Cezanne showed that this relation between forests and floods can be traced from preadamic times to the present. And in 1874 Michel Costa de Bastelica traced indications of torrential phenomena in what had been accepted as glacial deposits of times anterior to what Cezanne had designated the torrential era.

In accordance with these views arrangements were made by the Government of France for an expenditure of ten millions of francs in replanting with trees, and herbage, and bush, ground drained by torrents; and within ten years torrents which had been most destructive had become placid perennial streams, peaceful as a little child.

Of one torrent, that of Sainte-Marthe, near Embrunthe ravages of which by torrents are spoken of by M. Hérecart de Thary in a passage previously cited [p. S6] - of this torrent M. Costa de Bastelica, in a treatise entitled Les Torrents, leur couses, leur effets, moyens de les reprimer, et de les utiliser, leur action universelle, published in 1874 , writes :-

'In 1841, when M. Surell wrote his famous Etude sur. les Torrents des Hautes-Alpes, this torrent had acquired an unenviable celebrity by its violence. It carried away every bridge thrown across its course; at every storm of 
rain those living along its borders in disquietude feared they would see it burst its embankments and inundate the plain. The works of extinction were begun in 1864; and in 1869, when M. Cezanne, before publishing his work, procured for me the honour and satisfaction of showing and explaining to him our works, he officially reported that the extinction was then so complete that a simple footbridge, placed at only 50 centimètres ( 20 inches) above the torrent, now become a streamlet, defied the greatest floods. This footbridge still (1874) stands where it was seen by M. Cezanne. In the interval there has been no lack of violent storms, the meteoric conditions have in no way changed. The fact of the extinction of the torrentiality of the stream is thus established and certain. Ancl in proof, a Sydicate organised by proprietors interested to carry out defensive measures against the torrent having no longer any raison d'etre, has dissolved itself.'

This I consider a fair illustration of what has been accomplished in cases innumerable in the regions of the Alps, the Cerennes, and the Pyrenees.

In addition to what has been said, I feel prompted to cite the following statement by M. Gentil, Ingenieur en chef des ponts et chausées and rapporteur au conseil general des Hautes-Alpes, But I must premise it by mentioning :-

On the 28th of July 1860 there was issued a law on the reboisement of the mountains. Four years later, with more extended experience, on the Sth of June 1864, was issued a law on the gazonnement and reboisement of the mountains, enjoining the combination, where expedient, of the creation of a turf of grass and herbage with the planting of trees upon the mountains. And on November 10th, 1864, was issued a Government order for the carrying into execution of these two laws.

Copies of these laws, and of ducuments connected with them, have been given by me, with detailed information in regard to the practical measures taken during the first decade of these operations, and of results which have 
followed, in a volume of which I have made frequent mention in preceding chapters, Reboisement: or, Records of the Replanting of the Alps, the Cevennes, and the Pyrenees, with trees, herbage, and bush, with a view to arresting and preventing the destructive consequences und effects of torrents.

M. Gentil writes:- 'The aspect of the mountain has been all at once completely changed; the ground has acquired such solidity that the violent storms of 1863 , which have occasioned so many disasters in the High Alps, have been altogether harmless in the restored perimetres.

'The mountain has in a short time become fertile; there, where a few sheep could scarcely live by consuming everything, may be seen now an abundant herbage which may be mown.

'But it is of importance that examples and figures should be given; I shall therefore cite definite facts which relate to our roads and our projects. At Sainte-Marthe there was prepared in 1861-1862 the plan for a work to be constructed on the cone de dejection of the left bank of the torrent. This dyke, the expense of which was estimated at about 40,000 francs, had for its object to preserve the national road, No. 94, and the adjacent properties, against invasions by the torrent. To-day the torrent of Sainte-Marthe is completely extinguished, nothing more comes down now from the mountain. The proprietors and the engineers no longer dream of constructing dykes, simple enclosing walls suffice to protect the lands on the banks.

'As for the benefits by which the lands in the valleys situated near to the cones have profited, they are immense. Not only are the proprietors relieved from creating costly and precarious dykes, but, beyond this, their property being no longer exposed to the danger of being buried under gravel, has now an assured value. Cultivation is carried on with the hope of an assured harvest. This certitude is itself a benefit; and the proprietors, being able now to reckon on the future, no longer dream of leaving their homes and settling elsewhere. 
'As results of the works executed in the perimetre of Roissard, in Isère, the properties adjacent to the torrent of the Rif-Fol have been again brought under cultivation; and the village of Fau, formerly threatened by the torrent, has not been afraid to open across the restored perimetre a canal which leads off the water of the torrent itself to the basin of the public fountain; and there is now no interruption to the communication along the road from Grenoble to Sisteron.

'The town of Bourg-d'Oisans, built upon an old cone of dejections or rubbish brought down and deposited by the torrent of Sain-Antoine, and having its very existence threatened by this torrent, has now allowed to tumble into ruins the dykes, which the inhabitants had raised at great expense, but which are now no longer needed.

'Since the execution of the works of consolidation and reboisement undertaken in the perimetre of Luz-la-CroixHaute, in Drôme, the torrents and the ravines, the destructive effects of which spread themselves over the greater part of the lands in the plains, especially over the dwelling places in the hamlets of the Grisil and of the Granges, have become inoffensive water courses, almost never bringing down rubbish. And more than 120 hectares of fertile fields, representing a value of 300,000 francs, are now protected from the invasions formerly so frequent and so damaging.

'In the Lower Alps the value of the interests safeguarded by the works executed in the perimetre of Seyne is estimated at three millions of francs; and at another spot in the department the reboisement of the perimetres of Faun and of Saint-Pons will give protection to lands of at least an equal value.'

Again :- 'Amongst the perimetres of reboisement undertaken in the Lower Alps, that of Laboret presents to-day the most complete specimen of the results which we have a right to expect from the works entrusted to the execution of the Forest Administration by the law of $\mathbf{1 8 6 0}$. This perimetre combines indeed, on a limited scale it is 
true, but in a complete combination, all the difficulties which could be presented to the execution of the different works necessary to the extinction of a torrent by the entire reboisement of its basin of reception.

'The results obtained to-day make of this a typical case.

'The torrent of Laboret held in 1860 quite a special notoriety, due to the ravages which its deposits occasioned in the lower lying regions, to the frequent landslips of its confining hills, and the absolute bareness of its surmounting slopes. This bareness of the slopes of the Laboret, which was proverbial in the country, was such that the sheep had readily given place to goats, which finished by destroying the rare tufts of vegetation which still existed here and there.

' On every occasion of a storm, on every occasion of rain even, communication along the road was interrupted, and presented serious dangers for travellers, so that from the first appearance of the law of 1860 thoughts were entertained of applying it to the lands which included this dangerous torrent.

'The Decree of Public Utility was issued on the 18th June 1862, and the works were commenced at once. The works purely preparatory were completed in 1870, at which period they proceeded with a plantation of black pines in tufts over the whole surface of the perimetre, which were designed to constitute the dominant kind of tree in the forest of the Laboret, which forest may be considered as having been created and maintained since 1871.

'The whole aspect of this perimetre has been completely transformed; those great black slopes, unstable and desolate, are to-day covered with a dense vegetation of forest plants, of forest trees, both broad-leaved and conifers, and, in fine, with bushes of all kinds. The innumerable ravines which cut up these slopes, and supplied to the floods great quantities of materials, are to-day filled up, and their bed has disappeared under a dense growth of osiers and of 
broad-leaved shrubs further up. To-day [1874] the torrent of Laboret no longer exists. It has given place to a stream flowing over a succession of descents with a slope of some millimètres, carrying off no material, and showing, even after a storm, only clear water.

'The effect produced in the country by the happy results obtained in the case of the Laboret has contributed powerfully to modify public opinion in regard to reboisement.'

M. Delafont, Inspector des Eaux et Forêts, in a Memoire sur l'etat des Forets dans les Hautes-Alpes, writes in reference to the evil :- The sad results which I have pointed out are everywhere deplored. All who are not blinded by ignorance, or whose heart has not been dried up by selfishness, give expression to the thought that it is high time to arrest the ever-increasing progress of so fearful a devastation. They groan under the numberless evils caused by the de-boisement of the mountains, which seem to call upon us to come forward to save our forest riches. These reflections, these prayers, $\Upsilon$ have myself heard many a time uttered with an energy inspired by a profound conviction of a great evil, and of the imperious necessity which there is to suspend that course of procedure. Let us listen to the cries of distress of a population alarmed about their future!'

And Surell writes:- One thing which it is impossible to dispute, and is beyond all equivocation, is the influence which forests exercise on the conservation of even the soil of the mountains; and to him whowould pretend to deny this, we have only to point to our Alps, which give so powerful and deplorable proof of its being the case,-a proof evident, I shall not say to every intelligent being, but to every eye.

'How comes it about that a trutb so simple and one of so great interest to many has not from the first been so strongly established as to be understood and accepted by 
all? Is it not now high time that public opinion should take it up anew? The question is one deserving of some trouble being taken with it, for on the solution of it depends the future life or death of many departments of the land.' And again, 'I do not wish to have any barren compromise made. I wish to let it be seen that it would be better far to fight the torrents than to construct again at great expense masses of masonry and earthwork, which would always, do what you may, be costly palliatives, better adapted for concealing the plague than for extirpating it. Why then should not man call in the aid of these living forces, the power and efficiency of which have been so clearly revealed to him? Why not command these forces to do anew, and this time by man's orders, what they have already done in old times in so many extinct torrents, and that only by the orders of Nature?'

In a report to the National Assembly, made on November 25, 1872, by M. le Vicomte de Bonald, it is stated :-

'MM. Surell et Césanne in their valuable E'tude sur les Torrents des Hautes Alpes, have succeeded in demonstrating beyond question the truth of the following aphorisms :-

'That the existence of a forest on the ground hinders the formation of torrents;

'That the destruction of the forest delivers up the ground to the ravages of torrents ;

'That the development of forests brings about the extinction of torrents;

'And that the felling of the forest revives again the extinct torrents.'

'So fully are these facts regarded as established in Switzerland,' says a writer on forest management in the Edinburgh Review of October 1875, 'that at the Social Science Congress at Berne, in 1865, the question was raised as to the means of establishing a common legislation between countries watered by the same rivers, in order to protect their respective interests by the maintenance of 
the mountain forests, and the greatest possible attention is now paid to the subject by all the Cantonal Governments of Switzerland.'

I have cited [ante p. 110] an opinion expressed by $\mathbf{M}$. Reynard at a conference held in Algeirs in November 1881 , to the effect that it would be economically advantageous to incur an immense expenditure on reboisement in Algieria. In proposing the French Forest Budget for the preceding year, 1880 , the same argument was made use of by the Budget Committee of the Legislature.

Under the head of Constructions, Reboisements, and Gazonnements, an additional million was asked for chiefly for works of reboisement, for which it was stated good use would be found if a desired augmentation of 50,600 francs referred to were granted. After the disasters occasioned in 1875 by the overflowing of the Garonne and the Herault, and their affluents, the Minister of Finance and the Minister of Public Works had given assurance that measures would be concerted between the departments over which they respectively presided, to be taken with a view to prevent the re-occurrence of such calamities. Many surveys, which were subsequently undertaken, had been completed, but, in the absence of funds, the works of reboisement had not been begun. Subsequently the Minister of Public Works had, as bas been stated, solicited the co-operation of the Forest Administration to give a specification of works urgently called for in Savoie. Information furnished by the Engineers of Roads and Bridges showed that the four torrents of Saint-Martin, the Grillaz, the Pousset, and the Saint-Julien, all affluents of the Arc, were causing every year great destruction, and it was of importance to arrest this without delay. And, as was stated by the Minister of Public Works, every system of extinction of torrents is based on the reboisement of the basin of reception. The work was to be undertaken in the coming.spring by officials already designated, and they would be partially completed 
before the close of the year, But the execution of the works could not be undertaken if the necessary credit were not conditionally granted. The sum stated was the minimum which would be required. According to information in possession of the Administration, to execute the works in Savoie alone would absorb more than a million of francs ; and it was stated that it was impossible to attach too great prominence to the essential fact, which according to the opinion of the Corps of Engineers of Roads and Bridges and of the Forest Corps, completely covers and governs the question, and which is this-that the scourge of inundations cannot be averted without the preventive action of works of reboisement, and that there was consequently an urgent necessity to carry out these works with the least possible loss of time.

The Budget Committee, in reporting on this, called attention to the fact that out of the total grant applied for, there had to be met the expenses of the construction of forest roads, and subsidies to public roads facilitating the exploitation of forests, and the erection of forest lodges; and further, 1, To grant seeds and plants, and subsidies in money to communes and private individuals undertaking works of reboisement or gazonnement; 2, To acquire lands within areas in which works of reboisement were declared to be of public utility; 3 , The execution of works intended to buy ground and extinguish torrents by such works over areas in which they were compulsory; and 4, Subsidies to individuals and communes possessed of servitudes, to promote the substitution of cattle for sheep, and to secure the conservation of mountain pastures. And in regard to the extra million called for they entered at large on a detailed statement of what had been done, and with what results, giving tabulated statements as well as details, all showing how effectually reboisement had arrested torrents, and that for the completion of the works in the Alps, in the Cevennes, and the Plateau of Central France, and in the Pyrenees, there would be required 148 millions of francs (upwards of 
$\{6,000,000$ sterling), and 72 millions more (upwards of $£ 3,000,000$ sterling) for the purchase of land; and they recommend that the extra million applied for should unhesitatingly be granted.

'We are all,' say they in their concluding sentence, ' deeply impressed with the thought-better far spend a million in reboisement than have to give such a sum to sufferers from inundations;' and the grant was made unanimously by the Chamber, together with an addition of 5000 francs to be employed in developing roads to facilitate the exploitation of communal forests, the effect of which, it was anticipated, might be to raise the mean proceeds of 360,000 hectares, or 900,000 acres, of forests from five francs to fifty francs per hectare.

\section{Section C.-Effect of Reboisement in Fixing Down} and Utilising Drift Sand in Northern Germany.

In a volume entitled Pine Plantations on the Sand Wastes of France, I have supplied information in regard to such plantations on the Landes of the Gironde, and on the Landes of La Sologne. We have in Northern Germany another phase of the work.

In a preceding chapter [ante p. 96-100] have been narrated how some of the evils which came upon the land in the vicinity of Danzig, in consequence of the destruction of woods by which the mobile sand of the dunes had been previously bound down and kept in its place. Herr Wessely, from whose treatise, entitled Der Europäishe Flugsand und seine Culture, most of the narration was cited, goes on to say:-

'When, in 1793, the Danzig Republic was incorporated with the State of Prussia, the new Government soon brought under discussion the fencing, once for all, of the dry dunes. Not only would the continuous reduction to waste of the town's forest not be suffered, but it was determined to meet the growing danger which threatened the commerce of Danzig : as it was feared some one of these 
drifts might extend to the Vistula, fall into it, and thereby occasion a most disastrous sanding-up of the river, whereby the navigable course might come to be completely blocked.

'One of the burghers of Danzig, Soeren-Bioern, a Dane by birth, kept alleging and repeating that in his native country extensive stretches of sand dunes had been bound fast by planting them with sand grasses; and he recommended, as did Titius years before, the planting of Arundo arenaria, and the subsequent formation of pasture grounds, and the planting of different kinds of trees.

' In the year 1795 there was entrusted to him the fixation of a stretch of dunes a quarter of a German milemore than one English mile-long, and 140 klafters or fathoms broad, which was threatening the Vistula in the direction of Neufaehr. In the following year he executed this work to the general satisfaction, and thereupon he was installed Plantagen-Inspector, and conducted till his death in 1819 the Dunenbauten, or works for the arrest of the drift sands on the Danzig links.

'The active energy and enterprise of Bioern did not limit itself to this local undertaking, but from 1799 to 1802 he was repeatedly consulted by the Konigsberg Chamber in regard to the treatment of the dunes to the north of that town on the Lochstaedt and the Friesland [?] and Courland links.

' From the professional opinion given by him, and the printed documents connected therewith, it is manifest that Bioern continued to advocate the planting of fences designed to arrest the sand throwu up from the sea. These, however, were not to be above $1 \frac{1}{2}$ feet high, and were to be such as might be formed of sunk bushes, in no case planted very thickly, that they might not fail of their object, nor be destroyed by storms. A series of such fences, one behind another, were to be planted. After these were sanded up, and a gentle slope was formed in front of them, those slopes were to be sown with sand grasses-these plants being the only ones which could resist the action of 
waves. For culture on the inland patches he recommeuded more especially plantations of the white pine and of the black alder, also of birches, poplars, and aspens, groves of which he had seen in a state of vigorous growth between the dunes; while acacias, which had previously been recommended by Titius, had soon disappeared, though they also at first promised well. Always in the beginning it is not a lofty timber forest, but only a thick bush, which it should be sought to produce.

- With a view to the fixation of the seaward slopes of the dunes he erected on the crests of these a fence of $8 \mathrm{ft}$. posts placed at a distance of 15 feet from each other, to which he fastened with wooden pegs from three to five longitudinal pieces of paling, so placed that there were interstices between them at least an inch wide. The design was by these on the one side to keep off the sand, and on the other to keep off cattle, and to provide that, should they be blown down they could easily be put up again without being taken to pieces, which three men could do, as there were in the posts grooves or holes in which the colstaff could be placed. The whole of the patch to be fixed was, moreover, encircled by a fence of bushes at the base of the sandhills.

' Furthermore, Bioern had, at some fifty fathoms beyond the outermost seaward fence, what was called a "storm fence," which was constructed of light posts, with thin laths of paling nailed to them, between which were wrought in light branches of alder from eight to nine feet long. Next to these, and at right angles to them, he threw out what we may call "trap fences," which, commencing from two to six fathoms beyond the storm fence, were carried over some five and twenty fathoms from the crest to the depth beyond; and finally, upon the deeper places which had to be filled up, there were constructed fences of branches, cutting these up diagonally. With the plantations close to the crest, and on both sides of the fences of branches, he laid live hedges, in the free spaces between which he planted sand grasses, and in the deepest places 
of the cultivated area, and also near to what may, strictly speaking, be called Vordunen Platzes, he sowed grasses of the same kind.

'This was beyond question the first Prussian systematic Dunenbau, or culture of sand-drifts; and there is not a little which is interesting in its subsequent history.

'By the end of 1796 a great deal of the work was completed. Meanwhile, dunes to the west of the village of Neufaehr were extending themselves to the Vistula, and beginning to pour their masses of sand into the bed of the river. In consequence of this it became necessary in the beginning of 1797 at once to concentrate the whole working power upon this point.

'From this time onward the work of arresting and consolidating these sands, the cost of which, partly at first, and latterly entirely, had been met from the State Treasury, made regular and well defined progress; and they proceeded to the planting of the sands with the Kiefer or Scotch fir. In the time elapsing up to 1804 inclusive, the high dunes up to the village of Bohnsak were fixed; and thus all anxiety in regard to the Vistula was removed. The years 1806 and 1808 were devoted more especially to sylviculture; then were planted in the hollows, Salix arenaria and $S$. fusca, the downy mountain willow, and the brown-stemmed willow; and with them the Alnus incana, the hoary leaved alder, by means of cuttings. And from Bohnsak eastward the upper portion of the strand was sown with the sandrohr to produce a Vordune for a defence in advance of the works.

'In the course of the eleven years occupied with operations suggested by Bioern there were expended on fixing the sands 38,826 guilders* advanced by the town, and 48,807 guilders advanced by the State : in all, 87,633 guilders, or on an average 8000 guilders a year. The 
work was done by days' labour, and not by piecework, which greatly increased the cost.

'With the year 1807, in which Danzig was by Napoleon made a Republic, the work was brought to a stand for many a year. The new Republic could neither maintain the work already done nor stay the devastation which recommenced anew.

'In 1814 Danzig again became a part of the Prussian dominions; and with this there ensued a more active period of Dunenbar, or arrest and culture of dunes. The State repaired the injury sustained by the old works at an expenditure of 21,032 guilders. But Bioern did not live to enjoy the sight of the successful enterprise. $\mathrm{He}$ died in 1819. He lived, however, to complete the fixing of drift dunes which were imperilling Vogelsang and Kahlberg. Bioern, whose service had from 1797 been acknowledged by bestowing on him the rank and title of Royal Kammer-Commissioner Councillor, is regarded by some as not only the originator of the Prussian system, but of the new systematic Strand-dunenbau, or operations designed to arrest and utilise drifting sand dunes on the coast everywhere. His works successfully accomplished the object desired; and the principle was in its measure applicable by those who were engaged in carrying on similiar operations in island sand drifts; and it is acknowledged as such by them at the present day.

'At the same time it is not to be overlooked that Bioern had not so completely understood the nature of sand dunes as to found a work which would equally and that completely meet the requirement of the object, and the reduction of the work to a minimum of expense 'It is manifest,' says Wessely, whose narrative I am endeavouring to render into English, 'he did not value sufficiently the importance of a Vordune employed now-a-days to catch and retain the sand coming up from the sea; the mode of procedure which he adopted in the culture of the firs for the consolidation of the mobile sand was much more expensive than was necessary; and, in fine, we miss 
in them that complete knowledge of plants which at the present day is always at command.

'With the land connection of Danzig with the fortress of Pillau secured, the work of Dunenbau on the Frischen Nehrung was resumed, and it was determined to give more attention to the extension of plantations.

' In the year 1820, as the town would do nothing more in the matter, the Government of Prussia undertook the work entirely, and appointed for this purpose the Dune-Inspector Krause, who conducted the Dunenbau of the province till 1856. He has given explicit statements in regard to his mode of operations in a manual, or Lehrbuch uber den Dunenbau, prepared and published by order of the Government. With the entrance of Krause upon his duties there were appropriated 15,000 guilders, and thereafter 6,000 guilders annually to the resumed reclaiming, affixing, and improving, of a stretch of dunes from the mouth of the Vistula to Kahlberg, some $6 \frac{3}{4}$ German miles, or 30 British miles long, covering an area of about 5000 jock.*

'With these monies there were up to $1848,290,000$ guilders spent on this land, wherewith some 440 jock of the upper dunes were fixed, and 1330 jock planted with Weisskiefern, white firs, and birches.

'In 1832, in consequence of an urgent cry for help which was heard from outside this district, from the remains of a village destroyed in the previous century, called Polsk, which were in danger of being again overwhelmed by a rapidly advancing dune, this additional district was taken into consideration, and a special grant of money was made for operations there.

'There was taken in hand a portion of the Frisch Nehrung, some $2 \frac{3}{4}$ German miles [11 $\frac{1}{8}$ British miles] long, extending from Kahlberg to the boundary of East Prussia; and it was sought to cover with woods about 2500 jock

* The Austrian Jock, the measurement spoken of, I understand to be equal to three. fourths of an Imperial acre. 
which had been almost entirely stript of vegetation, and to fix the land in order that the small villages situate there, and amongst others Polsk, might be made safe; and to maintain the land communication between Danzig and Pillau, as well as to prevent a breaking through of the sea into the Frische Haff,* lying behind these strand dunes. In the first instance, Polsk had to be saved.

'In November 1833 the fixing of the sand began in very stormy weather. While this still continued, many houses were covered up with the overwhelming sand, and before these and others could be completely protected, it was well nigh the middle of January 1834; when a hard frost, and the money appropriated to the enterprise, had so far advanced the work that the safety of Polsk could be said to be secured. In point of fact, there was only one house entirely, and a second half covered up; and by and bye the work was so far advanced that pretty nearly the whole of the eastern dune district, well nigh 7000 jock, of open sands were fixed; and in 1843 only some 1500 required to be fixed.

' Krause, during the 35 years in which he conducted the West Prussian Dunenbau, or engineering operations to arrest and utilise the dunes, had altered the method of operations introduced by Bioern, as is described in his Lehrbuch, or Manual of Instruction, and by which the results following the operations conducted by him were obtained.

'In the first place he had recognised the necessity and importance of making the Vordune or sand-banks between the sea and the dunes to be more immediately operated on, whereby the whole strand, without interruption, is lined, and of fixing these by the planting of them continuously

* As has been intimated before, the Frische Haff is one of the extensive sand-formed projections into the sea, parallel to the shore, characteristic of that district, and not unknown on the coast of Eugland. They present the appearance which we should expect a bar of a river to take if it rose above the level of the sea, leaving an outlet, not in the centre, but at one end. The enclosed basin is designated the 'Haff' - the haven, gulf, or bay - while the low-lying land enclosed is designated the 'Nehrung.' A little further to the east is the Kurishe Haff, while further to the west a similar Haff is found on the mouth of the Oder, upon which is situated the port of Stettin. 
with sand grasses. He overlooked, however, the advantage of their complete formation, and, in point of fact, we miss this in the Strandbau, or strand-engineering, of that time. Krause confined himself in this to closing openings between the tops of dunes, which were not unfrequently pretty steep, with artificial Vordunes. Besides this he desired that the Vordunes should raise themselves somewhat steeply on the strand. In every case indeed the outer slope had a steeper inclination towards the horizon given to it than the strand in advance of it towards the sea. But if we would secure for this a proper slope, and secure the former against the dashing of the waves, and consequent damage, we must avoid giving a steep inclination to the Vordune. Finally Krause left the Vordunes simply to produce and cover themselves with plantations of grass, whereby the process of formation was for a time delayed. For the fixing of the flat sides of the high and drifting dunes, Krause recommended and practised planting them with Arenaria in a network, the meshes of which were greater or less according as the inclination and the direction of the wind shock determined. Such a proceeding is in every way rational, provided it relate to a locality in which only the Arundo arenaria is in question.

'Strange to tell, however, Krause laid it down expressly in his book that a continuous covering up is one of the necessities of life of the Arundo arenaria, and yet he recommended this plant also for the windward side of the dunes, and enjoined the work of fixing everywhere to be undertaken with this plant, and there where there could be no expectation of sanding up the same as elsewhere. Naturally in all such places the plants would die, and would render needful repeated expensive renewals, aye, and until these places had covered themselves naturally, which they would do mostly with Carex arenaria.

'In these circumstances the strand grasses naturally could do no other service than act as would some dead low bush, or very low bush hedge, and it is more than doubtful 
whether, in view of numerous and expensive after works, planting with strand grasses be the cheapest means of fixing the sands. And then there comes up the consideration that in another way the grass planting operates injuriously-namely the stiff leaves, half broken through by the wind, moved about by the wind, make circular furrows around each single plant, and loosening by this means the sand, and disturb the spread of vegetation.

' Krause had often, instead of the Amindo, let them plant cuttings of the sand willow. These grew well for a time where they were sheltered, but died soon where this was not the case; and where they did grow up they only increased the injurious irregularity of the dune. Where plantations were to be formed, this was done either on ground already fixed, or by means of a covering of branches in a way to be afterwards described.

'When the Royal Ober-forstmeister, Julius von Pannewitz, visited the works in 1821, he found a mode of fixing the ground practised, which deserves mention. It was an alternate planting of rows of cuttings of willow and sand grass. For the rows of willow cutting they adopted, according to the slope, a distance of from $8-42$, on an average 24', and for the intermediate rows of grass plants, $2-3 \frac{1}{2}$.

'The cuttings, $\frac{1}{2}$ and $1 \frac{1}{2}$ inches thick, and 2 feet long, of the Salix arenaria, the rods of which seem to succeed best when cut in autumn, were planted in furrows from nine inches to twelve inches deep, laid so closely that they touched one another, and after the furrows were filled up and troaden down they stood from three to four inches above the level of the ground. The sand grass was laid in slanting, and these low planted rows seemed nowhere to be blown out, which, with the previously higher planted rows, was everywhere the case.

'The results which Krause obtained deserve full recognition, for they took away the threatening character from fearful dunes; and if it was the case that only here and there they were covered with firm turf or wood they were 
yet clothed in such a way that the most violent storm could take but little more sand from them; and this was immediately replaced from the dune itself. A great part of the dune lands were also transformed into forests of Scotch fir, and this not only in low-lying parts, but to considerable heights.

'Besides this, the fundamental improvements which Krause introduced into Dunenbau, or engineering operations on dunes, and more especially the exposition of network plantings, became a benefit to the whole of Europe ; and the last named system of planting bids fair to be perpetuated in practice, so that the Krause period showed an important improvement in the art, the end of which we have not yet seen.'

The Prussian Stranddiinenban of the present [187:3] is prosecuted under the superintending direction of Oberlandbau-Director G. Hagen, who, in his valuable Manual of Hydraulic Engineering in 1863, devoted to this subject a thorough discussion, resulting in the fundamental development of the rules now observed in such works.

The most substantial feature of the new advance is the exceptionally excellent plan of a rational Vordune, which, by arresting the sea-sand continuously along the strand, and maintaining always a gentle slope towards the sea, shelters the high dunes from the lash of the waves.

Hagen in his valuable work states again and again that the Arundo arenaria only promises success, and is only recommendable, where there is a persistent sanding up - ' a fact,' says Wessely, 'which, it appears to me, has not yet been sufficiently attended to, and like as in Krause's time, when the strand-grass was looked to too much as the universal binding plant, so now it would be much better to combine with the use of it other means of arresting the drift.'

The dunes at Danzig offer many highly interesting phenomena, though they may be of but seconrlary importance in dune culture. 
On the way from Kahlberg over the dunes to the seastrand, for example, we pass by the side of the forest which formerly extended cver the whole Nehrung. Between this, and the place where the buried village of Schmergruhe lay, are to be seen a number of stumps of Scotch fir, the trees of which have unmistakably been cut down by the hand of man. The felling took place in the course of the 17 th and 18 th centuries, and was accompanied by the covering up of Schmergruhe. From these stumps the wooden material has entirely disappeared, and as a rule this has in the roots been replaced by white sand, which exhibits all the texture of the earlier wood. The bark has, however, in all cases been well preserved, and is only of a dark, blackish-brown colour, as if it had been made into charcoal ; and it forms still an enclosing vessel for these wonderful contents. The small remains of wood found there is also quite like fossilised woor. 


\section{CHAPTER III.}

FOREST EXPLOITATION.

WHILE much is being done to secure the conservation of existing forests, and the replanting of trees on lands from which forests have been cleared, and others where this can be done with economic benefit, attention has again and again been given to the waste accompanying the exploitation of forests under successive modes of conducting this, and endeavours have been made to secure the good without the accompanying preventable evil, with the result that there has been developed from one exploitation which might be considered as almost absolute loss, an exploitation which secures simultaneously a sustained production of wood, a progressive improvement of the forest, and a natural reproduction of it from self-sown seeds.

\section{Section A.-Sartage}

While man is yet a dweller in woods, living on fruits and roots, and the bodies of animals caught or killed by him, as best he may, he begins to increase his store of fool by the culture of plants by which food is yielded. For the growth of this a portion of the forest must be cleared of shrubs and trees. And we find this being done in many places by men in the state of civilisation to which I have referred.

In many places in which axes might be had trees are still brought down by kindling a fire around the lower portion of the trunk; and among people who have not made much progress in developing the capabilities of the land, a portion of forest is cleared by a fire confined to the spot which is desired for cultivation ; and one or two or more succes- 
sive crops are raised on the ground thus cleared, and enriched with the ashes of the trees. When the productiveness of this is considerably diminished it is abandoned; and the sanie operation is gone through elsewhere; while the abandoned land may or may not be recovered by the forest.

This usage is very extensively followed amongst tribes of people in the state of civilisation I have indicated; but it is not unknown amongst other peoples considerably more advanced. In France it is practised and known under the designation Sartage; I do not know of any specific English designation; and therefore I shall avail myself of this designation in further treating of it.

Sartage in France is now confined almost entirely to the burning of bush and brushwood and of débris of felled timber. The practice is practised chiefly in the Ardenn:s, in the districts of Liege and Luxembourg in Belgium, and in certain localities in Southern Germany. It is more like the burning of rank grass, rank herbage, and rank bush than a burning of the forest; every precaution is taken against its extending to trees which are valued; and it would be difficult to prove that at any previous time it was otherwise, though the idea may be suggested that thus have forests been extensively destroyed, as in Germany they have been uprooted, to give place to agricultural operations.

The designation is applied to a treatment to which, in certain districts, coppice woods, which are reproduced principally by shoots and by suckers from the stumps and roots of trees which have been felled, are subjected. After each cutting down of the coppice wood, cereals are cultivated for two or three years; and the ground is prepared for this by kurning on the surface of the soil all débris, brambles, and brushwood, such as elders, hazles, cornels, dog-wood, junipers, and thorns, together with the herbs and turf growing there, with a view to render the soil more favourable for the growth of the crop desired. 
It is a practice of great antiquity, and it is considered to have had its origin from a deficiency of arable land, through the poverty of the soil, the lay of the land, and the climatal condition of the country.

Of the form which it took at first, some idea may be gained from the form in which the practice is still maintained in various other countries. It may be seen in full operation in Finland, in Sweden, and in India,-in a more limited operation in South Africa,-and in a modified form it is carried out systematically in the British Dominion in North America.

Of nations in the north of Europe, the most distinguished for agriculture in regions bordering on the Arctic Circle are the Finns. With them the usage, under the designation Svedjande, has been practised so long at least as they have been known to history. The soil of Finland, throughout much of its extent, was originally little suited for regular husbandry, and there the mode of culture adopted consists in cutting down the forest on the ground they wish to sow, and burning the felled trees upon it, that the ground may be manured by the left ashes; it is then ploughed and sown with rye, barley, \&c. If the soil be of a very fertile description, it is sown after the first harvest has been reaped with oats and afterwards with buck wheat; after this the ground is allowed to rest, and to be again covered with forest.

This mode of culture has been observed to impoverish the soil so much that the forest destroyed is not always replaced by a new growth; and as thus the forests and the products of which Finland is so dependent have been much diminished, the Government has endeavoured to limit this destruction of the forests as much as possible, and now only in destricts where the uneven and stony condition of the ground renders it difficult to carry out regular husbandry does this mode of culture still prevail; in these, however, it is still practised.

From what is said by W. von Schubert, in his Resagenom 
Sverige Norrige Lappland, published in Stockholm in 1823, in 3 vol. Svo; and from what is said by Lars Levi Laestadius, in a work entitled, $\mathrm{Om}$ Möjlighsten och Fördelïn af allmenna Uppodlingar $i$ Lappmarken, published in Stockholm in 1824, it appears that the practice of burning over woodland at once to clear and to manure the ground now spoken of as having prevailed extensively in Finland, was at that time, and from other ircidental references to it, it appears still to be there a recognised usage in Swedish husbandry.

It is a practice, says M. Parade, extrêment ancienne, and such it appears to have been in France; but there may. be claimed for it an antiquity far greater than is indicated by the practice of it in France, in Sweden, or in Finland; for amongst the conservative tribes of India it has been practised to an extent which makes the Sartage of France, and the Svêdjande of Sweden and of Finland, appear as mere childish play. In the Canara district it is known as Kumari. In a document issued by the Board of Revenue in India, in 1859, it is stated that, "In some parts of Bekal, which is the most southerly of the taluks of Canara, Kumari cutting forms part of the business of the ordinary ryots, and as many as 25,746 , or one-sixth of the population, are supposed to be engaged in it; but to the north of the taluk it is carried on by the jungle tribes of Malri Kadeos and Mahratais to the number of 59,500 .' Here we have upwards of 85,000 men felling, burning, and destroying forests, for the sake generaily of one-or at most of two crops-sometimes, but rarely of three. 'After which the spot is deserted until the jungle is sufficiently high to tempt the Kumari. cutter to renew the process.'

By this practice vast quantites of most valuable timber has been destroyed.

A good crop of hill rice, or Nullet, is obtained in the first year after the consumption of the wood. A small crop is taken off the ground in the second year, and sometimes in the third, after which, as has been stated, the 
spot is deserted until the jungle is sufficiently high to tempt the Kumari cutter to renew the process. In the south, where land is more scarce compared with the population, the same land is cultivated with Kumari anew in 12, 10, or 7 years; but in North Canara, the virgin forest, or old Kumari, which has not been cultivated within the memory of man, is generally selected for the operation.

'This rude system of culture,' says Dr Cleghorn, formerly Conservator of Forests in the Presidency of Madras, 'prevails under various names in different eastern countries. It is called Kumari in Mysore and Canara, Pounam in Malabar, Punakad in Salem, Chena in Ceylon. Much information relating to it may be found in Buchanan's Journey through Mysore, \&c., Passim, and in Tennant's Ceylon, vol. ii., p. 473. .'

The name Kumari is peculiar to the Canara and the Mysore districts. It is thus described in an extract from the Proceedings of the Board of Revenue:-

'The name is given to cultivation which takes place in first clearings. A hill-side is always selected, on the slopes of which a space is cleared at the end of the year. The wood is left to dry till the following March or April, and then burned. In most localities the seed is sown in the ashes on the fall of the first rains, without the soil being touched by implement of any kind; but in the taluk of Bekal the land is ploughed. The only firther operations are weeding and fencing. The crop is gathered towards the end of the year, and the produce is stated to be at least double that which could be obtained under the ordinary modes of cultivation.'

Thus in South Africa do Bechuanas in some districts prepare virgin soil for culture; thus do the Boers burn down the Rhenoster bush, herbs, and arborescent shrubs, growing on the ground as a preliminary step towards bringing it under cultivation, converting it from veld into land; and in the vicinity of Uitenhage I have seen a 
portion of primæval forest cultivated in true Kumari style by Kaffirs, with the consent of the proprietor, for which a consideration had been given.

Aud in the British Dominion of North America the operation there designated Clearing, may be seen carried out systematically, ruthlessly, and recklessly, which is this, in a somewhat modified form, adapted to the circumstances of the case, clearing land of forests that it may be used for agriculture.

In a work entitled Historical and Descriptive Sketches of the Maritime Colonies of British Amernca, by John II'Gregor, published in 182S, in a sketch of the progress of at new settled location upon uncleared forest land, we are told the first object is to cut down the trees, which is done by cutting with an axe a notch into each side of the tree, about two feet above the ground, and rather more than half through on the side it is intended the tree should fall. The lower sides of these notches are horizontal, the upper niake angles of about $60^{\circ}$. The trees are all felled in the sime direction, and after lopping off the principal branches cut into $12 \mathrm{ft}$. or $15 \mathrm{ft}$. lengths, the whole is left in this state until the proper season for burning arrires, generally in May, when it is set on fire, which consumes all the branches and small woot. The larger lops are then either piled in heaps and burned, or rolled away to make fencing stuff. 'There follows an account of the agricultural operations which succeed, but it is the destruction of the forest with which alone we are concerned here.

Sometimes there is combined with such operations as have been detailed, the preparation of potash from the residuum of the wood consumed.

The making of salts is toilsome and laborious, but is considered profitable, especially where it is carried on in conjunction with clearing.

The extent of lasd which has been denuded of forest by such clearings is immense.

What is sought by Sartage is a temporary use of the 
land for horticultural or agricultural operations. It may be considered a primitive form of clearing; but this term is now generally applied to what, in contradistinction to that, is a clearing away of trees and bush to secure a clear space for permanent occupation of it as a site for some building, or as a garden, or as fields for the continuous culture of cereal or other crops.

This may be properly called an exploitation of the forest land-it can scarcely with propriety be called an exploitation of the forest. With more appearance of propriety Surtage may be so designated, in as much as one object is to utilise the ashes produced from the burning of the wood, and not simply to get rid of the trees; and in as much as it is practised in certain cases in the management of forests as a means of effecting improvement in these, which cannot be alleged of forest clearing, as that term is generally employed.

In a volume entitled Finland: its Forests and Forest Management (pp. 53-115, 217-220), the advantages and disadvantages of Sartage are discussed at considcrable length, and copious details are given of the practice of it in different lands.

\section{Section B. -Jardinage.}

Where the object is, not to clear the ground for agriculture, but more profitably to exploit the forest produce, the method of doing so generally followed has been, and in many places still is, to look out for a tree likely to serve the purpose designed, be this what it may, fell it and bring it out from the forest, leaving the others standing. Where it is firewood which is wanted, the woorl-cutter may go on cutting down almost every tree or shrub, and yet not capriciously as the onlooker may think, while felling many, leaving others. This is virtually the same thing; and this method of exploitation is by French foresters designated Jardinage, or gardeners practice, in 
allusion to the practice of the gardener in gathering vegetables, taking up what seems to him to be sufficiently grown, and leaving others to grow till they may be required.

Jardinage, as thus explained, is a method of exploitation which may seem to be a very natural one to adopt; and this supposition is borne out by the extent to which it has been adopted. But it has proved very destructive to forests in all lands, and in all times. The careful consideration of other things than merely making the most of the woods as a source of pecuniary supplies, with which this method of operation is followed by British foresters in woods and plantations under their charge, such things as the appearance presented by the woods as a contribution to the amenity of the locality, and the value put upon the shelter which they afford, these having often a value far beyond what may be represented by the price of the wood in the market, leads to its being practised in parks and policies in Britain in such a way that little, or, it may be, no damage is done to the plantations. But where it has been followed simply as a means of most easily and conviently exploiting the trees of a forest as supplying an article of trade, it has generally proved destructive.

Illustrations of the destructive effect upon forests of this method of exploitation may be found in Hydrology of South Africa, pp. 172-175; in Forests and Forestry of Northern Russia, pp. 89-100; and in the French Forest Ordinance of 1669, with Historical Sketch of Previous Treatment of Forests in France, pp. 35-39.

Section C,-Exploitation according to 'La Methode A Tire et Aire.'

I have had occasion elsewhere to quote a statement by MM. Lorentz and Parade, fathers of the School of Forestry in Nancy, that:-

' Towards the middle of the seventeenth century, if not 
before, it was found necessary to adopt legislative measures to protect, by prudent foresight, the interests of the future while supplying the requirements of the present; and in 1544,1576 , and 1579 , there were issued ordinances designed to regulate the felling of timber, and determining the duration of lengthened periods during which no fellings should take place in portions of the forest which had been cleared of trees deemed fit to be felled, that time might be afforded for the reproduction of forest by a new growth of trees; by the ordinance of 1669 the general practise of it [Jardinage] in France was terminated, and now it is only tolerated in circumstances in which the application of the more advanced forest economy of the present day would be productive of more evil than good, as would often be the case on mountain crests, \&c., where the woods afford shelter and protection, which, once destroyed, it would be difficult to restore, and impracticable to restore till after a time, during which damage, perhaps irreparable damage, would be done.'

In the management of plantations of conifers in the north of Scotland, it has been the practice in some places where all the trees in each plantation are of one age, to make a clean sweep of the plantation when the trees have attained a satisfactory size; and afterwards to replant the ground with another crop of trees. This morle of felling is known in French Forest Economy as felling ì blanc etoc. The practice applied thus to plantations, and successive plantations, might be considered a kind of gardening, or Jardinage: for thus do gardeners treat some of their crops; but it is not so designated, for, be it noted, that designation is applied to the treatment of trees; this is applied to plantations alone. And by a succession of periodical plantings on different spots every year, or every five years, or every ten years, there might be raised a series of crops fit for the axe at successive periods, whereby might be produced a continuous supply of wood, and of pecuniary returns. If this be realised, little difficulty will be experienced in 
concriving of a similar result being obtained by a series of successive fellings being carried out in an extensive forest, each of these fellings being confined to a specified section of the forest. If the forest were of considerable extent the series might be made to comprise not only many years, but many decades, giving time for the section first exploited being again replenished before the last section in the series has fallen under the axe. If a hundred years would be sufficient for the trees to attain the size desired, let the forest be supposed to be divided into ten sections, and for ten years the fellings be confined to one of these sections, and the same thing to be done in each succeeding decade till the whole forest has been exploited, by that time the cycle of successive fellings might be recommencerl. And the process might be continued ad infinitum or ad libitum, if by self-sown seed, or by a combination of artificial sowing or planting, with this natural mode of replenishing the forest, the forest were replenished.

Such a method of exploiting forests was introduced in France as a substitute for Jardinage, and it was for 150 years practised in various countries on the Continent of Europe-I may say it has been so for more than 200 years, for it is in some places practised still. The technical name given in France to this method of exploitation is La Methode à tire et aire-Cut and come: again-Use and yet retain possession. Details of provision for the adoption of it are embodied in the French Forest Ordinance of 1669, an orilinance which, when first promulgated, was hailed with delight in other lands besides France; and it still is spoken of as The Famous Ordinance of 1669 .

Of this Ordinance, it is stated by MI. Parade, of the School of Forestry in Nancy:- From the middle of the 16th century onward are found, in the Forest Ordinances of our kings, traces of management relating to fixed periods of felling successive portions of the forests. But it was more especially the celebrated Ordinance of 1669 which enjoined generally in royal forests and forests held 
in mortmain, the observance of this useful operation, the indispensable basis of all forest management.

'The method of exploitation referred to in this Ordinance was, as stated, La Methode ì tire et aire; it had for its object: in timber forests to substitute order and regularity of successive fellings of equal extent for the recklesness and disorder of Jardinage; in coppiçe woods to prevent the too frequent felling, and also the inconsiderate felling of reserved trees.'

The Ordinance comprises many prescriptions besides those relating to this method of exploitation. In regard to this it contains these:-

\section{Chapter XI.-Of Surveyors.}

1. "There shall be selected and commissioned in each department, a Surveyor, a man of experience and trierl probity, to accompany the Grand-Master while he is on his visitations, auction sales, and re-formations, and under his orders to make all surveys, measurements, and ordinary verifications, and those of re-formation; and two other's shall be appointed in each bailliwick or Maitrise.

2. "They shall only be accepted on testimony to their good life and behavionr, and they shall, before they enter on their duties, give security of a thousand livres, which shall be taken by the Grand-Master as assurance against abuses or malversations which they may commit in their work. They shall make of all fellings to be sold a figured plan, on which they shall indicate the corner trees, with their marks, the partition and boundary trees, with a statement of their number, quality, and all the marks upon them, the distance from one to another of the corner trees, and an outline of the felling, both in straight lines and in angles, and all the circumstances necessary to serve for the recognisance or conservation of all the trees reserved.

3. 'They shall make all the surveys and measurements 
required in their district, as well as in those held in Grurie, Grairie, Tiers et Danger, and by title of appanage, co-proprietorship, sale contract, and usufruct in the Maitrise, in our woods, grounds, and domains, and the same for those of ecclesiastics, communities, and holders of mortmain, together with all that may, for whatever reason, be ordered by authority of Courts of Justice. This they shall do preferentially to all other Surveyors, on pain of nullification of what may be done by others; but with permission to private persons to avail themselves of all acts, measurements, and voluntary deliverances of other Surveyors selected at their option, as may seem to them good.

4. 'The Surveyor of the Grand-Master shall be bound to follow him when ordered, and to make by his orders all allocations of sales, surveys, measurements, and verifications, plans, diagrams, determinations of fellings, and recognaisances of bounds, borders, and ditches, and generally all acts pertaining to his profession; and to keep a good and faithful register, of which he shall leposit a duplicate, with plans and diagrams, in the hands of the Grand-Master or the Registrar of the Maitrise, eight days after the completion of the work, and obtain a receipt for it, under pain of suspension the first time, and deprivation of office on repetition.

8. 'If any Surveyor have, by connivance, favour, or corruption, concealed a removal or alteration of boundaries, have suffered, or have himself made, a change in corner trees, he shall, for the very first case, be deprived of office, condemned to a fine of five hundred livres, and be banished for ever from our forests, unless the Officers, under pain of possible loss of office, mitigate or alter the sentence.

\section{Chapter XV.-Of Sales, Fellings, dec.}

1. 'There can be no sale made in our forests, woods, or thickets, excepting in accordance with the regulations 
which shall be ordered in our Council, or in letters patent, formally and duly registered in our Courts of Parliament and Chambre des Comptes, under penalty of restitution of four-fold the value of the wood sold, against the purchasers, and against the officials ordering such sales, the loss of their office.

4. 'The Grand-Masters shall every year, before the auction sales of our woods, make a visitation of the lots appointed to be sold, in making which they shall be accompanied by the Surveyor thereto appointed, to whom they shall point out the woods to be allotted for sale in the following year ; and they shall mark out for him in what form the boundaries shall be made for our greatest profit and advantage, of which they shall prepare an official report, which shall be signed by the Forest-Master or his Lieutenant, our Attorney, the Garde-Marteau, and the Sergeants of the Guard. A copy of this shall be delivered to the Surveyor to serve as his guide, and to this he shall be bound to conform himself, under pain of suspension or declaration of his incapacity for the office; another shall be sent to the Record Office of the Maitrise, and fifteen days after his return to the principal town of his department, he shall lodge a general statement of all the allotments in the Record Office of the Marble Table for reference.

5. 'Every year the Grand-Master shall make a copy of his mandements and ordinances for the allotments of the ordinary sales of our woods and forests, conformably to the regulations ordered in our Council, where he shall enter the number of arpents or acres, and the kind of wood to be sold; and in which he shall designate in detail the wards and trigonometrically measured lots, one or more of which may be embraced in a ward, so far as shall be practicable, following the observations which shall have been made in the official reports after visitation, which he shall senil to the Officers of the Maitrise, hefore the first of June in each year, who shall be bound forthwith to assemble and 
together devote a day to the making the allotments, which shall be done in their presence by the Surveyor.

6. 'The Surveyor shall make, in presence of the Sergeant of the Guard, the lanes and trenches required for the boundary; shall mark with his stamp as near to the ground as be can, such a number of corner trees, and division and partition trees marking the angles and connecting lines of the boundaries, as he shall consider sufficient, with indications of the side on which he shall have imprinted his stamp, the royal stamp, and that of the GrandMaster. He shall make mention of the fact if he have so imprinted any trees for corner standards, and of their age, quality, nature, and size, and of their distance from one another in poles and feet: as also he shall observe the names of the sales in which they occur, if there be any void spaces and their areas; he shall be required to avail himself of at least one of the corner trees of the former sale; and he shall prepare plans and diagrams of the place which he shall have portioned out; and of all this he shall make his official report, which shall be signed by the Sergeants and Guards, and he shall place a copy of it in the Registry of the Maitrise three days after having made it, which shall be initialed by the Forest-Master and our Procurator, with mention of the day on which it shall have been delivered, and another copy of it shall be by him sent forthwith to the Grand-Master.

9. "The trees marking the margin and the side of the plot shall be marked with the royal stamp and the stamp of the Surveyor on one side, differing in this from the corner trees, which shall be marked on each side facing a lot for sale.

10. 'The Surveyors can neither measure more nor less in each triage than that which shall have been prescribed to them by the Grand-Master for allotment, under pretext of rendering the outline more regular, or for any other consideration whatsoever, to such an extent that the reduction or addition shall exceed one arpent for twenty, 
or in this proportion, under pain of suspension and an arbitrary fine, to be determined by the Grand-Master; and if three times such an error have been committed by him, he shall be discharged, and declared incapable of acting as Surveyor.

11. 'The official report of the Surveyor being in the Registry, he shall cause it to be delivered in like manner to the Garde-Marteau for the martellage or marking of the trees, which he shall make in presence of the officers of the Maitrise, and to this effect the royal stamp shall be delivered up to the Garde-Marteau by those who have the keys, and $h=$ shall proceed with the officers to the triages in which the sales shall have been allocated, and by their advice he shall select ten trees in each arpent, of lofty growth, of great vigour, and of fine proportions, of oak, and, if possible, of good wood and competent size, which he shall mark as balliveaux or reserved trees, with the royal stamp, and together with them the corner trees and the trees marking out the boundary, and forthwith after the martellage the stamp shall be brought back and shut up in its case.

\section{Chapter XVI.-Of Recollemens, or Re-Surveys of Fellings after the Fellings.}

1. 'The recollemens of all the purchases shall be made, at latest six weeks after the time for clearing away and bringing out the produce has expired, by the ForestMaster, in presence of our Attorney, the Garde-Marteau, or Keeper of the Stamp, the Registrar, the Sergeant of the Guard, the Surveyor, and the Soucheteur, who shall have made the survey and the souchetage, or enumeration and specification of existant stumps, and of the Lieutenant, if so seems to him good, but without his interfering, excepting in the absence of the Forest-Master; and to this end the merchant-purchasers shall be summoned eight days before to meet on that day with other Sur- 
veyors and Soucheteurs, to make the new survey and souchetage of the purchase.

2. 'When the Surveyors and Soucheteurs, with those first employed, and those who have been appointed specially for the verification, shall have arrived on the ground, the official report of the felling to be sold, of survey, of ballivage, or specification of reserved trees, and of souchetage which shall have been made for the auction sale shall be produced, and they shall reconnoitre the trees reserved by the official reports and by the conditions of sale; and to this effect the Officers shall inspect carefully the purchases from end to end in all their parts, the pied comieres, parois, lizieres and balliveaux, or the trees marking the angles, the sides, and the margins of the allotment, and the trees reserved for seed, so as to see. that the lots have been well cut, treated, cleared out, and freed of all encumbrance - of which they shall prepare their otficial reports, containing details of encroachments, malversations, defaults, and defects, which they may have seen, and of any deficiencies of trees retained by the official reports of martellage and ballivage.

5. 'The official reports of the second souchetage shall be examined and collated with those of the first, and any difference which shall be found between them shall be noted minutely and in detail ; to which effect there shall be produced all the official reports of exoneration which shall have been made for the merchants and their factors, and there shall be observed any defaults and malversations which may be found to have been committed in the course of the use and exploitation of their purchases, of which they have not been validly exonerated.'

The circumstances in which this Ordinance was issued, together with the Ordinance in its entirety, are detailed in a volume to which reference has already been made, French Forest Ordinance of 1669 ; with Historical Sketch 
of Previous Treatment of Forests in France, in which volume some notices are given of this method of exploitation (pp. 40-44).

It may be perceived that these regulations proceed upon the assumption that the particular method of exploitation to which they refer was one well known, which was the case, as it was one which did not originate with the Ordinance, but had been practised, long both in Germany and France, though not so generally and extensively as it was subsequently to the promulgation of this Ordinance. To place the student of Forest Science of to-day on something like the same vantage ground as was enjoyed by those who some two hundred years ago were so jubilant over this Ordinance, it may be allowed to me now to supply some additional information in explanation or illustration of exploitation according to the method known as à tire et aire, even at the risk of being accused of repetition.

When the management of forests had commanded for some time the attention of men of a scientific spirit in Germany and in France, it was found that the long continued prosecution of Jardinage was diminishing the products of forests and imperilling their continued existence, and there was introduced this method of exploitation.

The exact import of the designation I have endeavoured in vain to learn. It has always been associated in my mind with the English phrase-Cut and come again. In the absence of information from French foresters and F'rench etymologists, I have been led to surmise that aire may be an antiquated abbreviated form of avoir, and that the phrase may have been designed to express the idea of uprooting and yet possessing, of felling and yet having or possessing-implying that though Jardinage might have failed, this method of exploitation would succeed, in securing a preservation of the forests. The English colloquial phrase I have referred to suggests itself to me, but it does not express what is expressed in the French phrase. 
It is more easy to make intelligible the treatment so designated than it is to render in English the designation given to it. The following may be taken as supplying a rough and rude illustration of it in its application to a coppice wood. If the coppice be one which may profitably be cut down every twenty years, by dividing it into twenty equal or equivalent portions, and cutting one, but only one of these each year, there may be obtained a constant supply of wood, the division cut in the first year being ready again for the axe in the twenty-first year of the operation, and again in the forty-first year, while the other divisions follow in their order.

This morle of exploitation has been extensively adopted in the management of coppice woods in Russia, though Jardinage is generally followed in the felling of timber. I have found that there on many estates held by private proprietors, there is carried out recklessly, and without system, a succession of clearings in successive years-one portion cleared this year, another portion next year, a third portion in the year following. On other estates, in connection with mining and smelting operations, a somewhat similar exploitation is carried out more systematically.

A similar mode of procedure has been adopted in several of the Crown Forests. By Professor Solsanoff, who at the time beld the Chair of Forest Economy in the Forest Corps at Lanskoi, near St. Petersburg, I was told when there in 1873, that it was not uncommon, and it might be considered the general usage, to fell the forest in long strips of 50 fathoms, or 3.50 feet, in breadth, alternating with strips of the same width on which the trees were left standing to sow the cleared ground. Where wood is scarce they clear these strips completely; where it is abundant they leave young trees unfelled to grow, or to be destroyed in the removal of the others, as may happen; and when a new growth of trees has been fairly established on the cleared strip, the strip of standing trees is cleared 
if there be a probability of its being re-sown or otherwise restocked with trees.

A similar account was given to me of the cutting of fuel for a smelting furnace in the government of Orenburg. Thirty years was deemed sufficient for the reproduction and growth of the firewood, and the whole was divided into thirty equivalent portions, each of which was allotted for one year's exploitation in the expectation that in thirty years it would be reproduced. Strips were the forms in which the several portions were laid out, and these, so far as was practicable, were made to converge towards the forge; and in felling each a strip was left unfelled for the production of seed for the natural re-sowing of the portion cleared. My informant stated that the strip left was either one-sixth or one-twelfth of the breadth of the strip cleared-he could not recollect which. I think it probable it was left at the side, and that those of two contiguous ridges were contiguous, whereby they might be conjointly one-sixth of the breadth of one cleared strip, but one-twelfth of the two if the fellings did not follow each other in due succession.

Advantages likely to follow such a method of managing forests suggest themselves at once, and, as described, it seems to be one which must be of easy application anywhere. But the practical forester who has given attention to my statement may have remarked that I have used the expression equal or equivalent portions. Good will result from the adoption of division into equal portions-much good, but with a large admixture of evil. Equal portions are not necessarily equivalent portions, and such is the variation in the productiveness of different portions of a forest, from variation in soil, in exposure, and in adaptation to the growth of the kind of tree which happens to be upon it, that it is very improbable that many portions equal in extent will be equal in productiveness, if any at all happen to be so ; and therefore the division of a forest into equal portions will not yield 
advantages equal to what would be obtained by the division of the forest into what I have, called equivalent portions.

With the attempt to do this commences the difficulties of the undertaking. Equivalent partitions cannot be obtained by divisions founded on equality of superficial contents, neither can they be obtained by divisions founded on the number of trees growing in each, or even on the cubic contents of these. The soil, the exposure, the kind of tree growing in different localities, the adaptation of the soil and of the exposure to the growth of the kind of tree, or of trees, growing in each, the age or ages of these trees, the rate of their annual increase at different ages, the age or ages at which they respectively attain their maximum growth, and at which they attain their maximum of value,--these, and twenty other points, must be determined to furnish the data necessary to determine equivalent partitions; and such partitions are necessary in order to ensure the full benefits of this method of forest mianagement being secured.

If by a tentative process, based on superficial extent, as it necessarily must be, modified in accordance with the number of trees, and with the cubic contents of these, it be sought to arrive at a division of a forest into equivalent partitions, it will be found that constant modifications of the division first made are seen to be necessary. By proceeding to the work of partition with an extensive knowledge of the natural history of the trees on the ground, of the process of tree growth, and of mucb pertaining to meteorology, and geognosy relating thereto, the work will be found to be more easy; but with all the forest science which has as yet been secured, the work must be to some extent tentative still; and this is accepted as a fact by the most advanced foresters of the day.

And while this has been accepted as a fact, it has also been found that divide the forest or coppice wood as you may, you do not secure a sustained production through 
successive cycles of the revolution or rotation of exploitations. The second crop is not equal to the primitive or original, nor the third to the second.

It is possible ofttimes to trace in the embryotic structure the rudiments of the organs of the fully developed organism ; but how different are the appearances presented by the two! How like, and yet how unlike, are the Chrysalis and the Butterfly! Similar is the similitude and the difference between the old system it tire et aire, and the new system of forest economy now carried out in Germany and in Erance. I know not of a name by which I can designate this for the purpose of contradistinction and specification. To give it a designation from the name of the country would be improper, inasmuch as while it is carried out in both these countries, it is not peculiar to either country alone. To give it a designation from the deviser would be premature, inasmuch as my readers are not supposed to be familiar with its history, and even in the case of many of those who are acquainted with the history of its evolution, to associate it exclusively with the name of any one man would do injustice to others, to whom it owes much.

There is in this system of management a three-fold object sought, production soutenue, régénération naturelle, and amélioration progressive; not one or other but all of these combined, and so combined not only that each shall be secured without detriment to the others, but that all shall be secured as the result of what may be done with a special view to the accomplishment of any,-what is done in view of all promoting each, what is done in view of each promoting all: a combination of ends gained in the accomplishment of one, such as is ofttimes seen in nature, for example in the honeyconb, where economising of space, of material, and of labour, are so combined, that apparently it may with equal propriety be described in the same phrase, with either of these three ends treated as if the one end in view.

What is sought is a sustained production throughout a 
period of indefinite, infinite, or perpetual duration-every year, every four years, every ten years, according as the case determined may be-giving an equal produce either in quantity or in value, according as the case determined shall be-equal to the maximum capability of the forest - without diminution, periodical or permanent-and without detriment to the forest-nor only this, but this without diminution of the forest-trees as felled being replaced by natural reproduction from self-sown seed, while the reproduction of the forest and the felling of every tree that is felled tends alike to the improvement of the forest - -so that it shall ever be rising in value as its products are withdrawn.

This is what is meant by sustained production, natural regeneration, and progressive amelioration of forests. It may be said, increaulously-If forest science, properly applied, can do all this, it can work wonders: it takes away one's breath to read it! Well, such is the end of forest cconomy as carried out in Germany and in France, and it is there being accomplished; nor there alone, but in various other lands; and it is that apparent perfection of forest management to which students of forest science throughout the Continent of Europe are seeking to bring the Lanagement of forests in the lands with which they are severally connected.

In the management of forests in the British dominions in India this system of exploitation is being introduced as fast and as extensively as money can produce the men necessary for the work, and as circumstances admit of free action; and $I$ know of no physical hindrance to the same thing being done in any of our colonies.

I have spoken of it as having arisen out of the adoption in Germany and in France of exploitation in accordance with the method known as à tire et aire; but it is now so different from this that it requires separate notice, and this the more that it is the method of exploitation now everywhere in Continental Europe approved by students of forest science. Details will be given; but it is expe- 
dient previously to bring under consideration another method of exploitation.

\section{Section D.- 'Furetage,' and 'Taillis Sous Futaie,'}

Furetage is a method of exploiting coppice woods composed of trees which reproduce shoots from the stump frecly, and can reproduce a wood or forest without the aid of self-sown seed. It may be considered a modification of Jardinage applicable to the exploitation of such trees, though not to others; and the designation given to it in contradistinction to Jardinage has been given from some fancied resemblance to that of a ferret ferreting out what it is in pursuit of, as the other designation has been given in reference to some fancied resemblance to that of the kitchen gardener in gathering his crops. But in practice it is assimilated to La Methode à tire et aire.

'Furetage,' says the late Professor Bagneris, Inspector of Forests, and Professor at the Forest School of Nancy, in a work entitled Elements of Sylviculture,* 'consists in cutting the strongest shoots out of a clump, and in leaving the weaker ones. The wood-cutter returns to the same place every eight or ten years, and if the poles are cut at the age of twenty-four or thirty years-(i.e., if the rotation is of twenty-four or thirty years) - the clumps are composed of shoots of three different ages.' It is a method of exploitation applied chiefly to beech coppice wood.

The beech is a tree which is not well adapted for exploitation as coppice; but it can be exploited thus advantageously. There are in France about 100,000 acres of beech coppice, belonging for the most part to private proprietors. These are situated chiefly in that part of France formerly known as Morvan, on the Swiss side of the Jura, and at the foot of the Pyrenees, and

* Elements of Sylviculture: a Short Treatise on the Scientific Cultivation of the Oak and other Hardwood Trees. Translated from the French by E. E. Fernaudez and A. Snythies, B.A., Indian Forest Service. London : William lider \& Son; Simpkin, Marsliall, \& Co. iss2. 
there they are frequently subjected to this mode of exploitation.

An exhaustive article on the Furetage of the beech in the Pyrenees, by M. E. Guinier may be found in the Revue des Eaux et Forêts for 1883, (pp. 469-477, 527-541). His object is to show how an improved modification of this method of exploitation may remedy several evils, and secure several advantages, in coppice woods, which are thus treated; and in pursuit of this object he addresses himself chiefly to the objections of those who are so satisfied with it that they are unwilling to make any change. After discussing at considerable length much which is involved in the failures which have followed this method of exploitation, M. Guinier passes under review objections which have been taken to any attempt to improve it, and answers these seriatim. The objections thus treated are following :-

It is said (1) Furetage is excellent inasmuch as it ensures the conservation of coppice woods; this has been established by experience: why seek for anything other than it is?

2. What is defective in Furetage lies not in the method, but in the practice and application made of this; and we ought not to hold the method responsible for abuses which have crept into it in practice.

3. Furetage comprises a collection of harmonious rules which have for their object to protect the interests of the regeneration of beech copse woods, which is a complex and delicate task; it is impossible to condense these rules into a formula-simple, brief, and precise, which may be applicable without peril to innumerable cases in practice; it is, moreover, sufficient that the agents who have to manage beech copsewoods should know the end they have to keep before them; it is then for them, from the resources supplied by their preparation and experience, to find out the means of accomplishing this applicable to the circumstances of each case. 
4. It should be borne in mind that treatment as a timber forest is that alone which properly suits the beech, and even the partisans of Furetage can scarcely consider this method of exploitation as other than provisional, and one which ought only to be applied pending the transformation of the coppice wood into a timber forest, which should be the end of all foresters. What good, then, can be expected from seeking at great trouble to modify the existing order of things?

Having replied to these several objections, M. Guinier states what he has to recommend, premising, however, that inasmuch as it admits the reservation of balliveaux, or seed-bearing standards, it is questionable whether the designation Furetage would still be applicable. And he expresses a kind of preference for another designation: he says:-'I believe we must surrender the name. As a matter of fact, the principle of Furetage is the removal of the shoots which are in a dominant state and the constitution of a reserve taken, except exceptionally, from the dominated shoots. And if we in principle prescribe the constitution of a reserve, more or less abundant, chosen from the dominating productions, we resume the principle of Taillis sous Futaie-copse as the under-growth of a timber forest; and whatever may be the proportions of the two constituents, a felling must present the aspect of one adapted to that mode of growth.'

In his treatise M. Guinier remarks that in view of the principle underlying this method of exploitation it seems to be a most certain and most simple mode of exploitation ; but in practice it is not found to be so. He alleges that from the first there do not exist the three well defined divisions of shoots. He adds that in the mountains where vegetation is slow the shoots of thirty years cannot be distinguished from those of twenty years growth when, by any means whatsoever, the full development of the former has been impeded. The shoots of different divisions often preponderate in some one or more positions 
instead or being dispersed equally among the others; and the removal of them occasions an unequal exposure of the soil, and of the younger shoots, which is contrary to the very spirit of Furetage; and further, from whatever cause it comes about, there is a very great diversity in the cubic measurement of the produce from exploitation in this method, which has given occasion for incessant modifications, and temporary suspensions of it, and for discussions. From all which many have arrived at the conclusion borne out by facts that it is a method of exploitation which is uncertain in its results and illdefined.

In the Pyrenees the formulas laid down for direction are very variable, and various. In some cases two periods of exploitation are established, in other cases three; and the prescriptions vary much with time and place. According to some, it is required to cut all shoots of a prescribed girth, and leave all others; and the measurement varies considerably. According to another prescription, all spreading shoots, all isolated shoots, all shoots under a certain size, and all shoots bearing secondary shoots of a certain size, should be reserved. But in the application of the rule great diversities are seen. A modification of this, determining more fully what shoots are to be reserved, has been proposed, but again variations occur in the practical application of this. For a time it was customary to reserve from amongst the most vigorous growing trees from fifty to sixty standards on every hectare, but this was abandoned on the ground that these standards were virtually bastard timber trees; and by some there has been advocated the reservation of a certain number of veritable balliveaux, trees reserved to supply seed.

By Professor Bagneris in his Manuel de Silviculture, published in 1873, it is remarked that the coppice woods treated thus were at that time little known, and had perhaps not been sufficiently studied. Thus may the diversities mentioned be accounted for. 
With the explanations cited M. Guinier proceeds to state what reserves he would propose. These are :-

1. Anciens; Modernes; Balliveaux de l'Age N., which are designations given respectively to trees left after one complete revolution of successive fellings; trees left after two of these; and trees left after three or more, and,

2. All underwood composed of spreading shoots or bushy suckers, and all shoots below a prescribed measurement, at a height of four inches.

Several explanations and illustrations of what is meant are given; and in regard to advantages to be secured, he says :- 'These are the following-

'1. Sufficient shelter, and this as complete as may be required according to circumstances, is secured for the stumps, by the reserving of underwood and balliveaux;

' 2 . The maintenance on the stumps (save with an exception always restricted) of twigs belonging to the underwood and the balliveaux, serving to keep up the flow of sap ;

'3. An advance of many years increase obtained by the reserving of the underwood ;

'4. The embroussaillement of felling proper to prevent damage done by cattle, and resulting also from the reserving of the underwood.

- These are advantages which it is sought to secure by the old method of Furetage, and they are common to both methods; the following, on the contrary, pertain exclusively to the new method, which is designed to accomplish, under like conditions, that in which the former is defective and calls for reform.

' 5 . The production of timber of large dimensions (if the ground be suitable) which may be employed in industrial operations.

'6. The enrichment of the standing wood material, and the progressive augmentation of the production;

' 7 . The production of natural sowings by means of the seed cast abundantly by the reserves; and the amelioration of the crop by the aid of natural reproduction; 
's. Preparation for a state of timber forest, by facilitating the management required for proceeding promptly to the transformation when the moment for this shall have come ;

'9. The application of treatment the most advanageous under every point of view, to the beech coppice which cannot be converted into timber forest, be it on account of economical considerations, or be it on account of the poveriy of the land.

'Let us compare now the spirit of the method proposed with that of the old system of Furetage, and cast a glance at the general results of the two methods of procedure.

'One can establish easily two essential differences.

'In the old F'uretage each shoot was considered indivividually; and the necessary precautions were taken to secure the life of the stump, and the prosperous growth of the shoots to be obtained. Further, the shoots in a dominant condition were exploited, and the dominated shoots were reserved, awaiting the attainment by these of a maximum of dimensions which was variable.

' On the contrary, by the employment of the proposed formula :

' 1 . The consideration of each shoot separately is abandoned in favour of the consideration of the prosperity of the crop in a mass. This method of looking at the subject is conformable to the modern and generally adopted method of attending to the culture of woods, the prescriptions of which relate to forest masses, and not to the trees individually. It is thus in the mancuvring of a corps d'armée, or of a battalion, or of even a platoon of soldiers, the individuality of the soldier is effaced. Attention to be given to the development of each subject pertains to arboriculture, whilst it is the development of the forest mass which is what pertains to sylviculture; no doubt the forest mass is composed of trees, as the army is composed of soldiers, and it is no more possible to lay down strictly rules of sylviculture without taking into account the requirements of the tree, than it is to determine the 
manœuvres of an army without having regard to the constitution of the soldier, to his strength, and to the maintenance of his health. But it seems as unreasonable to try to maintain any exploitation whatever without risking the loss of some shoots, or of some trees, the maintenance of which might be useful, as it would be strange for a warrior to hesitate to lead a battalion under fire, through fear that some men may be struck by the enemy's projectiles. In our fellings under this modification of coppice wood growing in a timber forest, what imports it that some stumps here and there may die? They will be replaced ten times, and a hundred times, more abundantly by the natural sowings.

' 2 . The exploitation does not relate any longer to shoots in the dominant state, as in Furetage; and it does not relate to shoots in the dominated condition alone, as in ordinary coppice woods under timber; it relates actually mainly to what is in the intermediate condition, and each exploitation removes first what is in this intermediate state, and then a portion only of what is in the dominant state, consisting of abandoned reserves.

' Is it further required to give the means of comparing this modified Furetage with the old Furetage?

'It is clear that the first-mentioned method stands to the second as Taillis sous futaie, coppice under timber, does in relation to simple coppice; but the difference, it seems, is more accentuated, as in simple coppice there are still reserved balliveaux, or standards selected from amongst the strongest shoots.'

M. Guinier discusses the matter in all its details; and he states at what places in France Furetage is practised, and the extent to which it is there carried out. But upon these discussions and statements I do not feel called upon to enter.

In regard to Furetage, Professor Bagneris writes in the work I have cited:- ' It does not appear to us that this method of exploitation should be generally adopted, 
because, in the first place, it seems preferable to grow the beech as a timber forest,-and for private proprietors, who possess forests of this tree, as coppice with seed-yielding standards. If the standards are cut early enough, they will not injure the underwood they overtop, especially if the rotation is sufficiently long, and they will shed seed by which the growing stock will be kept full. Moreover, although Furetage has hitherto preserved beech coppices in a more or less satisfactory condition, it presents many disadvantages. Thus it is exceedingly difficult to cut a certain number of shoots in a clump without injuring the rest; and in any case the labour is more costly. Besides this, cutting up the wood is not so easy when the shoots left standing are to be preserved from injury; and it is necessary either to remove the former on men's backs, or to allow carts to come in among the standing crops-a proceeding which is necessarily productive of damage.'

M. Guinier may allege that he has devised a method of securing the good without the evil. And I know of a modification of Furetage similar to what he arlvocates being carried out advantageously in the government of Ufa, near the Ural Mountains in Russia.

In order to the full understanding of what has been stated, there may be needed some knowledge of what is called Taillis sous Futaie. Besides different methodes of exploitation, there are different régimes of culture: there is coppice culture, and timber culture, and there is a culture of coppice wood in connection with the culture of timber forests. This last is the régime referred to, and the modified Furetage differs from the mode of exploitation usually followed in Taillis sous Futaie: being designed to avoid some of the disadvantages attaching to this as well as disadvantages attaching to simple Furetage. I have a clearer conception of what is common to both than I have of the points in which in practice they are essentially different; and yet I deem it of some importance here that the coppice culture and management in question 
should be known. As a preca!tion against my giving a misrepresentation of it I shall cite an account of it given in the Comptes Rendus de la Societe d'Agriculture de France, in a valuable paper On the disappearance of the oak in the forests of the north and north-east of France, read before the Society at a meeting held on the 17th April 1878, by M. B. de la Grye, a Member of the Society.

The gradual, but steadily advancing disappearance of the oak in the forests in that region of France, has been observed and proved, and has been considered a serious matter. M. de la Grye shows that it cannot be attributable to any climatic change. He adverts then to the different treatment given to coppice woods and to timber forests; and he goes on to say:-'It is, moreover, not in the timber forests but in the copse woods that the dis appearance of the oak has made itself conspicuous; and it is principally in forests subjected to this morle of treatment that it has manifested itself most distinctly.

'There it is not difficult to perceive that the mode of exploitation is sufficient to account for the progressive disappearance of this tree.

- The exploitation of coppice woods consists, as is known, in cutting down every ten years, fifteen years, twenty years or more, the whole crop, saving some selected trees destined to form a reserve. The reproduction is effected by shoots from the stumps, and to some small extent also by seeds produced by the reserves. The shoots proceeding from buds are nourished exclusively from material stored up in the stumps, and especially in the living portions of these stumps; and the shoots or suckers will be more vigorous in proportion as the stumps are stronger, and as their ligneous layers still alive are thicker.

'Experience shows indeed that young stumps alone produce vigorous and plentiful shoots; when the stumps are old, and especially when they have become disordered in their central parts-(a thing which cannot fail to happen)-there is, indeed, a production of suckers, but these quickly become pale, and they are not slow to dis- 
appear. The reproductive power of the stump becomes exhaustive of the reserve of aliment which they contain. The shoots then come to be progressively weakened, and the crops are not slow to disappear, if seed sowings do not come to meet the deficit occasioned by the death of the shoots; and here begins to appear what is the cause of the disappearance of the oak. The seeds of the yoke-elm, the seeds of the bois blancs [white woods-a designation given to alders, limes, poplars, and willows], and the seeds of the maple are light; they readily disseminate themselves; the young plants which proceed from them are robust, and can bear the shade. The acorns are heavy, and the young plants of the oak dread the shade. Thus, on the one hand, there is inferiority in the power of dissemination, and a greater demand in regard to light; while the secondary kinds of trees, on the other hand, are more numerous, and easily stifle the young oaks under their shade, and tend to substitute themselves for these.'

The author then adverts to the demand which there is for oak-bark, and to the bearing of this upon the point under consideration-the progressive disappearance of the oak. At the risk of laying myself open to a charge of wandering from my subject, I shall follow him, believing that the information may not be unacceptable to some of my readers. But before doing so, I remark that the seed of the beech, of which alone it is that M. Guinier speaks, is not so heavy as that of the oak; it may, therefore, be more extensively diffused, and the early growth of the seedling may enable it to make good its footing where an oakling might fail. M. de la Grye goes on to say :-

'But that is not all. The oak is the tree which, of all our indigenous productions, yields a bark the most suitable for use in tanning; everywhere where there are oak copsewoods that are exploited with a view to the production of bark. In order to this they are felled when the sap is in movement-that is the munth of May, and in order to 
reduce the work at this period of pressure, there are exploited in advance what are called winter woods. There results from this practice from the first that the stump cut in spring loses, through the escape which takes place over the large wound produced by exploitation, a great part of the material which it held in reserve, which is exhauster by the montlı of August, when with the second sap there are produced some buds destined to replace the fellerl perches. Then the stumps of other kinds of trees, which have not been subjected to this cause of alteration produce shoots which have, over those from the stumps of the oak, the double advantage of being more vigorous, and of having a start of some months. It is evident that these combined causes must produce successively the disappearance of the oak and the multiplication of other kinds of trees. This is what experience establishes. On the more fertile soils, where reproduction by seed goes on rapidly, the effect is less rapidly produced than in dry and poor soils; but in all forests treated as coppice the final result will be the same, and this will be the replacement of the oak by trees of secondary importance, or by heath plants.

'Is it necessary to conclude from this that the time has come to renounce entirely the treatment of forest as copse, or at any rate the treatment of them with a view to the production of bark? That would certainly be an exaggeration of the consequences of these observations. Private proprieturs can hardly afford to maintain timber forests; and oak bark is a product of such importance that it would be difficult to give it up.

' But every forest proprietor should be well assured that the treatment of woods as coppice is a mode of treatment altogether artificial, one incompatable with the perpetuation of the crops, and one that cannot be maintained excepting on condition of replacing in due proportion the trees of which repeated exploitations occasions the death. When through the exhaustion of the soil these replacements become impracticable, and there remains but one remedy, that is to abandon the régime of copse, and substi- 
tute for broad-leaved trees resinous ones, which may grow well on lands on which hardwood trees cannot live.

'To avoid recourse to this heroic remedy it is necessary to take care of the young seedlings, to clear the ground about them some years after the fellings, to avoid as much as possible late exploitations, and to cause the produce to be brought out before the appearance of shoots, so as not to compromise their future.

'The impoverishment of woods treated as copse is more speedy in proportion as the exploitations follow after short intervals. We find liard trees, and notably the oak, disappear more quickly in coppice woods felled every twelve or fifteen years than in those the revolution of which is fixed at twenty-five or thirty years; but to repair the evil in woods already ruined it will not suffice to prolong the revolution. In such cases it is to the replacement of disordered stumps that the proprietor shonld give his first attention; this he may accomplish by replanting after each felling, young oaks from the nursery in the void places previously cleared of herbage and dead woods, [a name given to the greater part of shrubs which ordinarily indicate a bad state of the forest, such as elders, hazels, cornels, privet, white byrony, the spindle-tree, holly, thorns, junipers, \&c.] If the ground be poor and covered with heath plants, this indicates an advanced state of impoverishment. These plantations have scarcely any chance of recovery; it is necessary in these cases to employ resinous kinds of trees which are less exacting than the oak.

'Dis-barking by steam gives now-a-days the means of abandoning felling during the flow of the sap without loss, inasmuch as it permits of the dis-barking in winter of wood recently felled. By proceeding thus, spring fellings may be entirely abandoned, which is a condition very favourable to the reproduction of shoots. Nothing is more damaging, indeed, than the repeated passing of workmen and vehicles through the midst of stumps covered with nascent buds, It is desirable that the course of procedure 
in question, which is eminently conservative, should become generally popular, for it suppresses one of the most powerful causes of the disappearance of coppice woods.'

\section{Section E.-Exploitation according to 'La Methode des Compartements.'}

When we consider what might be accomplished by a judicious exploitation of a forest carried on in accordance with $L a$ Methole ì tire et aire, contrasting this with consequences which have followed a reckles; exploitation by Jardinage, we need not wonder that the famous Ordinance of 1669 should have been welcomed with delight, as it was in many places, by foresters and forest administrators and forest proprietors. But even it did not ultimately produce all the good anticipated from it. In principle it was applicable to timber forests and coppice-woods aline; but the latter, from the shorter period required for the period of revolution, first made manifest that though it was based upon a sound principle, there were contingencies against which no provision had been made; and though complete and perfect, so far as it went, it was not a perfect and complete remedy for the 'evils complained of', or sufficient to prevent the slow but continuous destruction of forests. It was found that frequently the produce of the second series of fellings was not equal to that of the first; and the produce of the third was frequently not equal to that of the second. As a rough and ready method of producing approximately an equalisation between what was produced and what was withdrawn, it was valuable ; and from the middle of the seventeenth century till the close of the eighteenth century it was extensively practised. It is still practised, with a little modification; and in the Ural Mountains, and in the mining district adjacent, it may be seen in operation.

By Parade it is remarked:- ' If this régime had not entirely neglected to occupy itself with the conditions of the natural reproduction of forests, it would have left 
almost nothing to be desired. What was expected from it was that it would arrest the destruction of forests, and it may have done so to some extent, but not to the extent that was anticipated and desired. But the system of exploitation devised by Hartig, a distinguished forest official in Germany, and perfected by Cotta, his successor, promised to accomplish all that was desired and more.'

One difficulty experienced in endeavouring to secure this by exploitation according to the Methode à tire et aire, arose from the varying productiveness of different portions of the forest, and of different portions of the portion allotted for being felled within any given period-a century, a decade, or a year-arising from varying soil, exposure, differences in the kinds of trees growing upon it, and differences in the adaptation of the ground and situation to the vigorous growth of the kind of tree constituting the mass of the forest. Had in any case the forest, or the allotment for felling in the course of a lengthened period, been of one kind of tree, uniform in vigour of growth, and in the provision for the continuance of this, it might have proved a more successful method of exploitation ; or if one could have selected, and placed side by side, all plots uniform, or nearly so, in state and prospect, and formed thus uniform allotments of considerable extent, many advantages would have thence accrued: for even if it should have happened that one allotment for felling within a given period proved either exceedingly productive, or comparatively unproductive, the end in view might have been gained by simply making the extent of the area of different divisions laid out for exploitation inversely proportionate to their productiveness.

But, with a full knowledge of the contents, conditions, and areas of all the divisiuns of a forest, a chart might be prepared in which all portions uniform in all conditions might be indicated by uniform colours; and then arrangements might be made for exploiting all plots of one colour, as if constituting one continuous wood, and all plots of another colour as if constituting another, and all plots of a third colour as constituting a third. 
This, of course, would be at once fatal to a side by side continuously advancing exploitation, characteristic generally of the method known as à tire et aire, but the end for which that was enjoined would be gained.

There might at first be greater difficulty in bringing out the produce; but that might be minimised; and after one or two revolutions, the side by side progression might be carried out on a more extensive scale in allotting the allotments, if attention were given to the matter, varying plots and allotments might be so assimilated as to prepare them for a stricter application of the method referred to, if this should still be found to be desirable.

Such, in its general principles, was the innovation introduced by Hartig, proposing to treat similar patches, though separated from each other by portions of the wood or forest differing greatly from these, as if they constituted a continuous wood or forest, or as if only separated by bogs, or rocks, or fruitful fields. And the principle once admitted, it was found to be a method of exploitation which would admit of great and important improvements being made in the whole system of forest economy. In his work entitled Instruction in the Culture of Woods, there is discussed by him at considerable length, the system of i tire et aire, and the best method of so working the furests as to procure the reproduction of these from self-sown seeds, establishing an equalisation of produce and procuct, and at the same time a progressive amelioration of the forests, ensuring a more abundant and a more valuable supply, be it of firewood, or be it of timber, according as may be desired.

The publication of this work by Hartig was the commencement of a new era in forest economy in Germany. Hitherto all that had been attempted had been to secure a sustained production of wood, now there was to be combined with this the natural production of forests in such a way as to secure the progressive improvement of the forests in place of their coutinued deterioration. And 
Hartig not only showed that this was practicable, but he pointed out what measures should be adopted with a view to its being accomplished.

The subsequent publication of a treatise by Cotta on the fundamental principles of forest science, the first edition of which appeared in 1804 , carried still further the improvement of forest ecunomy.

A second edition of this work appeared in 1820. Meanwhile the work had been welcomed and studied in France, as in Germany: for science, like the love of God, and the light of the sun, and the air of heaven, is free and common to men of all lands, to all who can understand, and appreciate, and use it. And by the time the second edition of the work had appeared, France was prepared to take up the work free from the destraction of wars in which she had been involved by the Revolution and some of its consequences.

M. Lorenz, M. Parade, and others there, gave their best attention to the work of improving the forest economy of the day, nor did they do this without honourable acknowledgment of what had been done by German students of forest science.

'We,' says M. Parade, speaking of his countrymen, 'preceded our neighbours in the establishment of a regular and well-ordered management of forests, and in this we have served them as a model; but in what lies in advance of this they have returned with usury what from us they received: more especially is this the case in the most difficult and most important department of the work-the management of timber forests.'

By M. Jules Clavé, in an article entitled Etudes d' Economie Forestiere, which appeared in the Revue des Deux Mondis for January 1860, it is stated that 'Sylviculture, after having had in France its brilliant epoch, remained stationary during a quarter of a century, in consequence of the political events then engrossing the attention of all, but all the while it was advancing with giant strides amongst their German neighbours. It had taken in Germany a firm 
place en corps de doctere. Having there taken ces aplombs, Germany became so much the sooner the beacon-fire and guide of the administration of the management of forests, that there the same men were engaged in the prosecution of scientific research and in the management of practical operations - a combination which unhappily existed not in France in the last generation.'

All honour is due, and all honour was given, even by those who might have been supposed jealous of their success, to Hartig and Cotta. Before they entered upon labours much had been done by students of vegetation in France. Reaumur, Duhamel, Buffon, Du Petit Thouars, Merbel, Richard, and Decandolle, are names never to be forgotten. As has been intimated, the labours on which they and others like them might have engagerl successfully, were prevented by the commotions and wars consequent on the Revolution in France, But work they had accomplished was not all lost, and the German fathers of the advanced forest economy of the day gave to the study a new direction.

Captain Campbell-Walker, a distinguished official, occupying a high position in the Forest Service of India, who was selected to visit the forests of Germany and report, and who was subsequently selected to visit more than one British Colony to examine their forests and report what might be done to secure the conservation and economic exploitation of them, writes in his report on the exploitation of forests in the method now under consideration :-

' Forestry in Germany is truly a science, and differs very widely from anything I have seen called by the same name either in India or England. I do not advance the theory that the German system is perfect or applicable to all States or circumstances, and still less that we in England do not grow as fine trees, or do not know how to plant and rear young trees for timber. If any have 
doubts on these points, I would point to the Swinley Woods, under the charge of $\mathrm{Mr}$ Menzies, and portions of the New Forest under Mr Cumberbatch, which may challenge comparison with any oak plantations of the same age on the Continent; but I do think, and am sure that any who have studied the subject, and made themselves thoroughly acquainted with it by personal observation, will agree with me, that, compared with most of the German States, we are behindhand as regards the systematic and scientific management of forests on a large scale, and as a part of political economy to which it is incumbent on a Government to attend. In fact, looked at in this light, I venture to affirm that we are as far behind Germany in the knowledge and applicatian of scientific forestry as we are in advance with regard to agricultural pursuits.

'The Government [of India] haviug granted, by the gradual formation of a distinct forest service, the necessity of establishing a system of forest conservancy, and administering and working the forests by degrees on more well-defined principles and to the best advantage, the question naturally presents itself-Where are we to look for a model or precedent on which to work? and the reply appears ready. To Germany, where furestry, and particularly the management of forests by the State, has been carried on for hundreds of years, not the mere planting of a few hundred acres here, or reserving a few thousand acres there, but a general system of forest management, commencing by a careful survey, stock-taking, definition and commutation of all rights and servitudes, careful experiments in the rate of growth, the best soil for each description of tree; in fact, in every brauch of the subject, and resulting in what we find to-day in Hanover, for instancehundreds of thousands of acres mapped, divided into periods and blocks, and worked to the best advantage both with regard to present and future, and the annual yield of which now and for many years to come is known and fixed to within a few hundred cubic feet. 
'I do not think we have much to learn from the Germans with regard to the planting and rearing of young trees, but it is with regard to the best methods of managing groups of plantations or masses of forests that I consider we may with advantage take a leaf out of their book. For instance, I would certainly introduce in a tentative manner, and at first on a very small scale, their system of rotation, clearing, and periods, and endeavour to bring forward a second crop before the first is off the ground, encourage the growth of the better descriptions, keep down the less valuable, and to improve our "Planterbetrieb," or selection of single trees to be felled, so as gradually to arrive at groups of trees of the same age, description, and class, and eventually at blocks worked in rotation, and containing always a sufficient stock of crop coming on to meet the requirements of future years. To arrive at all this the most careful observations and experiments will have to be mare as to the rate of growth and yield per acre of each description of forest, the condition under which trees grow best and form the most timber, some requiring close and some open planting, some nurses and some not, some, like the oak, requiring a great deal of light, whilst others, like the beech, do well for many years in shade. All these points, and many more, demand attention, and till they are settled we shall be merely groping in the dark.'

By Varrene de Feuille there had been supplied long before, information in regard to the best means of obtaining from a coppice wood the greatest possible quantity of produce: and by implication how to obtain from a mixed wood the largest possible supply of firewood after having provided for a supply of timber; or what may be considered the couverse of this -how to secure from it the largest possible supply of timber, together with the largest possible supply of firewood. And by Reaumur information had been supplied as to the best means of obtaining from a timber forest the largest supply of timber of the best 
quality. From biographies of Hartig and Cotta loy Givin. ner in Furstliche Mittheilungen, it is evident that the works of Varenne de Feuille were not unknown to these distinguished foresters. A translation of some of the works of Duhamel into German was published in 1763, from which it may be inferred that works of the French students of the physiology of vegetation were known in Germany and valued there.

The Methude à tire et aire had been foreshadowed in a system of forest management enjoined on his forest administrators by Count Mansfeldt in 1595. And as the method of exploitation so designated may be considered an evolution or development of this of an earlier date, so may this La Methode des Compartements or Die Fachwerke methel, as it is called in Germany, be considered a further development of that. What we owe to Hurtig and Cotta is that they, in their circumstances, as did the others in theirs, made such an application of the knowledge in their possession-partly inherited, partly acquired by them through careful observations, and by experiments in which they were aided by disciples whom they had fired with a like spiritas issued in the development of an improved forest economy which commanded the approval of foresters in their own day, and the adoption of their devices by other.s to such an extent that forests which were going fast to destruction have been saved; and not only men of our own day, but generations yet unborn, are likely to reap the benefit.

The exposition which has been given of forest exploita. tion in accordance with La Methode des Compartements may suffice to give some idea of the general principles upon which it is conducted, substituting the exploitation of divisions of the forest yielding equal or equivalent products, for the exploitation of areas of extent, in equal periods. But while this is the principle upon which it is conducted, it is the case that in the application of the principle to the exploitation of a forest there are many 
things which may be taken into account with advantage in determining what area shall be cleared in order to obtain the products required, and, in determining this, good use may be marle of the observations of earlier students of arborescent vegetation.

It has been found by observation that a tree does not make equal increase annually throughout its growth; that it makes increase at one rate in early growth, at another rate in middle life, and another after what may be called its maturity; that different kinds of trees vary, not only in their rate of growth, but also in the ages at which these changes in the rate of increase occur; and that the increase varies with differences in soil, in exposure, and in climatic conditions. Estimates have been made of how much increase by growth might be made by different kinds of trees in different situations, and under different conditions; and of the ages at which different kinds of trees variously situated, would, if felled, yield the greatest quantity of wood. From these it appeared, to take in imaginary case in default of an actual one, that in the case of a tree which reached its maximum of growth at, say 90 years of age, after which period the decay in the course of a year equalled in quantity the new wood produced, and subsequently would exceed this, there might be more wood obtained in the course of 180 years from three crops felled at the age of 60 years than from two crops felled at the age of 90 years; but that wood of more value per cubic foot might be obtained by felling the tree at the age of 100 years, than by felling it at an earlier period of growth; and that the age of the tree by felling at which it would yield the greatesf pecuniary return, taking into account interest and compound interest, and the rent of the land, might, according to circumstances, be one or other of these ages, or might be another age altogether.

And thus became known also the limit beyond which fellings could not be practised without destruction to the forest, and the ages of different kinds of trees at which 
fellings should be made to secure in the highest degree what was desired-sustained production of wood by the forest, and a maximum of quantity, a rnaximum of profit, or a maximum of value, in the wood produced.

These are only adduced as specimens of the kinds of observations which have been made, accumulated, and made use of in determining the most advantageous form exploitation should take, and such observations are being made still.

In conriection with many of the Schools of Forestry on the Continent of Europe there have been established National Experimental Stations at which, as at those connected with Schools of Forestry in Austria, attention is given to such matters-while at others, other matters bearing upon the advancement of forest science, and of forest economy, or applied forest science, are being attended to, and subjected to experiment. Before the last century had closed endeavours were being made in Germany to turn to account discoveries of the kind indicated which had been made; and early in the present century great and rapid progress in this was made. The result of all this has been such a development of the system of exploitation carried on in sections of forest, that the produce of the clearing of one section is supplemented by the produce of thinnings in one or more others, these thinnings being so arranged, in accordance with the knowledge which has been acquired of the physiology of arborescent vegetation under different conditions, as gradually to prepare each section for being cleared, while, meanwhile the vigorous growth of the standing trees in it is promoted by the operation, and the continued growth of these trees is made subservient to the growth of a succeeding crop of trees produced from self-sown seed: all which is so arranged that every operation of the forester within the area of the forest upon which he is engaged shall tend to secure a sustained production of wood, combined with a natural reproduction of the forests, and an improved condition of 
these, so that without present loss the forests shall be handed down to coming generations undiminished in body, and enhanced in value, if not also increased in extent; and to secure each of these as efficiently as if it were the only object aimed at. Reference has been made to the ruaking of a honey comb as supplying an illustration of what is meant. In the honey comb each cell as formed supplies by its six sides what is equivalent to another cell-a sixth part of six others; and by its threesided bottom it supplies the third part of the bottom of three other cells on another plane parallel to this, on the other side of the plane of the bottoms of the cell. By this, then, there is secured a saving of space, a saving of material, and a saving of labour as complete as if any one of these had been the sole aim of the artificer. So is it here: the amelioration of the forest, its sustained production, and its natural reproduction, are each of them secured as efficiently from each action of the forester as it would have been if this had been the sole object of his work.

But we have not yet stated all the pre-requisites of this method of exploitation.

I have intimated that exploitation, according to $L a$ Methode des Compartements may be considered to be only a develupment of the method of exploitation known as $L a$ Methode à tire et aire; but it is, as that statement implies, the same with a difference. It is designated in Germany the Fachourke Method, in France La Methode des Compartiments, and in some other countries the Scientific method of exploitation, while in some countries I have heard it characterised by a designation conveying the idea that it is the rational, or most natural, method of exploiting forests of great extent. And certainly, as carried out in some lands, it goes (to make use of a school-boy expression) like clock-work. It does so; but as it is the cuse that the smooth movements and definite announcements made by the clock are brought about by complicated machinery each part of which is adapted to co-operate with adjacent 
parts, and together with these, and with all besides, to minister to the resultant end, so is it here; and in the one case as in the other, there is much besides the result ubtained that is admirable in the adjustments by which this is secured. The astronomer can not only tell what is at present the relative positions of all the constituent parts of the solar system; he can also foretell what their relative positions will be at any time in the future which may be specified. I have seen a railway chart, by a glance at which the directing engineer can tell what is, and what at any hour or minute of the day will be, the relative positions of all the regular trains under his charge. And it is almost essential to the perfect working of the method of forest exploitation now under consideration that the Forester-in-chief, or some one connected with the administration of the management of a forest, should be able to tell what is the actual state of the forest in all its parts, and what operations are going on in each of these,-but able also to tell with proximate accuracy what will be the state of each of these parts, and in what form different parts will be under exploitation, at any period of the future, within, say, the next hundred years! I have said with proximate accuracy, because there are contingencies the effects of which, with the amount of knowledge yet attained, cannot be determined with absolute precision. But every year's observations tend to reduce the measure of uncertainty which is still inherent in the forecasts made of the future, more or less remote. Meanwhile requisite corrections are made by what may be considered a tentative process, determined by experiment and observation.

In the application to forest economy of the knowledge which has been acquired in regard to the physiology of arborescent vegetation, it is necessary, in order to securing the greatest possible efficiency of this method of exploitation, to have preliminary surveys made of the forest as a whole, and of its several constituent parts, and to have the results of these surveys embodied in charts or diagrams; and 
it is necessary, along with the charts of different sectious, to have inventories of the trees upon them, with specification: of their kind, age, size, vigour of growth, and conditions favourable to this, or otherwise with indications of the extent to which these conditions are so. In making subsections it is necessary to class together plots or parcels which, at the time of exploitation, under one form or another, will yield equivalent products, or products so proportioued that the superabundance of those of one may compensate any deficiency in those of another; it is necessary to bring all the trees growing on each plot into as nearly as possible a uniform state and size; to convert, it may be, a coppice wood into a timber forest, or a timber forest into a coppice wood, or a wood consisting of a mixture of timber trees and coppice into one or other; or to convert a coppice wood permanently or temporarily into such a mixed wood; or, it may be, to bring a forest of mixed woods of different kinds into plots or parcels more or less extensive of one or other of the kinds of trees growing there.

In view of the whole ease, with charts and inventories before him, and a general knowledge of contingencies to be anticipated, the forest engineer-it may be the engineer-in-chief, it may be some one to whom hic has delegated the work to be done subject to his approval, it may be some professional official in the office of the Minister of State entrusted with the administration of the forests-it might, for that matter, be some professor of forest science and forest economy residing in another land-has to prepare a general scheme of operations for it may be a hundred years or more to come, divided into definite periods, it may be decades, periods of ten years, but generally it is periods of longer luration; a programme of opcrations which it is proposed should be carried through in the first of these periods; and a programme of operations proposed conditionally for execution during one or more of the periods following. In the programmes for single periods there are specified what plots 
are to be subjecteil to such of the different thinnings or fellings which have been referred to, with a statement of what produce may reasunably be expected from each operation, At successive stages of the work the results obtained are compared with the estimates previously formed of what they would be, and the programme may then, if necessary, be modified.

Some time before the close of each period the programmes for succeeding periods are subjected to revision; and in view of actual results obtained, and of other conditions which may have supervened, they also may be modified, with provision for like revision, and, if necessary, modification during its currency.

Such is the tentative process by which, in the present state of forest science, the sustained production of forests is secured. In all this much depends on the completeness and accuracy of the inventories, and of the estimates prepared of the cubic measurements of existing trees, and of what these may reasonably be expected to be at any specified period in the future. It does not come within the scope of my purpose here to enter upon an exposition of what means are adopted in the solution of such problems. The object aimed at is to procure from the forest in each period by first, second, or later thinnings and final clearings of different plots, material equivalent to the increase made in that period by growth; and not more than this that the forest may be in no darger of being exhausted and destroyed.

Besides the sustained production of furests which it is sought to secure by exploitation in accordance with Die Fachwerke Method or La Methode des Compartiments, is a natural reproduction of the forests exploited.

Discussions have taken place in regard to the relative advantages to be derived in this country from seeking the restoration of forests by self-sown seed, and by artificial plantiug. In the advanced forest economy of the Continent reliance is placed upon natural reproduction by 
self-sown seed; and artificial sowing or planting is einployed only to fill spaces which may have been left blank in this process, and in the creation of new forests, as in the reboisement of mountains, or the fixing and itilisation of drift sands.

To give full efficiency to the reproduction of forests by self-sown seed, a succession of fellings is necessary; and in these the most extensive felling is not the final one. Besides balliveaux left standing when the principal felling is made, to yield seed, and trees of greater age, destined for prolonged growth to produce timber of greater dimensions, there are left what is deemed a sufficient number of trees to afford shelter and shade to young seedlings. Subsequently some of these are thinned out, so as to leave only what will suffice to afford for a time partial shade by their shadows falling successively on different portions of the ground as the day advances; and not until after the seedlings or saplings no longer require the fostering thus afforded, does the final felling take place. Thereafter, surcessive thinnings according to prescribed regulations are made-all of which contribute to make up the quantity of produce required in the periods during which they occur. All of these successive thinnings and fellings are designed for the improvement of the growing crop; and that which clears the ground for the self-sown seed from which is expected another crop, may be reckoned the principal felling, to be followed by the final felling, when the rising generation no longer requires the shade and shelter of the older trees.

In arranging the order in which successive fellings are to be made, attention has to be given to considerations of how the produce may be brought out with greatest ease and with least detriment to the standing crop, and how growing crops may have secured to them, to as great an extent as possible, protection from prevalent winds and storms. In this matter the method of expluitation under consideration does not stand alone; but with the greater 
attention griven in it to ultimate, and it may be distant, results, this assumes in it greater importance than it does iu other circumstances and under other conditions.

By all of these measures conjointly and severally, and liy erery operation pertaining to them, the forests are by steady advance being brought into greater accordance with what is required for the most efficient working of the method of expluitation adopted, including uniformity of vigorous regetation and growth; and thus the amelioration of the forests is secured as efficiently as if it had been the unly object for the attainment of which everything had been done.

I have cited opinions expressed by Captain CampbellWalker in his Reports on Forest Management in Germany. In a republication of this, he says of scientific forestry, such is is practised in Germany:- 'The main object aimed at in any system of scientific forestry is, in the first irstance, the conversion of any tract or tracts of natural forest, which generally contain trees of all ages and descriptions, young and old, good and bad, growing too thickly in onc place and too thinly in another, into what is termed in German, a Geschlossener Bestand (close or compact forest), consisting of trees of the better descriptions, and of the same age or period, divided into blocks, and capable of being worked, i.e, thinned out, felled, and reproduced or replanted, in rotation, a block or part of a block being taken in hand each year. In settling and carrying out such a system, important considerations and complications present themselves, such as the relation of the particular block, district, or division, to the whole forest system of the province; the requirements of the people, not only as regards timber and firewood, hut straw, litter, and leaves for manure, and pasturage; the geological and chemical formation and properties of the soil; and the situation as regards the prevailing winds, on which the felling must always depend, in order to decrease the chances of damage 
to a minimum; measures for precautions against fires, the ravages of destructive insects, trespass, damage, or theft by men and cattle. All these must be taken into consideration and borne in mind at each successive stage. Nor must it be supposed that when once an indigenous forest has been mapped, valued, and working plans prepared, the necessity for attending to all such considerations is at an end. On the contrary, it is found necessary to have a revision of the working plan every ten or twenty years. It may be found advisable to change the crop as in agriculture, to convert a hard wood into a coniferous forest, or vice versa, to replace oak by beech, or to plant up (unter bau) the former with spruce or beech to cover the ground and keep down the growth of grass. All these and a hundred other details are constantly presenting themselves for consideration and settlement, and the local forest officer should be ever on the alert to detect the necessity of any change and bring it to notice, and no less than the controlling branch should he be prepared to suggest what is best to be done, and be conversant with what has been done and with what results, under similar circumstances, in other districts and provinces.'

In a paper read by him before the Otago Institute in Dunedin, New Zealand, on December 21, 1876, entitled State Forestry: its Aim and Object, he says in regard to the way in which operations are initiated in Crermany and France :-

'When a forest is about to be taken in hand and worked systematically, a surveyor and valuator from the forest staff are despatched to the spot - the former working uncler the directions of the latter, who places himself in communication with the local forest officer (if there be one), and the local officials and inhabitants interested, and ubtains from them all the information in his power. The surveyor first surveys the whole listrict or tract, then the several blocks or subdivisions as pointed out by the valuator, who defines them according to the description and age of the timber 
then standing, the situation, nature of soil, climate, and any other conditions affecting the rate of growth and nature of the crops which it may be advisable to grow in future years. Whilst the surveyor is engaged in demar. cating and surveying these blocks, the valuator is employed in making valuations of the standing crop, calculating the annual rate of growth, inquiring into and forming a register of rights and servitudes with a view to their commutation, considering the best plan of working the forest for the future, the roads which it will be necessary to construct for the transport of timber-in fact, all the conditions of the forest which will enable him to prepare a detailed plan for future management, and the subordinate plans and instructions for a term of years, to be handed over to the executive officer as his "standing orders." A complete code of rules for the guidance of the valuators has been drawn up and printed, in which every possible contingency or difficulty is taken into consideration and provided for. Having completed their investigations on the spot, the valuator and surveyor return to head-quarters and proceed to prepare the working plans, maps, \&c., from their notes and measurements. These are submitted to the Board or Committee of controlling officers, who examine the plan or scheme in all its details, and if the calculations on which it is based be found accurate, and there are no valid objections on the part of communities or individuals, pass it, on which it is made out in triplicate, one copy being sent to the executive officer for his guidance, another retained by the controlling officer of the division, and the original at the head-quarter office for reference. The executive officer has thus in his hands full instructions for the management of his range down to the minutest detail, a margin being of course allowed for his discretion, and accurate maps on a large scale showing each subdivision of the forest placed under his charge.'

With regard to measures adopted to secure natural reproduction of exploited forests, he says :- 
- Natural reproduction is effesterl by a gradual removal of the existing older stock. If a iurest track be suddenly cleared, there will ordinarily spring up a mass of coarse herbage and undergrowth, through which seedlings of the forest growth will rarely be able to struggle. In the case of mountain forests being suddenly laici low, we have also to fear not only the sudden appearance of an undergrowth prejudicial to tree reproduction, but the total loss of the soil from exposure to the full violence of the rain when it is no longer bound together by the tree roots. This soil is then washed away into the valleys below, leaving a bare or rocky hillside bearing nothing but the scantiest herbage. We must therefore note how Nature acts in the reproduction of forest trees, and follow in her footsteps. As Pope writes-

First follow Nature, and your judgment frame

By her just standard, which remains the same,

Unerring.

Acting on this principle, foresters have arrived at a systematic method of treatment, under which large tracts of forest in Germany and France are now managed. The forests of a division, working circle, or district, are divided according to the description of the timber and the prevailing age of the trees, and it is the aim of the forester gradually to equalise the annual yield, and ensure its permanency. With this object, he divides the total number of years which are found necessary to enable a tree to reach maturity into a certain number of periods, and divides his forest into blocks corresponding with each period or state of growth. Thus, the beech having a rotation of 120 years, beech forests would be divided into six periods of 20 years each-that is to say, when the forest has been brought into proper order, there should be as nearly as possible equal areas under crop in each of the six periods, viz., from 1 year to 20 , from 20 to 40 , and so on. It is not necessary that the total extent in each period should be together, but it is advisable to group them as much as possible, and work each tract regularly 
in succession, having regard to the direction of the prevailing winds. When a block arrives in the last or oldest stage, felling is commenced by what is called a preparatory or seed clearing, which is very slight, and scarcely to be distinguished from the ordinary thinning carried on in the former periods. This is followed by a clearing for light in the first year after seed has fallen (the beech seeds only every fourth or fifth year) with the objects of -1st, preparing the ground to receive the seed; 2 nd, allowing the seed to germinate as it falls; 3rd, affording sufficient light to the young seedlings. The finest trees are, as a rule, left standing, with the two-fold object of depositing the seed and sheltering the young trees as they come up. If there be a good seed year and sufficient rain, the ground should be thickly corered with seedlings within two or three years after the first clearing, Nature being assisted when necessary by hand sowing, transplanting from patches where the seedlings have come up very quickly, to the thinner spots, and other measures of forest craft. When the ground is pretty well covered the old trees are felled and carefully removed, so as to do as little damage as possible to the new crop, and the block recommences life, so to speak, nothing further being done until the first thinning. The above is briefly the whole process of natural reproduction, which is the simplest and most economical of all systems, and especially applicable to forests of deciduous trees. The period between the first or preparatory clearing and the final clearing varies from ten to thirty years, the more gradual and protracted method being now most in favour, particularly in the Black Forest, where the old trees are removed so gradually that there can scarcely be said to be any clearing at all, the new crop being well advanced before the last of the parent trees is removed. This approsimates to "felling by selection," [Jardinage], which is the primitive system of working forests in all countries, under which, in its rude form, the forester proceeds without method, selecting such timber as suits him, irrespective of its relation to the forest incre- 
ment. Reduced to system, it has certain advantages, especially in mountain forests, in which, if the steep slopes be laid bare area by area, avalanches, landslips, and disastrous torrents might result, but the annual output under this system is never more than two-thirds of that obtained by the rotation system, and there are other objections which it is unnecessary to detail in this paper, which have caused it to be rightly condemned, and now-a-days only retained in the treatment of European forests under peciliar or special circumstances.'

The application of this method of exploitation to artificial plantations appears to be no less satisfactory than it has been to the exploitation of forests with a view to secure a sustainell supply of produce. I am not in a position to form an opinion of the extent to which it is applicable to British arboriculture, which has not for its sole object the production of wood, or of a sustained pecuniary return. Nor does it comport with my purpose to gire here a full detail of all the various measures which are comprised within this method of exploitation. All that I have proposed to myself to do is to supply an introduction to the study of this. It is not impossible, and not improbable, that the study of this may suggest many things which might he done with advantage without a formal adoption in its entirety of this method of culture and exploitation. What I do know is that it supplies a system of forest economy such as is much needed in the treatment of extensive forests in newly settled lands, or in the treatment of State forests which have been impoverished and are ready to perish in lands which have been long peopled by colonists from other places.

The evil connected with the exploitation of such forests by Jardinage, the method generally and extensively adopted, is that this method of exploitation tends to extend and increase that impoverishment, and to destroy what yet remains of these.

Exploitation according to La Method it tive et aire is not 
in itself sufficient to prevent this disastrous consequence. But its a'evelopment, La Methode des Compartiments, with its capabilities of indefinite improvement without change of principle, seems to leave nothing more advanced to be at present desired.

Furetage, in its most improved form, is applicable only to coppice. 


\section{CHAPTER IV.}

\section{S Y L V I C U L T U R F.}

In so far as the modern scientific forest economy" of Continental Europe may arrest the continuous destruction of forests, and secure their conservation, to the full extent of that it has been a blessing to the world, ancl may be considered to have done what was required in the interests of the present and the fitture holders of this portion of the national possessions in the lands in which it has been adopted. But in connection with this, and without detriment to it, with benefit on the contrary to all concerned, something may be done to make this trust estate more productive, and to add to it, by restoring again to some extent what has been taken away effecting thus the extension as well as the conservation and improvement of the existing forests. And this is being done by sylvicultural operations in various parts.

The term Sylviculture, with its synonyms in different languages, is a term in as general use in discourse on such subjects on the Continent as is the term Arboriculture in Britain. In desultory converse the two worts may be used as interchangeable terms; but neither in theory nor in etymological structure are they synonymous. The matters to which they respectively refer may be said to differ as completely as do domestic and political economy. The one relates to the culture of the tree as a tree, the other to the culture of a wood, the constituents of which are trees, as the constituents of the tree are leaves and their rootlets, but having, like the. tree, a corporate existence as a whole. And the culturr 
of this may be as distinct, though not more so perhaps, as the economy of a nation may be distinct from the economy of the household. It may be considered that in the one case, and in the other alike, what relates to the whole relates to all its constituent parts; and it may be alleged that sylviculture comprises arboriculture. I am not disposed to question or deny the allegation; I content myself with remarking that arboriculture does not as a consequence comprise sylviculture, and it is sylviculture, or the culture of woods, comprising as this does the culture of the trees of the aggregate of which the woorls consist, which is here brought under consideration.

The sylviculture of the Continent is practised with different objects immediately in view; and with variations in these it presents different phases. It is practiced most extensively in connection with the management of existing forests. Information in regard to what is done in this way may be obtained by English students from a treatise entitled Elements of Sylviculture, by the late G. Bagneris, Inspector of Forests, and Professor at the Forest School of Narcy, which lias been translated from the French by Messrs Fernandez and Smythies, of the Indian Forest Service.

But besides being carried on with a view to maintaining and increasing the produce of existing forests, sylvicultural operations have also been carried on, and that upon an extensive scale, and with success, to counteract evils which have followed the destruction of forests. Sylviculture has been employed thus successfully to prevent desolations occasioned by torrents and inundations. Details are given in a volume which I have published entitled Réboisement in France; or Records of the Re-planting of the Alps, the Cevenries, and the Pyrenees, with Trees, Herbage, and Bush, with a view to arresting and preventing the destructive consegnences of torrents.

It has been employed to arrest and utilise sand-drifts. Details of some undertakings with this view are given in 
a volume I have pulblished entitled Pine Plantations on the Sund Wastes of France. A similar enterprise has been carried out with success tn arrest drift-sands on the Bannat in Hungary; and by similar means have been utilised extensive sand plains in Northern Germany, details of which have been given above [ante p. 120-131.]

It has been used on the Karst, in Austria, to counteract aridity produced by the destruction of forests, and with a like view it has been extensively introduced into Algeria. On the steppes of Southeru Russia it has been begun. And in Spain, along with extensive irrigation works, including canals, reservoirs, and artesian wells, there has been combined with the conservation of existing forests the restoration of blank spaces within their limits, and the extension of forest areas by plantations beyond their boundaries.

In Italy it has been introduced with remarkable success to counteract deadly malaria; and in more places than I can name plantations have been created as a means of securing supplies of wood and timber.

In the education, instruction, and training given to aspirants for employment in the State forests of different countries, special attention is given to this subject.

In the immediately preceding chapter some information [ante p. 120-131] is given in regard to the culture of the beech.

Like information in regard to the culture of the Maritime pine and Scotch fir is given in the volume entitled Pine P'lantations in l'rance (pp. 36-50, 143-157, 100-142.)

It may be well to give an illustration of the instruction given in regard to the botanical characteristics, the natural history, and the appropriate culture of different kinds of trees, in accordance with the advanced forest economy of the the day. The following in regard to the black or Austrian pine has been compiled from difterent sections of the Cours elémentaire de Culture des Bois crée a l' Ecole Foreestier de Nancy.

The Austrian black pine, Le Pin Noir of France, the Pinus nigra of Linnæus, the Pinus Austriaca of Hoss, 
the P'inus Laricio Austriaca of Endlecher, is, as is generally held, and as is indicated by the last mentioned botanical designation, very nearly related, or, according to some botanists, is a permanent varety of the Corsican piuc. In the Styrian Alps, in the mountains of Dalmatia and Croatia, as well as in a part of Hungary, and in the neighbourhood of Vienna, it forms considerable forests, sometimes alone, sometimes mixed with the oak, the ash, the Scotch fir, and the larch. During the last forty years this tree has been much cultivated in Germany, and more recently attention has been given to it in France. Its rapid grurvth, the good quality of its timber, and especially its hardy constitution, which permits it to thrive even in the most arid calcareous soil, justify the favour with which it regarded by sylviculturists.

Climate, Situation, Exposure.-The mountains where this pine is indigenous range from about 800 to about 1000 mètres in height. It is also found at greater altitudes, but with a visibly retarded growth. It also thrives on declivities and plateaux, and all exposines seem to agree with it.

Soil.-As already mentioned the Pin Noir, or black pine prefers especially light, dry calcareous soil, however destitute it may be of humus. This quality makes it very suitable for the reboisement of bare rocks, provided that there be fissures into which the roots can insinuate themselves. It will take root in earth which has fallen down, in a landslip, even when there is little depth, without seeming to suffer injury. Clay soils are not very suitable for it; and damp soils are positively injurious to it.

Flower and Fruit.-Both resemble those of the Corsican pine.

Young Plants.-Are very robust from the first, and fear neither cold nor heat.

Foliage. - The leaves are very close together, and they are of a dark green, and they remain on the tree for five or six years. The tree having numerous bushy branches, the shade is dense, and the soil is supplied with an abundance of detritus. 
hoots. - The roots are creeping and hardy, and extend a long way. There is almost no tap-root.

Growth and Length of Life.-The black pine grows rapidly, and continues to do so until a very advanced age. When circumstances are favourable, it will live for two or three centuries, and attain a diameter of a mètre or more at the foot, and thirty or thirty-three mètres in height. Some authors have asserted that the trunk is rarely straight. Zoetli, who for a long time superintended some forests of Austrian pine, and has published on the subject, does not speak of this peculiarity; and he considers the black pine supplies excellent building timber.

Qualities and Uses.-As we have seen, the black pine is much esteemed in Austria for building purposes, and wc are assured that its durability equals that of the larch. When under water, it is, so to speak, indestructible. It supplies good firewood, and the charcoal is as valuable as that of the birch.

Writers agree in saving it ought to be cultivated in the same way as the Scotch fir. In the eighth edition of $L a$ Culture des Bois, by Cotta, there are given the following directions :-

In order that it may attain its full development of size and qualities the Austrian pine should be subjected to a revolution of from 120 to 150 years, according as it occupies more or less elevated regions. In early youth it bears the shade of large trees a little better than does the Scotch fir, but in middle age it will not thrive where planted closely together any more than will the latter, consequently the ground is often covered with shrubs and thorns.

The coupes de regeneration should be executed in the same way as in forests of Scotch fir, -60 or 80 reserved trees per hectare will be enough for the coupes d'ensemencement. Removing the thorns and ploughing the ground is very useful in assuring the success of self-sown seed.

Les coupes d'amelioration, of which nothing is said in the work quoted above, should be effected according to the rules which have been given for forests of Scotch fir. 
Being very resinums, it is often gemme. It is probable that the twisted form of the trunk may be the result of this practice rather than of a peculiar tendency in the trec.

It is cultivated on the sand wastes of La Sologne, torgether with the Scotch fir and the Norway fir, after the soil has been previously prepared for this by the previous culture of the Maritime pine. Detailed information in regard to sylviculture in La Sologne are given in the volume cntitled Pine Plantations on the Sand Wastes of France (pp. 69-80).

This tree was introduced into Britain in 1835. It is propagated by seed, and grows on a sandy loam. But mention is made of it here solely to supply a specimen of the instruction given in regard to different kinds of trees in Schools of Forestry on the Continent of Europe. 


\section{CHAPTER V.}

\section{STUDY OF PATHOLOGY.}

WhiLe sylviculture is based upon a knowledge of the physology of arborescent vegetation, it is found to be necessary to the attainment of the best results, that the forester should have some knowledge of the diseuses to which different forest trees are liable-the nature, the symptoms, and the causes of these; and to the study of those great attention is given by the students of forest science.

In the museum of the Prussian Forest Institute at Eberwalde, the impression produced upon the mind of the visitor is that there are there specimens represcntative of every disease to which trees are heir, specimens exhibiting the progress of the disease from the attack to the consummation; and hard by, the bark, the wood, the insect, or the parasitic herb or fungus by which it has been induced: the insect and the fungus being exhibited under all the transformations through which they pass; while specimens of the effects of lightning and other physical causes of the decay or destruction of trees are not alacking.

And similar collections sufficient to afford facilities for the study of the diseases of trees, and of means of preventing or of remedying the evils done are to be found in many other similar institutions.

In an introduction to the study of modern forest economy it is only an illustration which is called for, or can be given. In selecting one I confine myself to a notice of fungi infesting the Austrian or black pine, of the culture of which some account has just been given. 
Experimental stations have been established in connection with many of the Schools of Forestry on the Continent. Amongst other subjects of investigation undertaken by that in connection with the School of Forestry established in the vicinity of Vienna, is the natural history of the Austrian or black pine, Pinus Austriaca, Hoess. And along with a monograph on this subject issued last year [1883] there appeared from the pen of Baron F. V. Thuemen the First Part of a Mycological Report, under the title Beitraege zur Kentniss der auf der Schwarzfoehre Vorkommenden Pilze; and a résume, by the author of that report, of the conclusions arrived at in regard to the fungi infesting this tree, appeared in the Centralblat Fuer Das Gesammte Forswesen, of which the following is a translation:-

'In the study of these fungi great difficulty was experienced from the lack of works supplying what might be considered preliminary information; in the whole range of literature at command there was found only one reference to the subject, and this not in a German work, i,ut in one published in Denmark, where, within the last ten years, amongst many other foreign trees, the Pinus Austriaca has been experimentally planted on a considerable scale. In consequence of this the work had to be commenced $a b$ initio. 'To this in part,' says the author, 'may be attributed the very small number of fungi described. But this is attributable in a higher degree to the limited number of the parasitic vegetables which infest this tree. It has but a small number of fungi to show compared with the nearly allied species,--Pinus sylvestris, $P$. laricio, $P$. Corsicana, and, if people will, also $P$. maritima. It is especially deserving of notice that scarcely any of these fungi which bave of late years been declared and acknowledged to be the cause of the appearance of the most injurious diseases, and which have proved everywhere so destructive to the common fir, have thus far, notwithstanding the most careful search, been found on the Austrian pine. Such are the Trametes pini, occasioning the 
Rothfaule, or red-rot, of the fir; and the everywhere dreaded Trametes raciciperda, attacking especially the roots, and proving in the highest degree injurious ; and the Armillaria mellea, the "Hallimash," with its rhizomorpha form. Should these parasites not appear, and especially if they do not come in great numbers to infest the black pine, then will this tree be saved from one of the most dangerous assailants of such trees; and its value and importance will thus be greatly enhanced.

'It may be also confidently affirmed that, so far as observation and experience goes, the black pine harbours fewer parasites than do its nearest relatives; and of all known conifers it is the poorest in fungi, and consequently by far the most healthful. It would be too soon to pronounce a definite cpinion in regard to the cause of this remarkable and satisfactory fact. Probably several things may co-operate simultaneously to produce this effect: there is in all parts of the tree an extraordinary abundance of resin; there is a great deal of space between the trees in a forest of black pine; and there is a consequent exposure and desiccation of the soil, \&c. The well-known student of fungi, Baron von Hohenbuehl-Heufler, in accordance with what has been said, says:- "A forest of black pines is for the mycologist a Lasciate ogni speranza. voi ch'entrate-Let all hope be left behind by him who enters here."

'Proceeding to the consideration of the different species on which observations have been made, it may be premised that the parasites as well as the saprophytes* were brought under consideration; and this on the ground, on the one hand, that our knowledge of the black pine fungi must be brought fully up to the knowledge of the present day, and on the other hand, because the cases are increasing in numbers in which saprophytes, in the earlier stage of their

* Parasitic fungi are such as absorb their nutriment from living organisms, animal or vegetable; Saprophytes are those which find their nutriment in the remains of dead organisms, or from organic compounds produced by living organisms.-J. C. P. 
development, do damage as parasites to the plants which supply to them a lodging place.

"The Peridermium pini, Lev., or Kiefern-blasenrost, and the P. oblongisporium, Fuck., or Kiefern-nadelrost introduce us to the kinds spoken of; both stand in the nearest relationship to one another, and are treated by many students as of the same species.' A discussion of their specific characters would lead us too far at present; and the anthor considers it preferable to treat them in his work as distinct species. "The habitat of both is pretty well known to every forester ; everywhere are they of no rare appearance, both in forests of the white and of the black pine. Only is injury done, or can be done, by the Kiefer-blasenrost, when it comes upon the branches or trunks. It kills in young woods many young trees, and it produces rents in the trunks of old pines, when it finds a home either within or below the crown, producing the well-known appearance of the Krebses or Kienzopses. The Coleosporium senecionis, Lev., found upon different species of Senecio, it is generally admitted, is a peculiar propagatis of both species of Peridermium, and no further investigation of the fact appears to be necessary here; nor is it necessary to discuss further the innumerable well considered measures for the prevention and destruction of this fungus which have been proposed.

'Postia (Polyporus) destructor, Thuem, the Zerstoerende Loecherschwamm, vegetates abundantly on wood work in dwelling-houses, damp cellars, stables, manufactories, old palings, and especially on wood which has been for a long time exposed to the influence of humidity. As it by no means rarely grows in shady forests on the bark of firs, pines, and black pines, and this not only when they are felled or dead, the conclusion come to by some seems to be justified, that the infection takes place in the forest; and that when, at a later time, the wrought wood comes into an atmosphere heavily charged with moisture, with limited access to the open air, the mycelia to be found in the body of the wood produce a new fructification. The 
biological development of this fungus also points to such a conclusion. The developed fungus is found on the bark of the tree; through the bark it sends only single threads of mycelium, but these become developed into large skinny paperiike patches, measuring many centimetres; and by means of this subcortical growth the connection between the bark and the tree becomes extensively perforated with holes; through these the moisture gains access, and the bark soon crumbles off. Here the advice may be given, keep a watchful eye open for the first appearance of the postia in the forest, and remove as speedily as possible any trunks seized upon by it, and get these removel to a distance, and disposed of as firewood, guarding strictly against their being used as timber or for building purposes.

'A very similar development in the wood is seen in the Merulius seppens, Fr., Der Kreichende Holzschwimm, the nearest relation of the dreaded Hanssch-chwamm. Thus far positive observations are awanting, but in any circumstances it would be well that the practical forester should keep a watchful eye upon this species. Analagous are the relations between the Stereum pini, Fr., or Kiefernhartschiebe, and the Cenangium ferruginosum, Fr., or Rostbraunen Leerschuessel-that is to say, there is a possibility that eventually, in one of its development forms, it does damage to the plant on which it has found a lodgement. The investigations and experiments on this point have not yet been prosecuted so far as to warrant a decisive statement on the subject being given.

' By far the most destructive of the fungi infesting the black pine is the Lophodermium pinastri, Chev., the producer of the Schuette. This species in its parasitic injurious form, growing on the living leaves of the tree, has not as yet been observed in the forests of black pine in Austria; but it has bren seen in Denmark, where, as has been intimated, this tree has been largely cultivated. But on dead leaves there, as everywhere, the species is known and is cummon on all species of Pinus and of Picen. But 
though thus far Austria bas escaped a visitation of this dreaded guest, it is felt that there is not the least reason to suspect that it will be so always.

'According to the investigations of Rostrub, in Denmark (who for years, by commission from the Minister of Finance, has studied profoundly the diseases of forest trees in his fatherland), the course of the disease is more rapid, or more slow, according as the fungus infection makes itself seen only in spots on the leaves, or as it has found its way into the body of the tree. In the latter case the further development advances in one or other of two different ways-namely, first when the mycelium penetrates to the topmost shoots, after which the tree always immediately and completely dies; or, second, when the mycelium finds its way only into one branch after another, mostly first into the youngest, the half-developed or altogether undeveloped leaves of which soon assume a brown colour, and within a short time the whole tree takes on a white colouring. The mycelium (with the presence of which in the body of the tree earlier investigators were not acquainted), is at first entirely colourless; later, it becomes brownish. It penetrates first of all the outer and inner bark, but later it penetrates also the body of the tree, and spreads itself at last through the entire organism. After it bas pressed its way into most of the leaves, it prodices, often even in the year of its first appearance, what are known as Spermogonia, or reproductive organs, which everywhere break forth over the surfaces of the, by this time, blanched leaves. So long as the Schuette-pilz only records its presence in the first-mentioned way, while it only comes upon single leaves, but does not seize upon the trunk and the branches of the tree, so long may the black pine still continue in the fresh spring to develope new leaves, and so for a longer time present the appearance of a bealthy tree. But when, by and by, the disease gains the upper hand, and the mycelium once penetrates into the branches, so that from a distance one can see the state of the tree from the numerous brown coloured leaves, 
only a short time can intervene before the death of the tree.

'For a time, indeed, the still living tree, though greatly reduced in strength, may put forth some desperate endedvours again to vegetate, during which it may bring forth some abnormal short dwarfed branches, growing in what may be called a rosette-like form, which, it may easily be imagined, take on a quite original and strange appearance; but even in this case, though the death of the tree may be deferred for a short time, the lifetime of the tree is, and always remains, more or less limited.

'Of fungi doing but little injury, perhaps ultimately it may be found to be doing neither good nor harm to the trees affectcd by them, there are these-Phoma pinastri, Lev., or Der Kiefern-pustelscorf, P. erythrellum, Thuem., or Der Rothliche pustelscorf', and Leptostroma pinastri, Desm., or Der Kiefern-duennscheibling; we consider that, we may pass over these without further notice liere. But a few words must be given in regard to another, the Cladosporium fumago, Lk., or Russthau, although it also does but little injury. By the Russthau, as is generally known, is understood the appearance occasioned by numerous fungoid threads, which give to living plants, from trees and shrubs of every sort, down to the most minute herbs and grasses, and even to mosses, a look as if they were covered with soot. Many investigators consider the fungi in question as Saprophytes; others, among whom we take a place, see in them parasites, as observation shows that the appearance of them is not necessarily preceded by that of honeydew (which Fleischman holds to be a regular precursor), but the Cladosporium fumago especially can vegetate with extraordinary luxuriance without honey-dew. One may therefore reasonably infer that the Russthau fungus is a parasiric organism, which, if it do possess no haustorium, still finds nourishment from the plant on which it has found a home; and which may therefure assuredly be reckoned amongst the injurious species. It is especially the case 
that the Russthau always comes upon the black pine without any preceding honey-dew, and in so far as it is concerned, it is a parasite and no saprophyte. The injury done by it, however, is by no means great. One thing which therefore appears of importance is that, as up to this time no preventive or remedial measure has been derised for this often widespread epidemic producing fungus, at least none applicable to it in the open air, it must be left to jump about at its own sweet will, without man being able to interfere to prevent it.

' The most remarkable fungus infesting the black pine is one recently studied, and described in the reports on the Vienna forest, the Coniothecu. Austricum, Thuem., or the Austrian Staublanienpilz. Upon leaves still to a great extent greeu and healthy, but partially of a yellow hue, may be observed long patches, extending to the length of a centimetre, dirty brown in colour, with well defined edges, in the centre of which is found a correspondingly long, and proportionally deep, hollowed dark-coloured furrow. This furrow is for the most part filled with a dry resinous substance, on the surface of which grows a fungus mycelium, but neither on the bason nor sides of the furrow are any traces of this to be seen. The resinous substance is, probably through the combined influence of the atmosphere and of the fungus, of a blackish colour; and it exhibits growing spore-heaps on a poorly developed, creeping, brown mycelium. The constituent spores or cells vary in shape from a globular to a compressed elliptical form, and in position from solitary ones, to an agglomerated mass of numbers connected by short branching chains. This fungus, easily distinguishable from other species, was first discovered on sunny slopes not far from Liesing, in Lower Austria. There were here only remains of a former forest, consisting only of a number of decaying black pine perches, of about the height of a man, sending out from the ground shrub-like branches. The resinous furrows were found sometimes at the bases, sometimes at the points, 
of the leaves; but there was invariably only oue on each leaf. When the leaves, or at least a great part of them, were yellow, then the brownish patches so apparent on the green leaves were no longer to be seen, but instead thereof the whole leaf had taken on a similar colour, from which it follows that the disease in question, in a longer or shorter time, causes the whole leaf to wither and to die. The occasion of the appearance of the disease rests, in any case, on insufficient nourishment bringing about a disturbance in the vegetation, in which a rupture in the cuticle and the adjacent cell walls takes place. These latter are then also killed, and are absorbed in the extension of the brownish patches, and are intensely browned, while simultaneously with the rupture of the epidermis there occurs a great effusion of resin, which fills to the top the aforementioned furrows. But from this it follows that the origin of any disease appearing in connection with this fungus, does not lie in it, or in any other parasite, but must be considered a pathological incident. The Coniothecum must also be considered as only a pseudo-parasite, which does not induce any injurious change on the tree; but which from the first settles down upon the resinous secretion from a wound, when any such has been produced by some foreign influence; and which also, when it has taken possession of the whole surface of this, does not pass on to the portion of the leaf surrounding it, but satisfies itself exclusively with drawing its nutriment from the resin : never is any trace of mycelium to be found in the leaf. As, moreuver, experiments in endeavours to infect leaves with it yield nothing but a negative result, we may with assurance advance the conclusion that whatever appearances to the contrary may present themselves, Coniothecum Austriaca is not a fungus injurious to forests.

'We have, in this brief résume considered only the more injurious parasites, and this newly-discovered species Coniothecum Austriaca; all others being considered as Saprophytes, up to the present time at least, we have passed 
over. And thus has been made apparent how extremely limited is the number of species of fungi which are destructive to the Austrian pine. Serious injury is done to it only by the Peridermium pini and the Lophodermium pinastri, in so far as we have seen; injury of lesser magnitude and scarcely calling for consideration, is done by the Peridermium oblongisporium and Leptostroma pinastri, and also in the long run by the Phoma erythrellum and the Russthau. With regard to some kinds, as for example, the Hutpilsen, must the question in regard to injury being attributable to them be left undecided. Notwithstanding this, however, and considering that the most deadly malady of all, the schutte, has not as yet shown itself on the black pine in Austria, at this time the expression is quite justitiable-the black pine is one of the healthiest of forest trees in the land, and the one least injured by parasitic fungi.'

As has been stated in regard to the natural history and culture of the black pine, it may be stated here that this paper has been translated and inserted solely in illustration of how the pathology of trees is studied by foresters in conuection with the advanced forest science of the day. 


\section{P A R T I I I.}

\section{FOREST A D I N ISTRATION.}

Is all of the operations pertaining to forest conservation and economic exploitation, to sylviculture and reboisement, to which reference has been made in precediug chapters of this volume, there may be traced a desire to secure for the present and for succeeding generations the full benefit of the usufruct without detriment to the inheritance, the use of the forests without abuse or waste-literally, $\grave{a}$ tire et aire,-to obtain from the forests, and use the full quantity of their produce by growth within any specified period, a day, a decade, or a century, but to leave the capital undiminished. And the principle involved in the action taken in the exploitation of the forest produce may be said to be :Ascertain what the produce by growth is; use it all, but nothing more; make available all the information which professional students of the matter have amassed; if others than they must have the administration of what is State property, let the State administrators have the information, counsel, and aid of such at command; let nothing be done at haphazard: and put a stop to all malversations and all thieving; let all depasturing in the forests of flocks and herds which might do damage to the trees, either young or old, be stopped; and let all chance of fire be met with precautionary preventive measures; let all rights of usage and servitudes be respected, but so far as possible let them, by equitable arrangements, be extinguished; and let all State forests be treated as a trust estate, honourably managed, and made to yield to the generation in posses- 
sion all the benetit possible, without detriment to those who are to follow.

Such I understand to be the principles of modern scientific forest economy followed on the Continent of Europe.

But this improved system of forest management cannot be carried out without the assistance of men who are, by education, instruction, and training, able to take into view the whole case, with all its circumstances and all its conditions. In France, the wasteful destruction of forests which gave occasion for the preparation and promulgation of the famous Forest Ordinance of 1669 , was consequent on the alministration of the State forests by so-called noblemen and ecclesiastical dignitaries of high position; and it was traced to a great extent to their malversations, peculations, and illegal exactions. Amongst those who were found guilty of these were monks and bishops, sieurs, barons, marquises, and at least one duke, a peer of France, Procureurs de Roi, lieutenant-generals, superintendents, and at least one Grand-master des Eaux et Forêts, the head of the staff. And some idea may be formed of the maguitude of the malversations committed by them from the penalties to which these officials of high social position were subjected: besides restitutions, pecuniary penalties to the amount of 275,000 livres were exacted. All the officers and officials of Mouliere had to demit their offices, and they were declared incapable of holding any office, or discharging any function in the forests of the king; one, an official of a contractor, was 'condemned to do penance in his shirt-head and feet bare-a rope round his neck, followed by the public executioner, and holding in his hand a torch two pounds in weight, before the gate and principal entry of the Palais Royal of the city of Poictiers, and to be banished for ever from the county of Poictou and Guyenne.' A sergeant of the forests of the province of Alenson was condemned to the galleys; and the Master des Eaux et Forêts of Epernay was condemned to death.*

\footnotetext{
* Details are given in Firench Furcst Ordinance of 16,63 , with Historical Sketch, de. (pp. 13-34).
} 
In England it has long been the practice for nobles and princes of the Royal family, and sovereigns, to be appointed rangers of the Windsor Forest; and for well nigh half a century the office was held by the famous Duchess of Marlborough. She held the office from 3702 , when she succeeded the Earl of Portland, till her death in 1744, eighty-four years of age if not more, setting the Court at defiarice in a very termigant fashion. She was succeeded by William, Duke of Cumberland; by Henry Frederick, Duke of Cumberland; by King George III. ; by King William IV.; by the late Prince Consort; and by H.R.H. Prince Christian.* And in British Colonies. as at the Cape of Good Hope, the practice of appointing district magistrates and civil commissioners to be conservators of forests, and field-cornets to be forest warders, has long been the practice.

The existence of gross abuses in the management of Crown woods and forests of England, similiar to what prevailed in France well nigh 200 years before, was brought to light by evidence collected by a Committee of the House of Commons in 1848 and 1849, and printed by command of the House. Cases of reckless waste in the exploitation of forests in the Colony of the Cape of Good Hope, and of depredations which should not have been tolerated, came under my notice, and were reported by me to the Executive and the Legislature, in a Memoir on the Conservation and Extension of Forests as a means of counteracting the disastrous consequences following the destruction of busle and herbage by fire, appended to the Report of the Colonial Botanist for 1863; in Memoirs on the Forests and Forest Lands of South Africa, and on 'The Forest Economy of the Colony, abstracts of which were appended to the Report of the Colonial Botanist for 1866 ; and in evidence given by me before a Select Committee of the Legislative Council of the Cape Colony, appointed 14th August 1865, to consirler the Colonial Botalist's Report; and after I harl left 
the Colony similar evidence was collected by a Commission appointed by the Government.

With the introduction of exploitation of forests according to Die Fachwerke Nethod-La Methode des Compartiments -it was found expedient to modify considerably the arrangements existing in some countries for the administration of State forests; to educate, instruct, and train men specially for the conservation, exploitation, and extension of forests ; to provide appropriate salaries for their remuneration; and to give to Mlinisters of State entrusted with the administration of State forests the command of the advice and service of these educated foresters, And to provide instruction and training for these educated foresters, Schools of Forestry have been established in almost every country in Europe. In a notice of this fact which appeared some time since in the Times, it is stated :-

'So much interest has been excited by the recent discussions on the subject of forestry, and by the fact that England alone of all European nations possesses no School of Forestry, that the following résume of those now in operation on the Continent may be useful. Austria heads the list with nine schools-viz., the Imperial High School of Agriculture and Forestry at Vienna, with six professors and 329 students; the Eulenberg School, with six professors and 50 students, the course lasting two years; the Weisswasser School, with five professors and 80 students; the Lemberg School, with 12 professors and 40 students; the Aggsbach School, near Melk, with two professors and 24 students; the course of forestry in the technical high school of Gratz; the Styria Forest Culture School, with three professors and 26 students; the Carinthia School; the Vorarlberg School. Prussia has three institutions, commencing with the Royal F'orest Academy at NeustadtEberswalde, with a director, 14 professors, and other assistants. The course is $2 \frac{1}{2}$ years, and the number of students about 57. The Muinden Royal Forest Academy has a 
director, 10 professors, and 78 students. The Forestry School at Grosse-Schönebeck and the forestry courses to the Army Forestry Battalion are for the training of lower forestry officials. At the former school are four professors, at the latter eleven, all of them practical foresters. Saxony has an excellent forest academy at Tharand, with ten professors and assistants. In Wurtemburg instruction is given at the Royal Agricultural Academy at Hohenheim and at the University of Tübingen. In Baden the forestry department of the Carlsruhe Polytechnic has 40 students. Bavaria has a forest academy at Aschaffenberg, with a director and seven professors, in addition to which are six chairs of forestry in the University of Munich; Hesse-Darmstadt has a forestry institution attached to the University of Giessen ; and Saxe-Weimar has possessed one since 1808, with a director and four professors. In Switzerland the department of forestry forms the fifth division of the Federal Polytechnic School at Zurich, in which are 30 students. France possesses a School of Forestry at Nancy, and one of forest guards at Barres, in addition to several agricultural schools and agronomic industrial schools, in which forestry is taught. Russia has four schools - viz., the Agricultural and Forestral Academy at Petrovsk, near Moscow, the Agronomic Institute at St. Petersburg, with courses in sylviculture; the Forest School at Lissino, and the Forest Division of the Agricultural Institute at New Alexandria. There is an Italian School of Forestry at Vallombrosa; a Spanish School of Forest Engineering at San Lorenzo del Escurial, near Madrid; a Danish school, attached to the Royal Veterinary and Agricultural College at Copenhagen; and a Swedish forest institute at Stockholm, besides 13 private elementary schools. In the United States forestry is taught in the State Agricultural College at Lansing, in Michigan State, which possesses a good labelled arboretum and a large collection of native and exotic trees under cnltivation. Great Britain alone, which needs more attention than any country in the preservation of what forests she has left, possesses no school whatsoever.' 
The education, instruction, and training given in these Schools of Forestry is of the most comprehensive character, being unsurpassed in this respect by any arrangements for professional studies in Britain. In illustration, I might cite at haphazard the published programme of study at any one of them. I take that of Spain.

In Spain the School of Forestry bears the designation La Escuela Especial de Ingenieros de Montes (The School of Mountain Engineers). In France not a little has been done by les Ingénieurs des Ponts et Chaussées (or the Engineers of Roads and Bridges), in carrying out, in connection with officers of the Forest Service, the reboisement of the mountains, or the replanting of them with trees, \&c., with a view to arresting and preventing the destructive consequences and effects of torrents. The designation of the Spanish School of Forestry indicates that something similar to this is the main and the special duty of the corresponding body of engineers in Spain. Their duties relate primarily and especially to the creation rather than to the exploitation of forests. The school is located in the old palace of the Escurial. It is under the control of the Minister of Instruction; and it is regulated under a decree issued under date of $24 \mathrm{th}$ October 1870 . Under a previous decree, of $23 \mathrm{rd}$ October $186 \mathrm{~S}$, the prescribed course of study embraced a period of three years. By that now in force the curriculum has been extended to embrace a period of four years.

In order to gain admittance to the school, the applicant must be accredited by certificates or diplomas of having passed an academic examination in the following subjects, -Spanish grammar, Latin grammar, geography, and the general and detailed history of Spain; and he is admitted only after passing, with approval, an examination in the school on the elements of natural history, the elements of the theory of mechanics, descriptive geometry and its application to projections and to perspective, physics, chemistry, lineal, topographical, and landscape drawing, and his knnwledge of the French and German languages. 
Every year there are issued p"ngrammes specifying the subjects on which applicants for admission must be prepared to be examined. According to the programme for the year 1877, the one I happen to have before me, the preliminary entrance examination through which applicants must pass embraces amongst others the following subjects:-Theory of mechanics; the general principles of statics, and their application to the determination of the centre of gravity; the general principles of dynamics, including inertia, momentum, reaction, vital force, movements of points and movements of bodies under varied conditions, and the establishment of equilibrium. Descriptive geometry; its application to projections and perspective, embracing points, straight lines, circles and planes, triangles, polyhedrons, sections and intersections of these, tangents, cylinders, cones, lines of revolution, involution, plane and conic sections, the projection of shadows, and the geometrical laws of perspective. Physics: properties of bodies, gravity, specific gravity, characteristics of solids, of liquids, capillarity, gases, atmospheric pressure, elastic force of bodies, flotation, and temperature. Accoustics: propagation of sound, and distinctive characters of sound. Heat: expansion of bodies in a solid, a liquid, and a gaseous state, and operations by which it is affected ; hygrometry, and transmission of heat. Optics : propagation of light, photometry, reflection from plane and curved surfaces, refiaction and dispersion of rays, structure of the eye, optical instruments, double refraction and polarization of light. Electricity and magnetism : static electricity, distribution by conductors, measure of electric force, magnetism, dynamic electricity, electro-magnetism, electro-telegraphy, thermoelectric currents, electric induction. Meteorology: thermometrical observations, winds, aqueous phenomena, electric phenomena, luminous phenomena. Chenistry: chemical notations, combining proportions, theory if chemical equivalents, specific heat, atomic theory, metalloids and their more important compounds, other clemen- 
tary bodies, the more important combinations of hydrogen, combinations of oxygen with other quasi-elements, fluorate of silica, carburetted hydrogen, cyanogen, general properties of metallic and other salts, special study of the more important metals and their compounds. Natural history: distribution of existing bodies in groups and kingdoms, distinctive characteristics of species of organs, apparatus and functions, mode of studying minerals and determining their production, composition, and importance, crystallography; classification, nomenclature, and chemical properties of minerals. Botany: structure and forms of vegetables, organs of vegetation, roots, stems, leaves, with their variation and arrangement, and effects of this on ramification; flowers, inflorescence, calyx, corolla, stamens, pistils, and ovàry; fruits, seeds, vegetable physiology, nourishment and growth, reproduction, classification, and specification of properties common to classes of plants. Zoology: difference between animals and vegetables, animal structure, organography, and physiology ; classification proposed by Cuvier and modified by Milne Edwards ; characteristics of mammiferæ, with description of the principal families of rodents, of pachydermata, and of ruminants; characteristics of birds, and description of the principal families of gallinaceous, of wading, and of webfooted birds; characteristics of fishes, and description of the principal families of soft finned fishes; characteristics of the principal families and the more remarkable grenera of the coleoptera, of the orthoptera, hymenoptera, and lepidoptera; and the geographical distribution of animals, with causes influencing this.

On these subjects the candidate for admission is examined before he can enter the school. He is free to pass through these preliminary studies when he pleases, and there are specified works on the several subjects, from which information preparatory to examination may be obtained.

It is stated that in the examination in drawing there will be requirel manifest facility ${ }^{\circ}$ in copying correctly an 
order of architecture, or a machine; some model drawing of a landscape in Les Etuds d'après Nature, by Calame, and a pen-and-ink representation of mountains, sands, rocks, and arable land, according to the method of Rindavets. And in French and German are required correct translations from these languages into Spanish.

Application for admission must be made previously to the 1st of September in any year.

It is not requisite that the applicant should be examined in any one year on all of the subjects embraced in the entrance examination, and he is required to specify those on which he desires to be examined. If he pass any examination with approval, this will be certified, and when he has been examined in all with approval he will be admitted, and enter on the special studies of the school, which embrace the following subjects:-Physical geography, land surveying, mensuration of wood, applied mecluanics, applied chemistry, applied mineralogy, applied - botany, applied zoology, applied geology, laying out of forests, sylviculture, meteorology, and climatology ; mountain geography and classification of mountains; forest industries; political economy, with a special reference to its application to forest questions; elements of the administrative direction of forest management; and drawing in its application to the course of study required.

For conducting these studies there are appointed a director, who is head of the school ; nine professors, of the body of engineers; two assistants, who must also be engineers; and to these are joined the following subordinates :-A collector, preparer, and conservator of objects of natural history; an official assistant secretary; an official assistant librarian; two clerks; a steward; a resident in charge of the school forest; a porter; three servitors; necessary warders and subwarders for the protection of the land and momatins appropriated to the service of the school ; and labourers and peasints rerpired for work on the same. 
The instruction is given (1) by oral lectures and lessons in drawing by the professors; (2) by written exercises, calculations, ard analyses on the subjects embraced by these lectures; (3) by the detailed study of the animals, rocks, plants, and forest products which constitute the collections and adjuncts of the establishment; (4) by the practice of topography, land surveying, the study of natural history and of mountains in the field; (5) by excursions to the plantations and mountains.

The school sessions extend, with specified holidays, from the 1st of Ostober of one year to the 31st of May in the year following. Field exercises are included in this session; but according to what may be required in different classes these may be extended over the months of June, July, and August.

The material provisions for study are specified as consisting of the buildings, lands, forests, nurseries, gardens, and their dependencies; appropriated to the school is a meteorological observatory ; the furniture of the institution, a library and collections of charts and drawings; a laboratory and cabinet of chemistry, with apparatus and re-agents; collections and museums of topography, land surveying, and cabinets of illustrations of natural history, of mountains, of mechanics, and of forest industries; the collection of iron implements employed in the practical working of the school lands or in the study of the pupils; herbaria and collections of plants and of fruits; and in conclusion, the workshops and machinery, with all the iron tools belonging to these, and the equipments and arms of the warders and dependents.

The students do not live in the school. Each is required to lodge his address with the secretary of the school, and to keep him informed of any change of residence made by him. They are required to supply themselves with all text-books, mathematical instruments, writing and drawing implements, and the uniform enjoined upon students; but beyond this I know of $\mathrm{n} n$ pecuniary charge made upon them. Regular and 
punctual attendance, studious attention, and respectful and orderly behaviour are enjoined.

Occasional absence, even with consent of the instructor, want of punctuality, inattention, \&c., are punished by deductions from the numerical value attached to the attendance required in order to obtain a diploma at the close of the course; disobedience, insubordination, \&c., are punished by expulsion or suspension till the decision of the Government is obtained.

The programme of study in the School of Forestry of Spain has been taken by me-I may almost say at haphazard-from among a dozen of others in the bookcase before me. Almost any one would have given correspondent results. The following are several at command for comparison wherein they differ :-

In The Schools of Forestry in Europe: a Plea for the Creution of a School of Forestry in connection with the Arboretum at Edinburgh, are given details, more or less explicit, of arrangements at Aschaffenburg in Bavaria, pp. 13.16; at Schools of Forestry in Russia, pp. 17-22; in Stockholm, pp. 23-29; at Nancy in France, pp. 30-45. It The Journal of Forestry, vol. $i_{\text {., }}$ is given iuformation in regard to the course of study followed at Hohenheim in Wurtemburg, pp 81-87; at Carlsruhe in Baden, pp. 394-398; and at Evois in Finland, pp. 545-557, 701-707. And in regard to this last additional details are given in Finland: its Forests and Forest Management, pp. 147-174.

In accordance with the academic attainments of which such a course of study and such examinations can guarantee is the status assigned to forest officers. They take rank with military men, and other Government officials of recognised social position; they have an official uniform; and in one country at least they draw a higher salary than that accorded to lnilitary men of corresponding rank, which higher salary may be some coupensation for the monotonous life they lead in the forest, while the 
military man has access to the gaities of city life, and the excitement of the military station.

The depressing influence of continuous life in the forest is, I have been told, very considerable-day after day, month after month-trees, trees, trees everywhere-trees and shade, trees and shade--shade which reminds one of the expression the valley of the shudow of death. In most if not in all of the Schools of Forestry the students are trained in the use of the rifle. At one institute I asked why this was done seeing that the students would be exempt from military service. The answer was " partly to enable them to shoot game for the maintenance of their household; but also partly to fit them for finding relaxation in the chase, when they may feel lonely in their forest home'

In accordance with the salary and social position assigned to forest officials on the Continent is the salary assigned to officials in the forest service of India, and in that of the colony of the Cape of Good Hope and other British dependencies.

Amongst Hebrew apothegms which have come down to us, there is one to the effect, There is that scattereth, and yet increaseth; and there is that withholdeth more than is meet, and it tendeth to poverty; and another to the effect, The liberal heart deviseth liberal things, and by liberal things shall it be established, or stand. Illustrations of large returns having been obtained from liberal expenditure judiciously applied, is supplied by the history of forestal operations in India during the last five-and-twenty jears. Reference has been made [ante p. 39] to distress having been occasioned in India through a great destruction of wood in connection with railway operations there, when these were begun. The cunsideration of this gave a great impulse to a movernent which had previously been initiated to secure the conservation and extension of woods in different parts of India. Interesting and valuable information in regard to this, and to the earlier operations, is supplied in a 
volume entitled The Forests and Gardens of South India, by Hugh Cleghorn, M.D., F.L.S., Conservator of Forests, Madras Presidency, published in 1861. Subsequently, the operations in question came extensively under the lire: tion of Dr Brandis; and through his exertions arrangements were made to get aspirants for employment in the Forest Service of India trained at one or other of two Schools of Forestry in Hanover and France; and liberal arrangements were made for meeting the expense of the training and the remuneration of such. The expenditure became very great, but so did the returns.

The following will show what are the requisites for employment in the Forest Service of India :-

Under date of July 1872, were published the following particulars respecting the selections of candidates for nomination to junior appointments in November 187.2 , in the Forest Department in India:--'An examination will be holden on the 18th day of November 1872, and following days, to select five young men, if so many are found duly qualified, to be trained in France and Germany for the Forest Service of India.

'Applicants must be natural born British subjects, above 17 and under 23 years of age on the 18 th of November 1872. They must be unmarried, and it they marry before they leave this country for India, they will forfeit their appointment as Junior Assistants.

'They must send to the Revenue Department of the India Office, on or before the 14th of October next-

'1. Their names and parentage, a certificate, or other satisfactory evidence, of their birth, and, if under age, a statement of consent from parents or guardians.

'2. A statement of the places of education at which they may have been since they were nine years old, accompanied by testimonials of good conduct during the last two years, and proof of their having attained a certain standard of proficiency in the following branches of knowledge :--(1) English writing from dictation, and English 
composition. (2) Arithmetic in all its branches. Algebra, elementary principles, simple and quadratic equations, ratios and proportions, logarithms, arithmetical and geometrical progression. (4) Geometry (1st, 2d, 3d, th, and (ith book of Euclid), and Plane Trigonometry. (5) Freehand drawing. (6) A good colloquial knowledge of French or German, with the facility of translating from une of these languages.

'A preference will be given to those candidates who, in addition to the above, show proficiency in surveying and land measuring; and in the elements of mechanical and natural philosophy, chemistry, botany, geology, and mineralogy, and in plan drawing.

'They must appear personally at the India Office on the 18th or 19 th of November next, between the hours of 11 and 4 .

'As active habits and a strong constitution are most important, such applicants as are admitted to be candidates will be directed to appear for medical examination before the Indian Medical Board.

' Those who are passed by the Board will be examined ou the 21st and following days in the various brauches of knowledge mentioned above, by the Civil Service Commissioners.

'The regulations above stated are liable to alteration in future years; but no candidate, in this year, or hereatter, will be chosen who does not come up to the requisite standard of proficiency in each of the prescribed subjects.

'From among the candidates who attain this standard, Her Majesty's Secretary of State for India will select those whom he deems best adapted to the Service.

'The rules and conditions under which candidates for the Forest Service in India will in future years be selected will be notified hereafter.

- The candidates accepted by the Secretary of State must undergo a regular course of training of two years and a-half in the management of forests and the science of forestry, in surveying, road making, and the natural 
sciences. For this purpose, those candidates who possess a sufficient knowledge of German will be directed to proceed to Germany; while, for those who pass in the French language, the course of training will be in France, if the state of affairs in that country admits of their being sent thither. Until such time, they are to understand that their appointments may be kept in abeyance, or that they must subject themselves to such other training in this country or elsewhere, as the Secretary of State may direct.

'The course of training will commence on the 1st March 1873, and end in the autumn of 1875 .

'During the course of training the candidates will be expected to conduct themselves throughout in a proper and gentlemanlike manner, to obey the injunctions of the officers and professors appointed to instruct them, to use due diligence in the practical work and in their studies, and zealously to improve every opportunity for learning that may be offered them. Candidates who do not conduct themselves in a proper and gentlemanlike manuer, or do not show satisfactory progress in their studies, will be removed, from the list of candidates on the report of the officer intrusted with the general direction of their studies.

'After completing the course prescribed, an examination will be held by the officers and professors intrusted with the instruction of the candidates. Those who give proof of a satisfactory progress in the subjects in which they have been instructed will be nominated Junior Assistants in the Forest Departments in India.

'According to the estimates framed, the cost of this training will not exceed $£ 500$. This sum will, it is believed, cover the cost of board, lodging, and instruction for the whole term of two years and a half.

'To those candidates whose progress and conduct are satisfactory, Her Majesty's Secretary of State engages to pay a stipend at the rate of $£ 50$ for each half year. This stipend will ordinarly be paid half-yearly, on the recom- 
mendation of the officer intrusted with the general direction of the studies and training of the candidates; but the periods of payment may vary according to circumstances. In the case of those training in France, the first payment is usually made after eight, instead of after six months. One half of the stipend, or $£ 2.5$ for each half year, will be retained for payment of the fees and remuneration to the appointed Instructors.

'In the interval between the conclusion of the course of instruction on the Continent and the departure for India, the candidates will be required, if they have not had the opportunity of doing so before, to pass some time, probably not less than month, with one or more approved foresters in Scotland.

- Within a month of his nomination as Junior Assistant, each nominee must sign a covenant, in the form appended hereto, describing the terms and conditions of his appointment; and he must embark for India when required to do so by the Secretary of State, who will provide for the expenses of his passage. Any nominee not embarking when required will forfeit his appointment. Otherwise he will be allowed pay at the rate of 250 rupees (which is about the equivalent of $£ 25$ in English money) a month, from the date of his signing the covenant.

' On arrival in India, the nominee will be required to report himself to the Government of India (or to the Government of Bombay or Madras, in case he should be sent to one of these Presidencies), and he will then be posted to such part of the forests as the service may require.

"The salaries of the appointments in the three Presidencies range between $£ 300$ and $£ 1,900$ a year. Promotion to them will depend upon efficiency, and the occurrence of vacancies.

- On reaching the place to which he may be appointed, the nominee will become entitled to all the rights and privileges, in respect of pay and promotion, accorded to officers of the Forest Department by the rules and regula- 
tions for the time being, and to leave of absence and retiring pensions under the leave and pension rules of the Uncovenanted Service for the time being. No rise of pay or promotion will, however, take place before he has passed an examination in such one of the native languages as may be prescribed by the Government under which he is serving.

'There will be another examination for five candidates in November 1873, when the present system of training for the Forest Department in India will come to an end.'

In the statement issued in 1867 it was prescribed:'Those of the candidates who will be selected by Her Majesty's Secretary of State for India must agree to undergo a regular course of studies and training of three years and a half in the natural sciences, in the practice and science of forestry, and in those branches of surveying and engineering required for the profession of a forest officer in India. The first, or purely scientific part of this course of training will take place in Great Britain; for the second part, comprising the instruction in forestry and the subjects immediately connected therewith, arrangeinents will, for the present (until an efficient forest school ii Great Britain or in India shall have been established), be made on the Continent, that is, in France for thosc candidates who are sufficiently acquainted with French, and in Germany for those who are familiar with the language of that country. One year and a half is assigned to the first or purely scientific part, and two years to the training in forestry and the subjects intimately connected therewith. The following are the arrangements to be followed by candidates, but Her Majesty's Secretary of State reserves to himself the right from time to time to make such alterations in the course of studies and training as may be expedient.

'The studies of candidates during the first or scientific part of their training shall comprise the following subjects :- 
'I. Mechanical and Natural Philosophy.-The elements of mechanics, hydrostatics, hydraulics, optics, heat, climate, rainfall, and the first elements of electricity and magnetism.

'II. Chemistry. Inorganic. - The non-metallic elements and the principal metals. Organic.-Elements only, with special reference to the chief collstituents of the vegetable and animal organism, the chemical principles of the process of nutrition and of respiration in plants and animals. Fermentation, decay, putrefaction, destructive distillation.

III. Botany.-Characters of the principal European natural orders. A.bility to describe any common phaenogamous plant of ordinary structure, systematically and with accuracy, from a living specimen. The elementary facts referring to the development and nutrition of plants.

'IV.-Geology.-Elementary portions of descriptive geology.

'V. Either the French or the German language. Good colloquial knowledge, with the facility to read and translate into English easy passages taken frum the works of some classical writer.

' Candidates are at liberty to choose the place of study, but they must, before being admitted to the second or practical part of instruction, pass an examination before the Civil Service Commissioners in the branches of science and in one of the languages enumerated above. This examination will be held in July or August 1869, and the candidates must, on the day previous to the examination, report themselves at India Office, and prociuce testimonials from the professors or masters under whom they have been studying.

' Candidates who fail to pass the examination in sciences and one of the languages at the close of the first year and a half, may continue their studies for another year but they will not be allowed to present themselves more thim twice for this examination. 
'Those candidates who fail to satisfy Her Majesty's Secretary of State that they have attained a sufficient proficiency in the subjects mentioned will be removed from the list of candidates.

' Those candidates who, from previous study, feel themselves competent to pass the second or science examination at the same time as the first, or examination for admission, will be permitted to do so. Application for doing so should be made by them when sending in their papers and testimonials.

'Candidates who have taken academical degrees or honours in science and mathematics will, wholly or partially, be excused from the examination of ardmission, as well as the examination in sciences, and only be required to furnish proof of a sufficient knowledge of German or French. Candidates who have passed any examination requiring a sufficiently high standard of proficiency will be excused examination in those branches in which they have been previously examined. Her Majesty's Secretary of State for India will determine how far the certificates of candidates may entitle them to exemption, either entire or partial, from examination.

'It is very desirable that candidates should, before proceeding to the Continent for their professional training, devote two months to a practical apprenticeship with an approved wood manager or forester in Scotland. Early spring is the best season of the year for this purpose. A certificate of their having done so will entitle them ts a stipend of $£ 20$, to be paid in case they pass the science examination.

' The course of training in forestry abroad will commence on the 1st September 1869, and be concluded on 1st September 1871.

'The following' arrangements have been made for those candidates who are qualified in French. They will proceed to Paris and report themselves at the "Direction Générale des Forèts." The months of September and Octoher will be spent in a forest district for preliminary 
practical training. By the 1st November they will proceed to Nancy, where they will be received as students at the Imperial Forest School, and pass through the regular biennial course of studies, practical exercises and periodical examinations with the French students. The whole expense of their residence in France has been estimated at 300 francs per month, or $\$ 144$ per annum. The instruction is gratuitous.

'No entrance fees are paid at the schools. A small remuneration may have to be paid in addition to the above sum for the preliminary practical training.

' Those candidates who possess a sufficient knowledge of German will proceed to Hanover and report themselves to Mr Burckhard, the director of forests in the former kingdom of Hanover, who will undertake the general direction of their studies and practical training.

'During the first year the candidates will be placed with an executive forest officer in charge of forest district (Oberforster), where they will serve their apprenticeship in the practical work of a forester, and at the same time receive instruction in the science of forestry. The director will from time to time see them, and they will occasionally accompany him on his tours of inspection.

'During the second year the candidates will live at Hanover, where they will continue their studies in the different branches of the science of forestry, as well as in surveying and engineering, in so far as may appear requisite for a forest officer in India.

'They will occasionally accompany the director, or others of the principal forest officers, on their journeys of inspection, and will from time to time be sent to different forest districts, to become acquainted with the different kinds of forests, and the various methods adopted for their management. Should such hereafter appear expedient, the time assigned to Hanover may be spent at a forest school, as may be arranged by the director.

' The whole cost for maintenance and instruction during their studies in Germany has been estimated at 100 
thalers per month, or $£ 180$ per annum. This includes all remuneration paid for instruction.'

Such were the arrangements at the time specified. They are substantially the same still. By many it is held and argued that an equally good appropriate and efficient education, instruction, aud training, might be obtained in Britain, if there were established a School of Forestry in connection with some one or other of our existing educational institutions; that this might be done at much less expense; and that probably an expenditure not exceeding what is at present incurred in the European preparation of candidates for employmeni in the forest service in India might, if judiciously applied, cover the whole expense of maintainning such a school for the iustruction of candidates for employment in the forest service of India, and the forest service all the world over. But at present we have only to do with the expenditure which is at present incurred.

A large measure of the expense of the education of the officials is met by Government; a larger measure of the expense of nutfit and passage to India is met by the Government; and their salaries, exclusive of allowances, range, as has been stated, from $£ 300$ to $£ 1,900$ a year.

The expense has been considerable, but the results liave justified the steps taken. By progressive amelioration of their condition, forests in India have risen greatly in value and they have been vastly extended, and the revenue from them has been increased apparently by hundreds of thous inds of pounds. According to Resolution of Government of India, Financial Department, No. 2012, dated 11th March 1871, the latest to which I happen to have access, the estimated charges for the following year 1871-72, as settled in the Public Works Department, and as modified in the Einancial Department, were $45,11,000$ rupees $(£ 4.51,100)$, anıl the receipts, $57,32,200$ rupees $(\mathfrak{f 7} 73,220)$, showing it surplus of revenue over expenditure of $12,21,2(0)$ rupees 
(£122,120.) I learn that in the year 1873-74 the forest revenue was $£ 700,000$, and the expenditure $£ 414,000$ odds, leaving a surplus of $£ 285,000$, both revenue and expenditure being about double what they were in 1874-6.5, ten years previously. All which had been accomplished not by an impoverishing of the forests, but by a progressive amelioration of these, and an increase of their pecuniary value in something like a corresponding ratio.

In illustration of this latter allegation, I cite the following statement, made by Captain Campbell Walker, in the paper On State Forestry: its Aim and Object, read before the Otago Institute, Dunedin, 21st December, 1876 :

'The Chunga Munga plantation, in the Punjab, has an area of 7,000 acres, commenced in 1865 , contains chiefly Indian blackwood (Dalbergia sissoo.) The expenditure up to end of 1873 had been $£ 26,000$, including $£ 5000$ spent during the first five years in unsuccessful experiments; $£ 5000$ had been received from petty thinnings (firewood and minor produce, grazing dues, \&c.) From a careful valuation, and calculations made in 1873 , it is estimated that the expenditure up to 1881, when the capital account closes, will be $£ 97,000$, and the value of the plantation be then $£ 170,000$. In considering the above results, it must be borne in mind that the rainfall in the district is under 15 inches, with great heat in the summer, and sharp frosts in winter. The whole plantation has to be irrigated from a neighbouring canal, being debited with a charge of $4 \mathrm{~s}$ per acre per annum for the use of the water alone. Another important fact must be mentioned, viz., that, whereas the land on which the plantation stands was formerly almost valueless, and would not fetch an annual rental of $2 \mathrm{~s}$ per acre; $12 \mathrm{~s}$, or even $20 \mathrm{~s}$ per acre is now readily obtainable, and the former has been offered for the whole or any portion when cleared. The rents mentioned, of course, include the water-rate of $4 \mathrm{~s}$ per acre per annum. This plantation is intended eventually to cover 30,000 acres, and will undoubtedly prove a great success, both as 
regards direct financial profit, a supply of timber or firewood, which is much required, improving the soil, and rendering it fit for cultivation with cereals, and ameliorating the climate. The Nelamber tea plantations, in Madras Presidency, cover 3000 acres, the oldest portion having been planted thirty years ago. The total expenditure, including purchase and lease of some 19,000 acres of land from a native raja, has been $£ 30,000$, and the receipts from thinnings \&c., $£ 10,000$. These plantations were valued last year at minimum rates at $£ 150,000$, and Col. Pearson, lately officiating as Inspector-General of Forests in India, estimated their value, when mature, at no less than two millions sterling.'

\section{Conclusion.}

It may be that some of my readers, and others who have not read, but only glanced at the preceding pages, may be ready to say,-This is not the kind of Introduction to the Study of Modern Forest Economy which we expected; and it may be so. Disappointment may be expressed and felt that little or nothing has been said about sowing, and transplanting, and pruning, and thinning, and felling, and cutting up, and transplanting, and selling, and the economic applications which are made of forest products. Such is the case; and one very simple reason for this may suggest itself: These operations, though carefully studied and treated of in the Modern Forest Science upon which Modern Forest Economy is based, are by no means peculiar to this; they pertain to Arboriculture as well as to Sylviculture; there is no lack of information in regard to all of them in volumes appropriated to the special discussion of them, and it is not an exclusively Arboricultural Exhibition to which those for whom this volume has been prepared have been invited; but an International Forestry Exhibition, and in view of this it has been prepared. Therefore have the subjects treated of been brought under consideration, and not those others 
to which allusion has been made, the importance of which is fully realised.

The Exhibition having been designed by its promoters as a means of 'promoting a movement for the establishment of a National School of Forestry in Scotland,' this has not been lost sight of in the compilation of the information embodied in the volume. And it is hoped that, while the possession of this information may enable readers of these pages to look more intelligently upon many of the objects which may be exhibited, it may prompt them to aid in the accomplishment of the ulterior object of the promoters of the Exhibition.

At a meeting of the Society of Arts, held on the 1st March 1882, a paper On the Teaching of Forestry was read by Colonel G. F. Pearson, resident at Nancy to superintend the education there of candidates for employment in the Forest Service of India; in the conclusion of which paper, after having described some of the Crown forests and private woods of Britain, he said :-

'It is impossible to speak too highly of the admirable work done by the able men who have created these forests at Scone, Blair Athole, Dunkeld, in Strathspey, on the Findhorn, and at Beauly, in Scotland, as well as in some of the English Crown forests. In our Colonies, including India, there are millions and millions of acres of forest land, some of which is of the greatest value, so that Great Britain is perhaps the country most richly endowed in forest wealth, of all the countries of the earth. Every one, not only in our own country, but elsewhere, is interested that all this great forest wealth should not be wasted or frittered away by a single generation of men. But, nevertheless, what is the future of all the forests? I have visited many of them, and scarcely anywhere did I see any of that young growth which are the links uniting the forest now on the ground with that of the future. Can any one say, then, that the future of these forests is assured? As at present they exist, one of two conditions must befall them. Either they will be cut down and the 
timber sold, or they will in due course perish naturally, and disappear of themselves. In either case the result is deeply to be deplored, for when once a forest disappears, it can only be replaced at a great expense of time and money.

'It is for this reason that I am here to advocate the establishment-be it on the smallest scale even, to commence with-of some system of national instruction in scientific forestry. Hitherto, we have been entirely dependent on Continental schools for this training, and at the present moment we have officers of the French forest service, who have been lent to the British Government, at the head of the forest administrations both at the Cape of Good Hope and at Cyprus. It seems, then, time that some stir should be made to help ourselves in this matter. It would, perhaps, suffice at first to establish a course of lectures on forestry at one of our public educational establishments, at which young men desirous of following a forest career might attend; provision being made for their instruction in practical work, if possible, in our own Crown forests, but otherwise, in some of the State forests on the Continent. It might be hoped that the Indian and Colonial Governments would, as an encouragement, place some appointments in their forest services at the disposal of young men so educated.

'As a proof of what has been already effected in India by the forest officers educated in the Continental schools, I may $m$ mntion that in that country there are at the present date 9,820,000 acres of reserved forests, the whole of which are managed generally on the principles above detailed, and 2,493,000 of which are protected from fire, as well as cattle and sheep grazing, and, consequently, are now in a condition to reproduce themselves under the natural system; and as, perhaps, the most convincing proof, from a practical point of view, of the value of the system, I may a ld, that the forest revenue of India, which in 1870 was only $£ 357,000$, with a net revenue of $£ 5 \%, 000$, in 1850 reached $£ 54.5,000$, with a net revenue of $£ 215,000$. 
That is to say, the revenue had increased 56 per cent., while the charges had only increased 8 per cent.

'In South Australia a serious commencement has been made in the right direction also. By an Act passed in 1873, the sum of $£ \dot{2}$ per acre is paid to land owners, in certain districts of the colony, to form plantations of trees. In 1875 , a Forest Board was constituted, as certain districts of the colony were formally defined as forest reserves. In 1878 a Forest Act was passed, and a conservator of forests (Mr Brown) was appointed. Last year about a quarter of a million trees were planted out, and the forest revenue amounted to $£ 6,517$ - of which $£ 1,380$ was for timber sold-against an expenditure of $£ 6,200$.

'If, then, so much has been done by the Indian and Colonial Governmests to secure the future of their forests, can nothing be accomplished at the headquarters of the Empire? This is the question now before us, and I trust that it may be answered by instituting a course of instruction which may eventually develope into a forest school for Great Britain.'

THE END. 



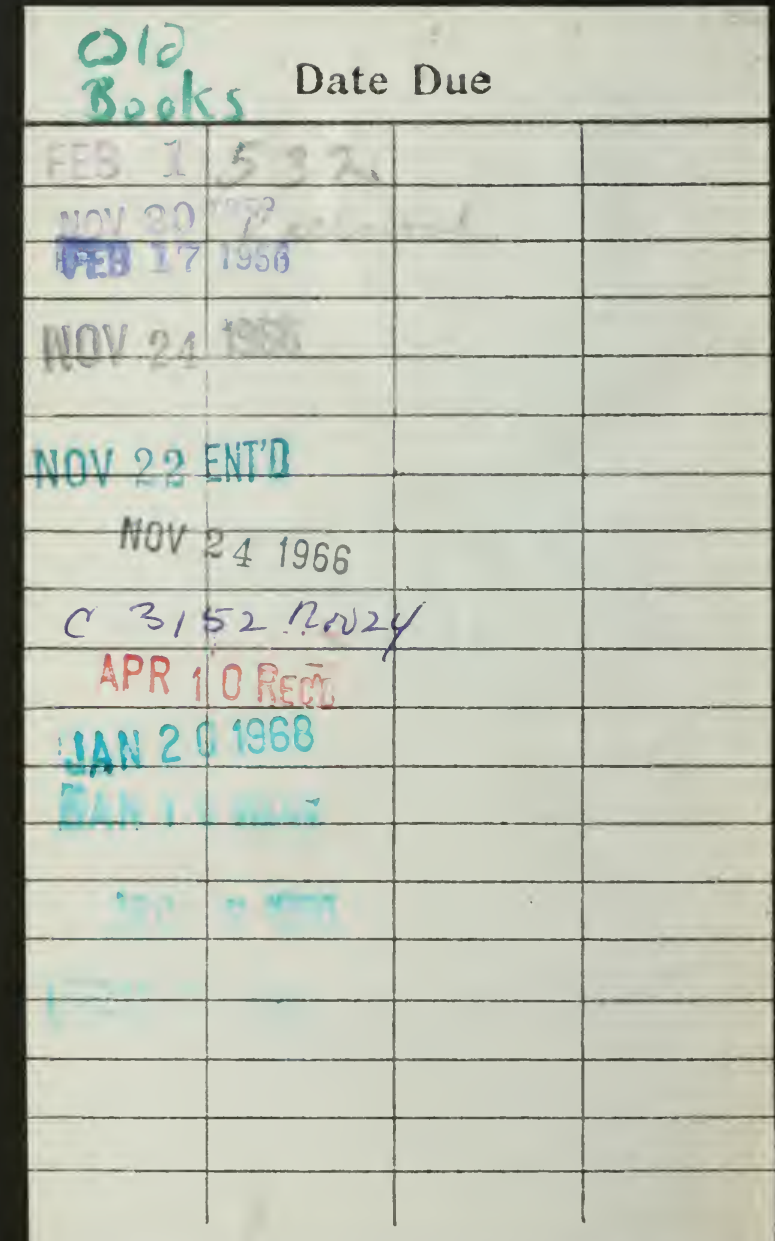




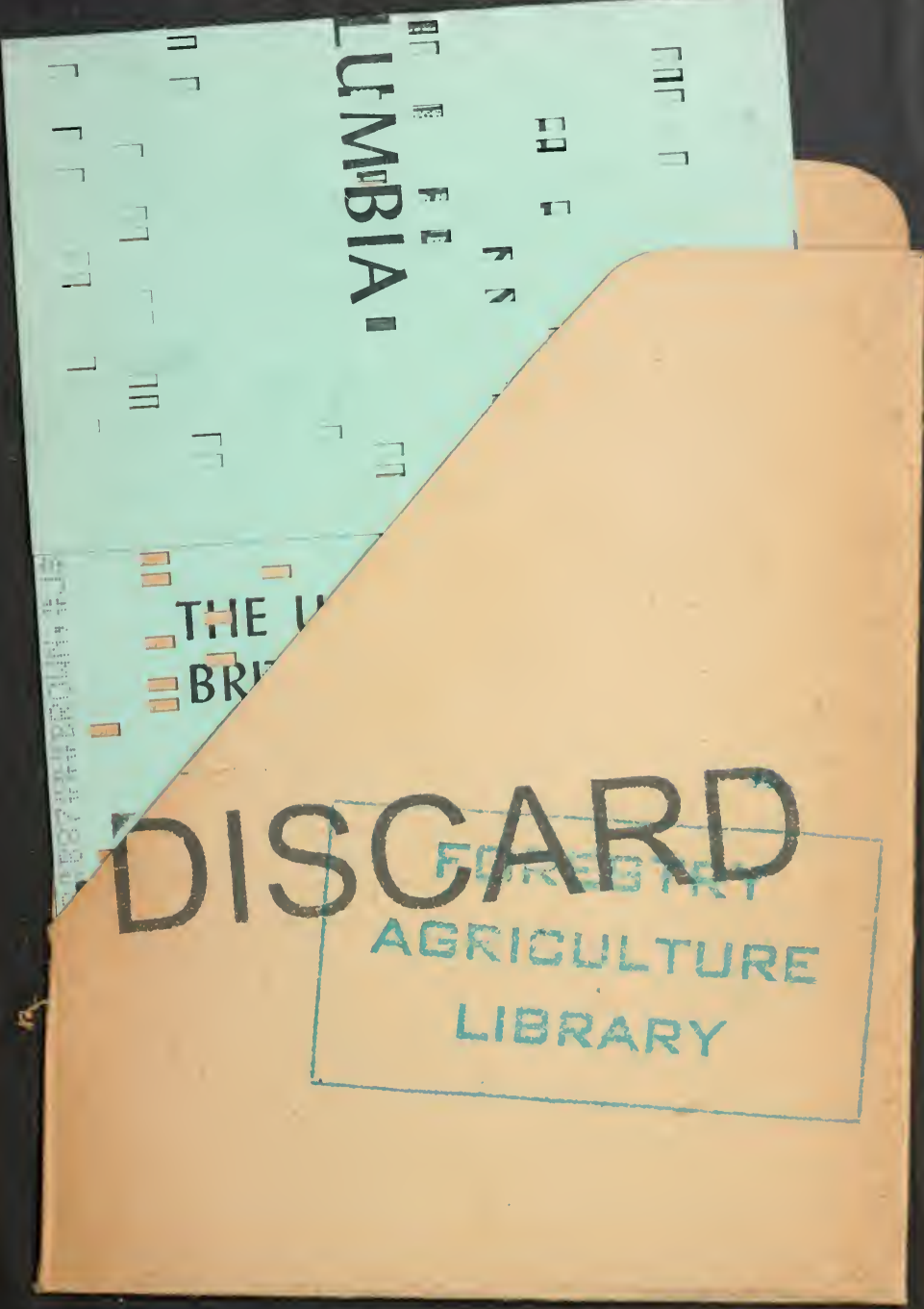


